\title{
THE ROLE OF CURCUMIN IN MODULATING COLONIC MICROBIOTA DURING COLITIS AND COLON CANCER PREVENTION
}

\author{
Rita-Marie Thomas McFadden
}

A dissertation submitted to the faculty of the University of North Carolina at Chapel Hill in partial fulfillment of the requirements for the degree of Doctor of Philosophy in the School of Dentistry (Oral Biology).

\section{Chapel Hill}

2014

Approved by:

Pawel Kiela

Christian Jobin

Ceib Phillips

Roland Arnold

Silvana Barros 
(C) 2014

Rita-Marie Thomas McFadden

ALL RIGHTS RESERVED 


\section{ABSTRACT \\ RITA-MARIE THOMAS MCFADDEN: The Role of Curcumin in Modulating Colonic Microbiota During Colitis and Colon Cancer Prevention \\ (Under the direction of Pawel Kiela)}

Background: Inflammatory bowel diseases (IBD) are a major risk factor for colon cancer. Intestinal microbiota have been identified as the target of inflammation that affects the progression of colitis-associated colorectal cancer (CAC). With diet being a key determinant of the gut microbial ecology, dietary interventions are an attractive avenue for the prevention of CAC. Curcumin is the most active constituent of the ground rhizome of the Curcuma Longa plant, which has been demonstrated to have anti-inflammatory, anti-oxidative, pro-apoptotic and anti-proliferative properties. However, the exact role of curcumin in colon cancer prevention and modulation of the microbial communities are yet to be determined. Methods: A mouse model of CAC was utilized in which $1 l 10^{-/-}$mice on $129 / \mathrm{SvEv}$ background develop progressive colitis. On the starting day, WT or $1 l 10^{-/}$mice received a $100 \mu \mathrm{L}$ i.p. injection of $10 \mathrm{mg} / \mathrm{kg}$ body weight of azoxymethane (AOM) or sterile saline (continued once a week for six weeks total) and were started on one of the following curcumin-supplemented diets: $0 \%, 0.05 \%, 0.1 \%$ or $0.5 \%$. Mice were monitored for weight loss, rectal prolapse, rectal bleeding, and stool consistency. Stools were collected every four weeks for microbial analysis (Illumina 16S rRNA profiling). At the conclusion of the study, mice were assessed for tumor burden, colonic histopathology and colonic cytokine profile. Results: Curcumin-supplemented diets increased survival, decreased colon weight/length ratios and reduced tumor burden in a dose-dependent manner. Distal colon 
histopathology in $I l 10^{-/}$mice exposed to AOM with the $0.5 \%$ curcumin diet demonstrated a reduction of inflammation score and a reduction in the frequency of adenocarcinoma detection. Curcumin altered the microbial ecology in the gut of $I l 10^{-/}$mice fed the $0.5 \%$ curcumin diet. DIfferences in microbial diversity were observed in mice with tumors vs. without, as well as in mice that had spontaneous vs. AOM-induced tumors. Conclusions: In a dose-dependent manner, dietary curcumin results in a less severe presentation of colitis, in a reduced risk of progression to $\mathrm{CRC}$ upon exposure to $\mathrm{AOM}$ and a more diverse colonic microbial ecology in the $I l 10^{-/}$mice. This suggests that curcumin functions as an effective agent for restoring healthy gut homeostasis. 
"We make a living by what we get, but we make a life by what we give."

Winston Churchill

To all my friends, family and co-workers who never stopped encouraging me to strive to my fullest potential during the peaks and valleys of graduate school.

A special thanks to my mom, who reminded me that, unlike so many things in life, education can't be taken away from you, once you've got it, so go get it! 


\section{ACKNOWLEDGMENTS}

Funding for the study was provided by the NIH R01DK67286 and my graduate stipend was supported by the Dorrance Foundation Fellowship in Pediatric Gastroenterology and Nutrition.

Experiments were conducted with the assistance of Dr. Claire B. Larmonier, Monica MiduraKiela, Dr. Rajalakshmy Ramalingam, Faihza Hill and Christy A. Harrison in the lab of Dr. Pawel Kiela and Dr. Fayez Ghishan at the University of Arizona in Tucson. An additional acknowledgment to my mentor, Dr. Pawel Kiela, for his intellectual contribution to my dissertation research and for his dedication to graduate student training and guidance.

Training and assistance in analysis of microbial diversity using the QIIME software was provided by Dr. J. Gregory Caporaso and John Chase at the Center for Microbial Genetics and Genomic at Northern Arizona University in Flagstaff, AZ.

Bacterial sequencing was generated by IGSB-NGS (Institute for Genomics \& Systems BiologyNext Generation Sequencing) Core Facility at Argonne National Laboratory by Sarah Owens.

Immunohistochemical data generated by the TACMASS Core (Tissue Acquisition and Cellular/Molecular Analysis Shared Service) is supported by the University of Arizona Cancer 
Center in Tucson, AZ with the help of Edward Abril and Dr. Kathleen McDaniel. Staining was scored by Dr. Charmi Patel. Support Grant, NIH CA023074

Histological assessment and tumor scoring was done by Dr. David G. Besselsen with the University Animal Care at the University of Arizona Health Sciences Center in Tucson, AZ.

H\&E staining was generated by the Department of Cellular and Molecular Medicine Histology Service Lab by Andrea Grantham. 


\section{TABLE OF CONTENTS}

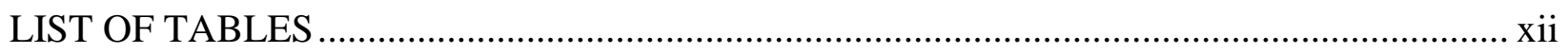

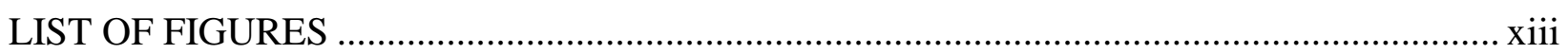

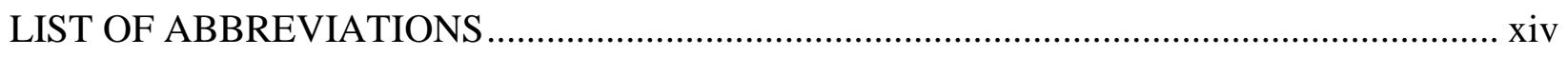

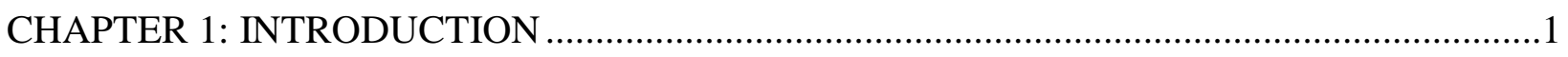

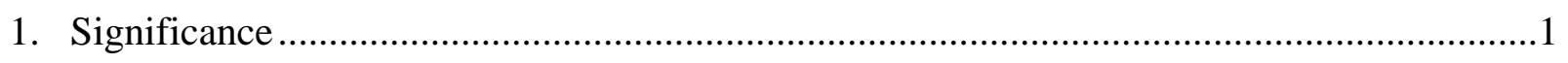

2. Inflammatory bowel disease and colon cancer...................................................................

2-1 Overview of inflammatory bowel disease (IBD) ................................................

2-1-a Crohn's Disease (CD) ......................................................................

2-1-b Ulcerative Colitis (UC) ……………………........................................

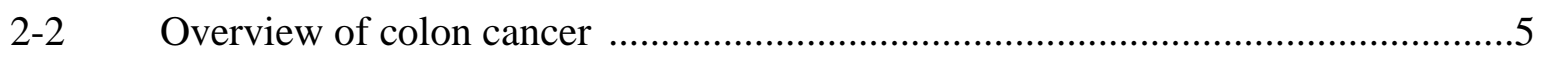

2-3 Immune system responses contributing to colitis-associated colon

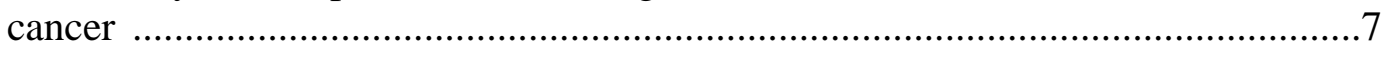

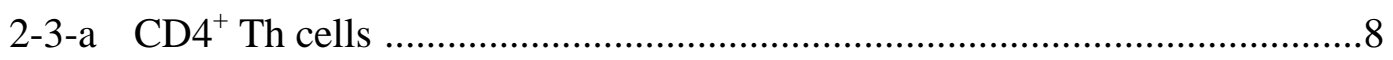

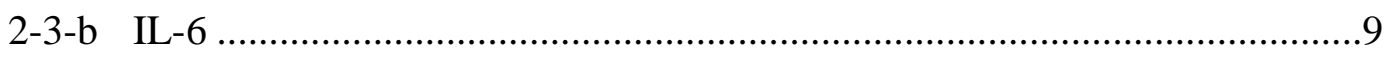

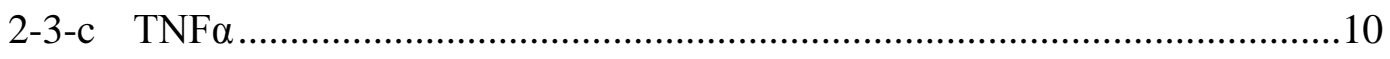

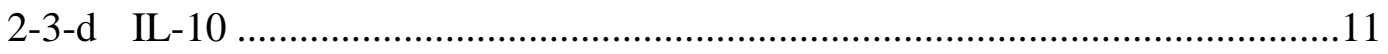

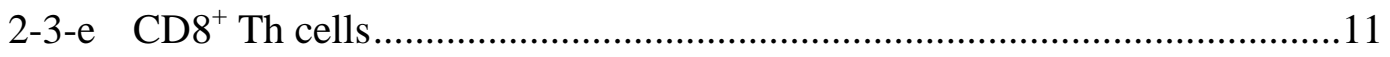

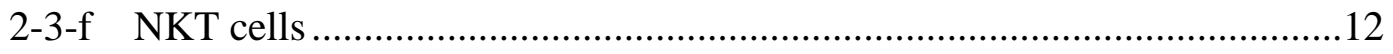

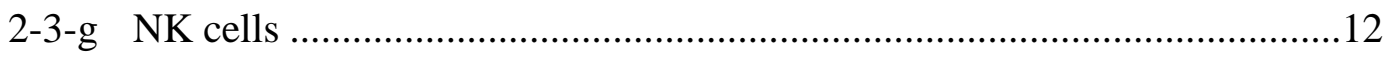

2-3-h M1 and M2 macrophages …………………...................................13 


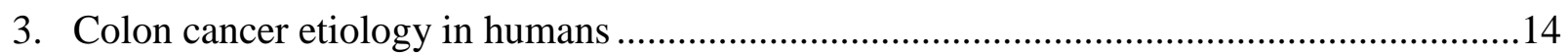

4. Colon Cancer Modifiers and Research Models.................................................................17

4-1 Non-rodent models of colon cancer...............................................................17

4-2 Rodent models of colon cancer.....................................................................

4-2-a Diet-associated ...............................................................................

4-2-a-i $\quad$ Western diet ...........................................................

4-2-a-ii PhIP (2-amino-1-metyl-6-phenylimidozo [4,5-b] pyridine) …………………………………………....18

4-2-b Genetics-associated (Apc ${ }^{\text {Min }}$ mouse) .....................................................19

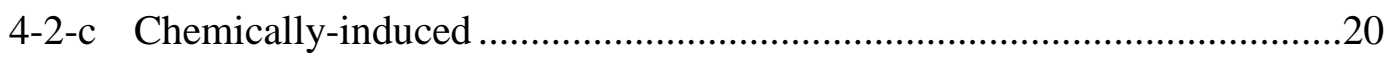

4-2-c-i Nitroso compounds ...............................................................20

4-2-c-ii Azoxymethane …………………………….....................21

5. Chronic inflammation is linked to perturbation of the established gut microbiota...............23

5-1 Assessing microbial diversity ......................................................................24

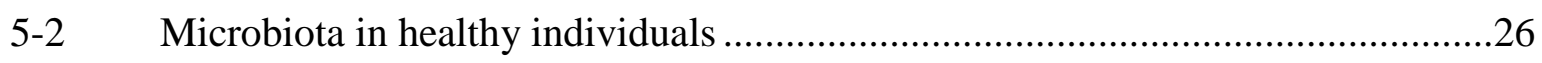

5-3 Microbiota and gastrointestinal cancers.........................................................28

5-4 Microbiota and colon cancer.........................................................................29

6. Curcumin: bridging the therapeutic gap between inflammation and colorectal carcinogenesis

6-1 Structure and components ................................................................................

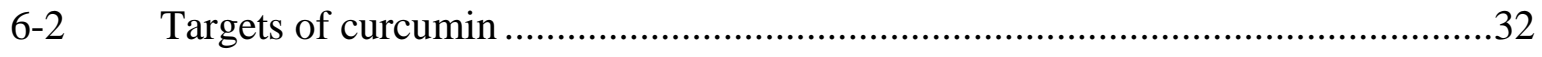

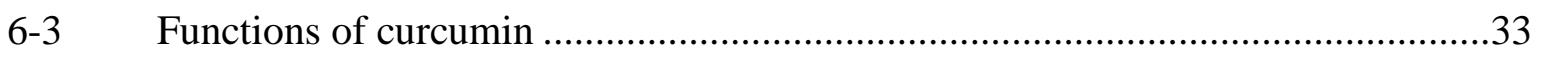

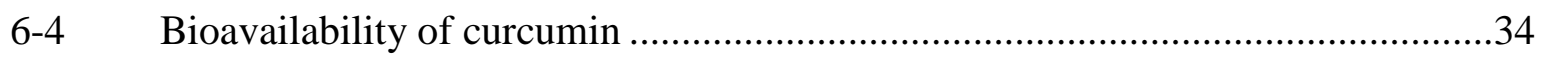

6-5 Curcumin and cancer therapeutics .....................................................................35 


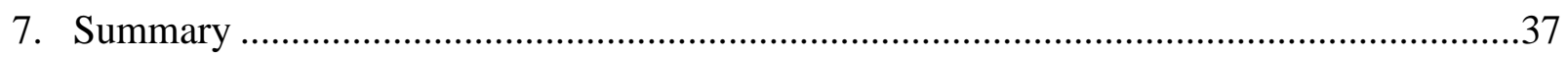

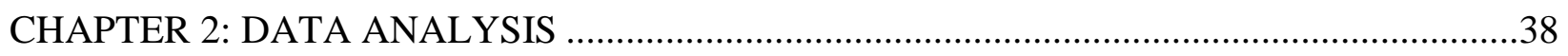

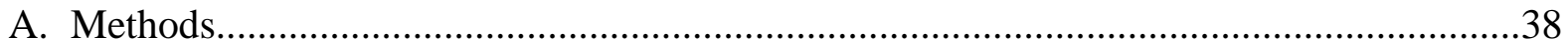

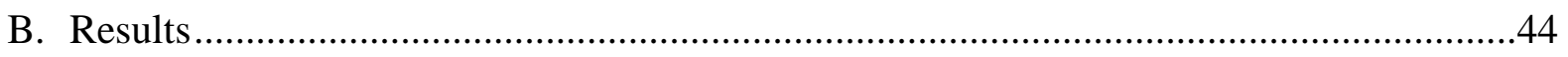

1. $\quad I l 10^{-/} / \mathrm{AOM}$ Colitis-associated colon cancer mouse model system................................44

2. Curcumin increases survival of $1110^{-/-}$chronically-inflamed mice, but becomes toxic at very high doses when administered with azoxymethane carcinogen ..................46

3. Curcumin reduces hyperplasia in AOM-treated $\mathrm{Il}_{10}{ }^{-/-}$mice ........................................4 48

4. Curcumin reduces histological scoring in AOM-treated $\mathrm{I} 110^{-/-}$mice in a dose-dependent manner

5. Curcumin reduces tumor burden in AOM-treated $1 l 10^{-/-}$mice

6. Curcumin reduces aberrant localization of beta-catenin in AOM-treated $I l 10^{-/-}$mice.

7. Curcumin's role in reducing tumorigenesis is independent of anti-inflammatory functions.

8. Baseline gut microbial composition patterns between WT and $1110^{-/-}$

Mice

9. Microbial analysis of the effect of curcumin-supplemented diet.

10. Microbial composition patterns associated with colon cancer induction

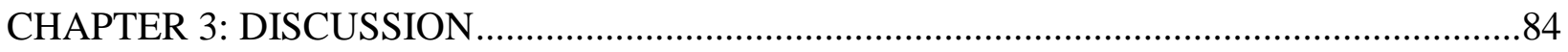

A. Effects of microbiota on progression and incidence of colon cancer ............................84

1. How this data fits in with current research in the field .........................................84

2. Future directions of influences of microbiota on colon cancer...............................86

B. Curcumin functions as an effective anti-colon cancer agent ......................................88 
1. How this data fits in with current research in the field ........................................8

2. Future directions of curcumin as an anti-cancer agent ........................................92

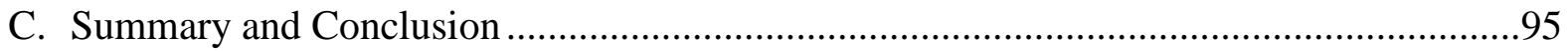

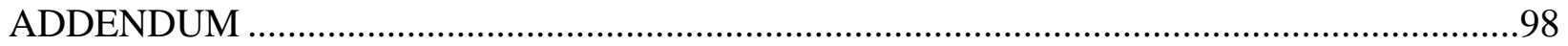

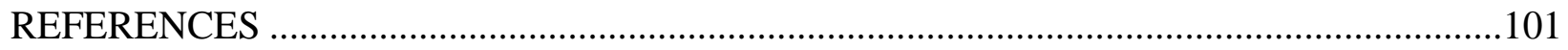




\section{LIST OF TABLES}

Table 1.1 Specific changes in microbial composition during colon cancer.............................30

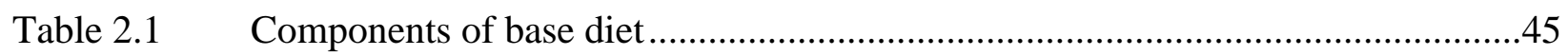

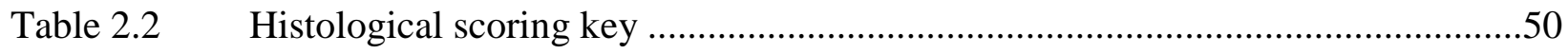

Table 2.3 Beta-catenin IHC Histological scoring ……......................................................5

Table 2.4 Specific changes in microbial composition of $I l 10^{-/-}$mice compared to WT

Table 2.5 Predictions of microbial metagenome and function based on microbial composition of $I l 10^{-/}$mice and WT mice

Table 2.6 Microbial composition profile of the AOM-injected $I l 10^{-/}$mice on the control diet ( $0 \%$ curcumin) compared to the untreated WT mice on control diet

Table 2.7 Microbial composition profile of the AOM-injected $I l 10^{-1-}$ mice on the $0.5 \%$ curcumin diet compared to the untreated WT mice on control diet

Table 2.8 Microbial composition profiles of the AOM- $I l 10^{-/}$mice on their Respective diets, $0 \%$ or $0.5 \%$ compared to untreated WT mice on control diet

Table 2.9 Predicted pathways based on microbial composition profiles of the AOM-injected $I l 10^{-/-}$mice on their respective diets, $0 \%$ or $0.5 \%$ compared to untreated WT mice on their control diet

Table 2.10 Microbial composition profiles of samples from mice with spontaneous tumors, induced tumors and no tumors

Table 2.11 Predictions of pathways in mice (spontaneous tumors vs. induced tumors) based on microbial composition profiles. 


\section{LIST OF FIGURES}

Figure 1.1 Comparison of Crohn's Disease (CD) and Ulcerative Colitis (UC) .....................5

Figure 1.2 Immune system during colon homeostasis ............................................

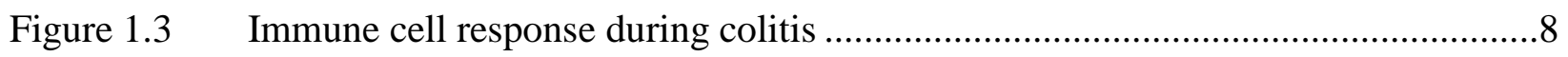

Figure $1.4 \quad$ Vogelstein model of colon cancer induction ...............................................15

Figure $1.5 \quad$ Ascending vs. Descending colon cancer...................................................16

Figure 1.6 Azoxymethane (AOM) processing ..........................................................23

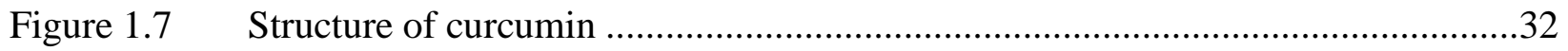

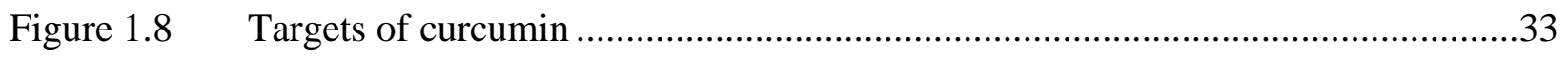

Figure 2.1 Experimental setup............................................................................ 45

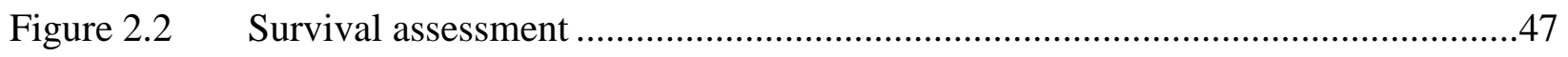

Figure 2.3 Hyperplasia assessment in gross colonic tissue .........................................48

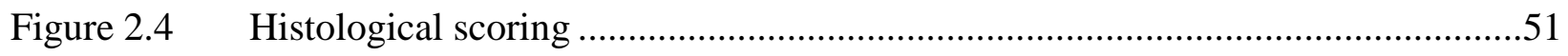

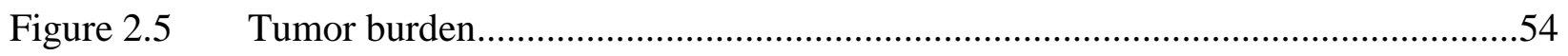

Figure 2.6 beta-catenin localization in colonic tissue .................................................56

Figure 2.7 mRNA expression of colitis-associated cytokines within colonic tissue..............60

Figure 2.8 Baseline gut microbial composition patterns between WT and $\mathrm{IllO}^{-/-}$

mice.

Figure 2.9 Microbial analysis of the effect of curcumin diet ........................................71

Figure 2.10 Microbial composition patterns associated with colon cancer

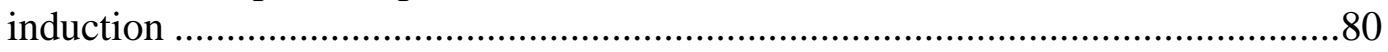

Figure 3.1 Summary of major findings of curcumin treatment....................................97 


\section{LIST OF ABBREVIATIONS}

16S rRNA

ANOSIM

AOM

APC

BAX

BRAF

CAC

CCR

CD

Cdc

CEC

COX

CTLA

$\mathrm{Cu}$

CXCR

DC

DCC

dNTP

DSS

ELISA

FAP
$16 \mathrm{~S}$ ribosomal RNA subunit gene

Analysis of Similarity

Azoxymethane

Adenomatous polyposis

BCL2-associated X protein

v-raf murine sarcoma viral oncogene homolog B

Colitis-associated colorectal cancer

Chemokine, C-C motif, receptor

Crohn's Disease

Cell division control protein

Colonic epithelial cell

Cyclooxygenase

Cytotoxic T-Lymphocyte Antigen

Curcumin

Chemokine, CXC motif, receptor

Dendritic cell

Deleted in colon cancer

Deoxyribonucleotide triphosphate

Dextran sulphate sodium

Enzyme-linked immunosorbent assay

familial adenomatous polyposis 


\begin{tabular}{|c|c|}
\hline GF & Germ free \\
\hline GI & Gastro-Intestinal \\
\hline HRP & Horseradish peroxidase \\
\hline HSP & Heat shock protein \\
\hline IBD & Inflammatory bowel disease \\
\hline IEC & Intraepithelial cell \\
\hline IEL & Intraepithelial lymphocytes \\
\hline IFN & Interferon \\
\hline IL & Interleukin \\
\hline iNOS & Inducible Nitric oxide synthase \\
\hline i.p. & Intra-peritoneal \\
\hline KRAS & Kirsten rat sarcoma viral oncogene homolog \\
\hline KO & Knockout \\
\hline LPS & Lipopolysaccharide \\
\hline MLH1 & mutL homolog 1 \\
\hline MLN & Mesenteric lymph nodes \\
\hline MNNG & $\mathrm{N}$-methyl-N-nitro-N-nitrosoguanidine \\
\hline MNU & N-methyl-N-nitrosourea \\
\hline MSH2 & mutS homolog 2 \\
\hline NF-kB & Nuclear Factor Kappa B \\
\hline NK & Natural killer \\
\hline NKT & Natural killer T cell \\
\hline OS & Observed species \\
\hline
\end{tabular}


OTU

PBS

Pcoa

PD

$\mathrm{PhIP}$

PICRUSt

PTS

ROS

RT

RT-PCR

SCFA

SDS

SPF

STAT

TCR

TE

TGF

TGFßIIR

Th

TIMP

TLR

TNBS
Operational Taxonomic Unit

Phosphate buffered saline

Principal coordinate of analysis plot

Phylogenetic Diversity

2-amino-1-metyl-6-phenylimidozo [4,5-b] pyridine

Phylogenetic investigation of communities by reconstruction of

unobserved states

Phosphotransferase system

Reactive oxygen species

Reverse transcription

Reverse transcription polymerase chain reaction

Short chain fatty acid

Sodium dodecyl sulfate

Specific pathogen free

Signal transducers and activators of transcription

T cell receptor

Tris-EDTA

Transforming growth factor beta

Transforming growth factor, beta receptor II

$\mathrm{T}$ helper cell

Tissue inhitor of metalloproteinases

Toll-like receptors

2,4,6-trinitrobenzene sulfonic acid 
TNF

TP53

UC

WT
Tumor necrosis factor

Tumor protein $\mathrm{p} 53$

Ulcerative colitis

Wild type 


\section{CHAPTER 1: INTRODUCTION}

\section{Significance}

Chemopreventive agents, which are utilized to prevent the onset of cancer, can have numerous side effects that prevent their efficacy and long-term administration to high risk patients. However, plant-based dietary supplements circumvent this problem by providing effective and less toxic alternatives. A promising chemopreventive agent is curcumin, a component of the cooking spice Turmeric, which derives from a rhizome of the Curcuma longa plant. Curcumin has been demonstrated to function as an antiseptic, analgesic, antiinflammatory, antioxidant, antimalarial, and chemopreventive agent. It is primarily administered orally as a dietary supplement, which would potentially have direct contact with the gut microbiota. A gap in the field is the impact of curcumin on the microbiota of patients. Dysbiosis of a patient's gut microbiota is associated with chronic inflammatory bowel disease and an increased risk for colon cancer. Understanding the exact mechanistic roles of curcumin is a rapidly expanding field due to the promise of this naturally-derived treatment for cancer patients. This laboratory has extensively studied the benefits of curcumin in reducing colonic inflammation through direct inhibition of neutrophil migration (Larmonier et al., 2011), through

an IL-10-dependent mechanism (Larmonier et al., 2008), depending on the type of inflammation 
(Th1 or mixed Th1/Th2), which varies by mouse strain (Billerey-Larmonier et al., 2008) and through inhibiting IFN-ץ signaling in colonic epithelial cells (Midura-Kiela et al., 2011). This laboratory has also demonstrated that curcumin can interact with PTPN1 tyrosine phosphatases to increase dephosphorylation of cortactin, which inhibits cortactin's function in cancer cell motility and invasion (Radhakrishnan, et al., 2014).

This thesis proposes that the role of curcumin is closely linked to the regulation of microbiota during the onset and persistence of inflammatory bowel diseases (IBD), such as ulcerative colitis, as well as the associated progression to cancer. Ulcerative colitis is characterized by severe colon inflammation and the formation of numerous polyps. $5-10 \%$ of patients who have been diagnosed with ulcerative colitis for 10 years progress to colon cancer, while the risk of developing colon cancer in patients diagnosed with ulcerative colitis for over 30 years increases to $15-40 \%$. Colon cancer is the third most commonly diagnosed cancer in the United States of America (U.S.A.) with an estimated 136,830 new cases diagnosed in the year 2014. Colon cancer has one of the highest mortality rates of cancers in the U.S.A. at 9\%, which is greater than that of pancreatic cancer and leukemia combined. Colon cancer is the third leading cause of cancer related death in both men and women in the U.S.A (American Cancer Society, 2014). Despite effective screening and diagnostics, incidence and mortality remains high, while the mechanisms underlying the link between colon inflammation and cancer progression remain poorly understood.

Elucidating the effect of curcumin on gut microbiota would potentially provide a novel therapeutic for IBD, as well as for colon cancer. Furthermore, the impact of this research may extend to other fields where diseases are characterized by an improper regulation of inflammation, such as autoimmune disorders. 


\section{Inflammatory Bowel Disease and Colon Cancer}

It is estimated that 1 million people in the United States of America (U.S.A.) have inflammatory bowel disease, split evenly between Crohn's Disease and Ulcerative Colitis (Crohn's \& Colitis Foundation of America, 2014). Incidence of IBD is estimated to be $396 / 100,000$ people worldwide. Age of onset is typically $15-30$ years of age with $10 \%$ of cases in patients below 18 years of age. Major risk factors include genetic predisposition (family history of IBD) and environmental factors, such as "Westernized" diets high in red meat, high in fat and low in fiber. There is an increased incidence of colon cancer in patients with IBD, particularly with Ulcerative Colitis. The incidence is higher for "Westernized" nations. Within the United States alone, it is estimated that 1 in 19 people will develop colon cancer in their lifetime (American Cancer Society, 2014). However, the link between inflammation and carcinogenesis in the colon remains unclear.

\section{$\underline{2-1}$ Overview of inflammatory bowel diseases (IBD)}

\section{2-1-a Crohn's Disease (CD)}

Crohn's disease is characterized by chronic inflammation that can affect any area of the gastrointestinal tract and any layer of the intestinal wall. It can have "skip lesions" with areas of healthy mucosa in between. Symptoms include diarrhea, cramping, fever, fatigue, rectal bleeding and blockage of the intestine resulting in vomiting, cramping and bloating. Ulcerations can occur and develop fistulas, which can become infected in 30\% of patients on average. Medicinal strategies include aminosalicylates, antibiotics, tumor necrosis factor blockers, such as Infliximab and drugs used as to aid in immunosuppression, such as Azathioprine, Mercaptopurine (6-MP) and Methotrexate. Patients may undergo surgery to remove affected 
areas in the colon. The Center for Disease Control (CDC) estimates that the worldwide incidence of Crohn's is $0.1-16 / 100,000$ people. This is a conservative estimate, due to lack of proper or inconsistent diagnoses. CD trends towards a higher prevalence in women. $\mathrm{CD}$ is more prevalent in smokers than non-smokers (CDC, 2014).

\section{2-1-b Ulcerative Colitis (UC)}

Ulcerative colitis is characterized by chronic inflammation that primarily affects the mucosa layer of the colon. The distal most region of the colon is affected and the inflammation may progress proximally and continually. Symptoms include bloody stool, cramping, bloating, weight loss, feeling the severe need to have a bowel movement, nausea and fever. The symptoms can have periods of remission and flare-ups. Patients can develop bleeding ulcers and ruptures within the colon. Children with UC may experience stunted growth. Medicinal strategies are the same as listed above for CD, although colectomy surgery will "cure" UC, as it only affects the colon tissue. The CDC estimates that the worldwide incidence of UC is 0.5 24.5/100,000 people. Ulcerative Colitis has received much attention in colon cancer research due to the increased incidence of those patients to develop colon cancer, although patients with CD also develop colon cancer (CDC, 2014). 


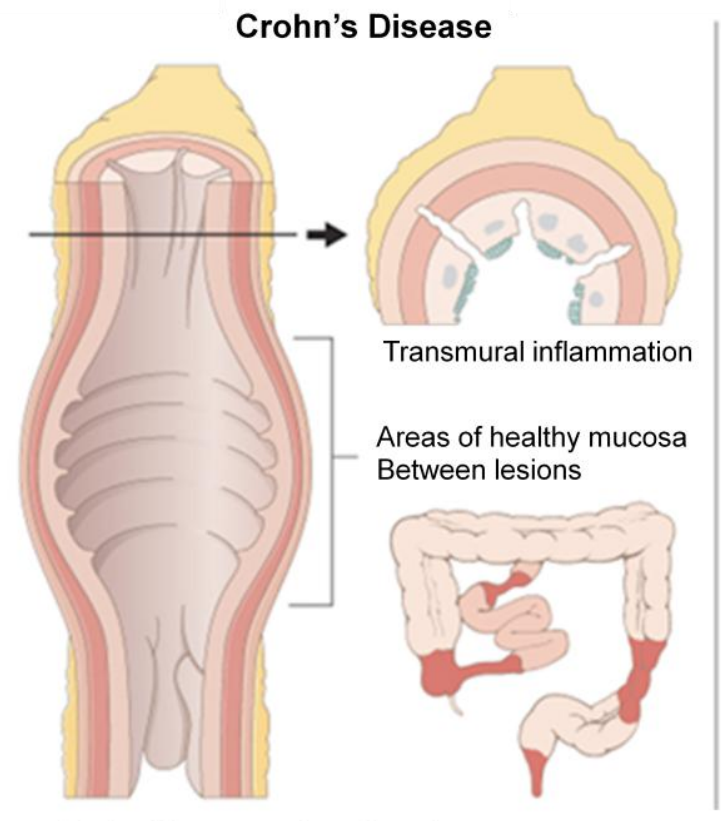

Entire GI tract can be affected

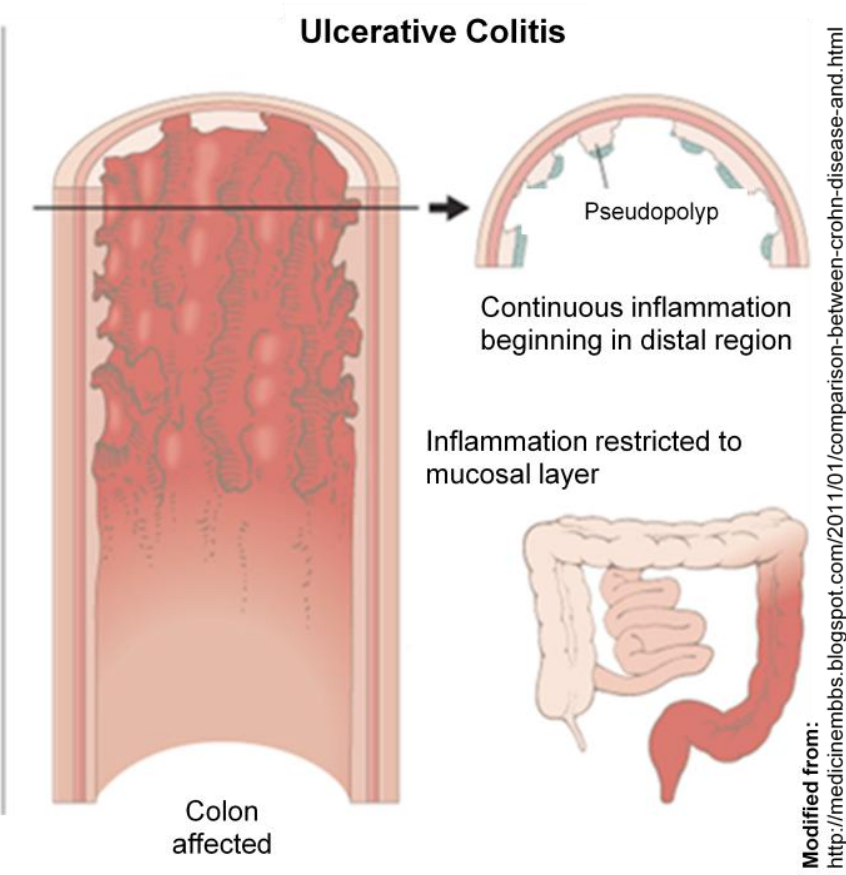

Figure 1.1: Comparison of Crohn's Disease (CD) and Ulcerative Colitis UC)

\section{$\underline{\text { 2-2 Overview of colon cancer }}$}

The immune system is the body's coordinated network of cells and proteins that help distinguish and eliminate mutated cells, as well as foreign materials, such as macromolecules, chemicals and microorganisms (Abbas et al., 2007). If improperly regulated, the immune response will begin to harm and eliminate healthy cells. Furthermore, many cancers, notably colon cancer, can arise during conditions of chronic inflammation. Cancer is defined by the American Cancer Society as a group of diseases characterized by the uncontrolled growth and spread of abnormal cells (American Cancer Society, 2010). Cancer is a broad term encompassing diseases that cross gender, ethnic, age and socioeconomic boundaries. Cancer is the second leading cause of death in the United States of America preceded only by heart disease and it is characterized by the following hallmarks: 1) self-sufficiency in growth signals, 2) 
evading apoptosis (programmed cell death), 3) sustained angiogenesis (formation of blood vessels), 4) Insensitivity to antigrowth signals, 5) limitless potential for replication, and 6) tissue invasion and metastasis (Hanahan and Weinberg, 2000). Inflammation is characterized by an influx of phagocytic "innate" immune cells, followed by more specific "adaptive" immune cells that coordinate the response to infections, wounds and foreign antigens. However, the cancer cells arise from host cells and a) may not be recognized as foreign and b) produce factors or gain mutations to facilitate evasion of the immune response and cell cycle control. There is a delicate balance among the commensal microbial flora and the resident tissue cells that normally undergo a large amount of proliferation, as well as programmed cell death, termed apoptosis, as those resident tissue cells slough off to aid in proper bowel function. Thus, the colon is an ideal location for development of cancer, since the healthy colon tissue is already rich in growth factors to support the high proliferation rate of gut epithelial cells. Colon cancer is the third most commonly diagnosed and the third highest cause of cancer mortality in the U.S.A. It is estimated that 136,830 people will be diagnosed in the U.S.A. during 2014 and 50,310 will die from colon cancer in 2014 (American Cancer Society, 2014). Incidence has decreased due to better screening for malignant growths via endoscopies and colonoscopies. Colon cancer symptoms are fairly non-specific, including cramping in the abdomen, decreased appetite, unintentional weight loss, constipation or diarrhea that lasts for days, narrow stool, dark-colored stool and/or bleeding from the rectum. There is a close association with a medical history of chronic inflammatory bowel disease and the progression to colon cancer. A question arises concerning the transition from inflammation to colon cancer and the regulation of the immune system during this disease process. 
Figures 1.2 and 1.3 summarize the immune responses, including sub-populations of Tcells, such as Th1 and Th2 and their associated cytokines, which contribute to homeostasis or IBD. The immune system within the intestine contributes to wound healing, protection from pathogens and physiologic immune tolerance of luminal antigens. During IBD, aberrant mucosal infiltration within the lamina propria can occur by neutrophils, macrophages, dendritic cells, as well as T and B cells. This process correlates with increased production of the pro-inflammatory cytokines TNF $\alpha$, IL-1 $\beta$, IFN $\gamma$, IL-6, IL-1 $\beta$, IL-12/23 p40 and IL-17.

\section{$\underline{\text { 2-3 Immune system responses contributing to colitis-associated colon cancer }}$}

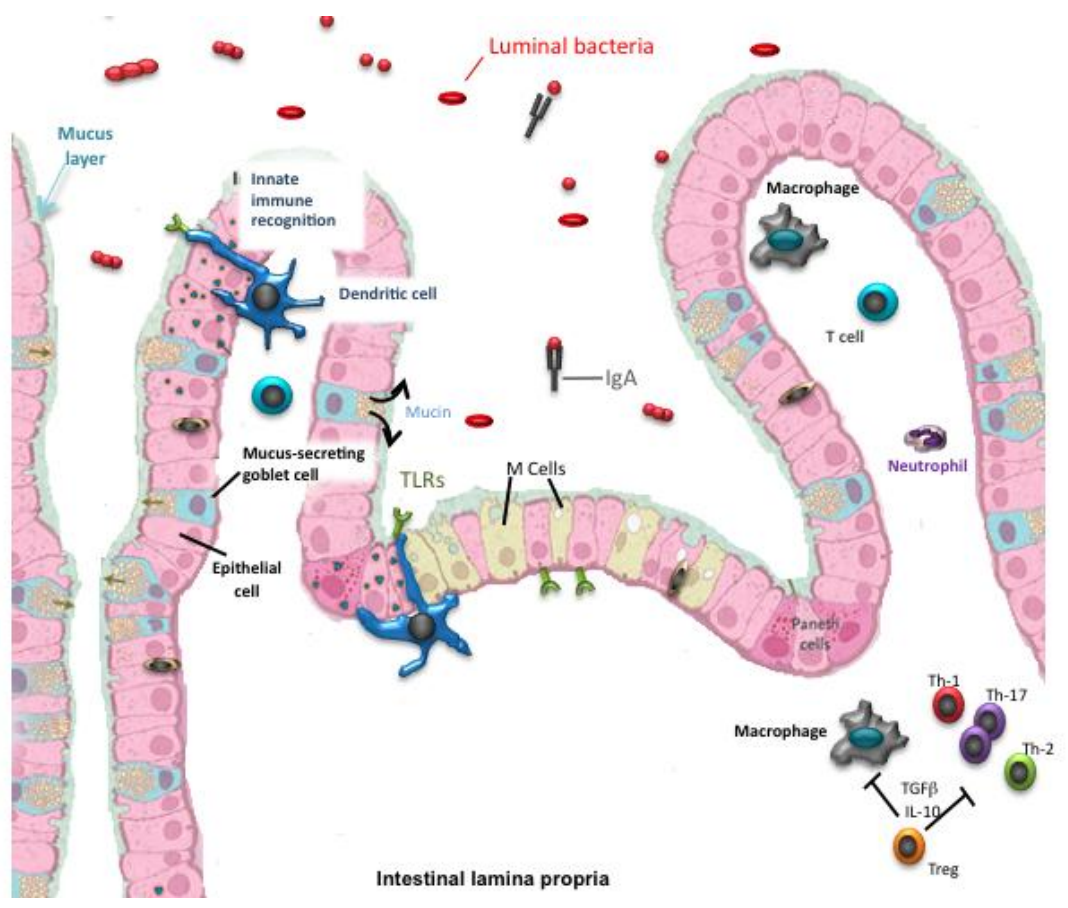

Figure 1.2: Immune system during colon homeostasis

Modified from: Larmonier, C. 2010. Novel therapeutic strategy for the treatment of Inflammatory Bowel Diseases. Doctoral thesis. 


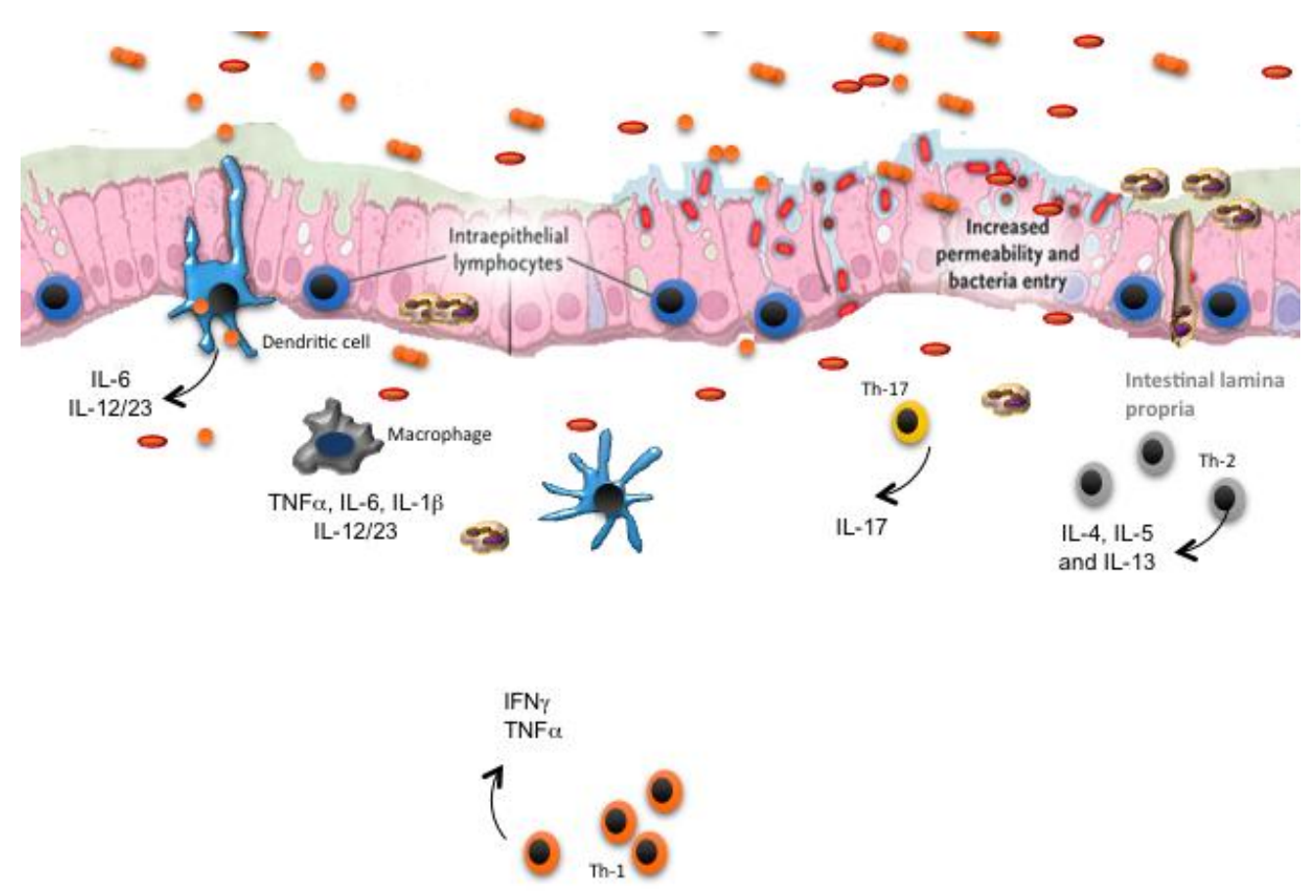

Figure 1.3: Immune cell response during colitis

Modified from: Larmonier, C. 2010. Novel therapeutic strategy for the treatment of Inflammatory Bowel Diseases. Doctoral thesis.

\section{2-3-a CD4 ${ }^{+}$Th cells}

The two types of IBD, Crohn's Disease (CD) and Ulcerative Colits (UC) are classically thought to differ by $\mathrm{CD} 4^{+}$Th responses and cytokine production. $\mathrm{CD}$ is characterized by a Th1/Th17 response with increased IL-2, IL-12 and IFN- $y$ cytokine production. CD can occur anywhere along the gastrointestinal tract and contain skip lesions with areas of normal mucosa in between. UC is characterized by a Th2 response with increased IL-4, IL-5 and IL-13 cytokine production. UC tends to occur in the distal most region of the colon and progress proximally and is restricted to the mucosal layer. Ifn- $\mathrm{Y}^{-/}$mice deficient in IFN-Y production have increased production of IL-4 and IL-5 and are skewed towards a Th2 response. These mice have increased tumor burden, which correlates with the clinical observation that human patients with UC are more likely to progress to colon cancer than patients with $\mathrm{CD}$, indicating a possible connection between Th1 responses and better prognoses. However, other factors may be biasing the results, 
such as the role of IFN-y to activate cells with anti-tumor functions, such as cytotoxic $\mathrm{CD} 8^{+} \mathrm{T}$ cells and NK cells. Experiments that were conducted to skew Th1 responses to Th2 responses used neutralization antibodies to p40, a subunit of IL-12. However, this subunit is shared by IL23, which is critical to maintenance of Th-17 cells. Mice deficient in the transcription factor for Th-17 cells, RORYt, are resistant to inflammation. The IL-17 cytokine produced by Th-17 cells promote the expression of TNF- $\alpha$, IL-6, IL-1, iNOS and various metalloproteinases and chemokines that are associated with the onset of colitis-associated colon cancer (Rizzo et al., 2011). This indicates that there are differences in severity and progression of colitis based on the $\mathrm{CD}^{+}$Th subtype. For these reasons, mRNA expression of IL-17, IL-6, TNF- $\alpha$, IL-1, IFN- $\gamma$, IL12 and IL-23 within colon tissue was tested.

\section{2-3-b. IL-6}

Interleukin-6 (IL-6) is of particular interest as it is a pro-inflammatory cytokine that has been demonstrated to have increased expression in patients with active UC and those who have progressed to CAC, compared to individuals in a control group. Furthermore, IL-6 expression contributes to resistance to apoptosis in T cells, as well as in normal and transformed colonic epithelial cells (STAT-3-dependent mechanism). A study disrupted the suppressor of cytokine signaling 3 (SOCS3), which would normally limit the IL-6 activation of STAT-3. As a result, the colonic tumor burden and average size increased (Rigby et al., 2007). The inhibition IL6/STAT3 mechanism was shown to underlie the anti-cancer effect of a small molecule inhibitor, Embelin against colitis-associated colon cancer (Dai et al., 2014). IL-6 can inhibit TGF-3 signaling via induction of Smad7, contributing to an uncontrolled immune response. Mice deficient in Smad3, a regulator of TGF-3 signaling, develop CAC. Transforming growth factor 
(TGF)- $\beta$ plays a regulatory role to suppress the immune system. Deficiency of the receptor TGF-ßRII in dendritic cells is sufficient to cause autoimmunity in multiple organs (Ramalingam et al, 2012). The numerous direct and downstream effects of IL-6 indicate that it has a pivotal role in CAC.

\section{2-3-c. TNF- $\alpha$}

TNF- $\alpha$ is of special interest in the field of digestive diseases. Anti-TNF- $\alpha$ is a therapy currently utilized in the clinic for CD and UC patients. A retrospective study addressed the efficacy of the anti-TNF- $\alpha$ treatments infliximab and adalimumab in 33 pediatric patients and showed that mucosal healing occurred in over $44 \%$ of the patients and that the overall clinical response was improved to greater than $80 \%$ for both medications (Nobile et al., 2014). TNF- $\alpha$ is critical to the progression of chronic inflammation and CAC due to its role in activation of NF$\mathrm{K} \propto \mathrm{B}$, a transcription factor for pro-inflammatory cytokines and factors that increase cell proliferation, angiogenesis, apoptosis-evasion and metastasis. When NF-KB activation is blocked through deletion of IKK $\beta$ in the intestinal epithelium, epithelial cell apoptosis increases during early tumor development and the incidence of CAC decreases (Greten et al., 2004). Furthermore, chronic, elevated production of TNF- $\alpha$ is associated with elevated tumor burden in experimental models. Mice deficient for the p55 subunit for the receptor of TNF- $\alpha$ did not develop tumors (Popivanova et al., 2008). Tumor burden and size decreased in mice treated with MP6-XT22, a neutralizing monoclonal antibody to TNF- $\alpha$, during an AOM/DSS colitisassociated cancer induction model (Onizawa et al., 2009). This indicates the crucial role of TNF- $\alpha$ in CAC. 


\section{2-3-d. IL-10}

A cytokine that functions to suppress the immune system is Interleukin-10 (IL-10). Mice deficient in IL-10 spontaneously develop colitis and treatment with exogenous IL-10 restores a healthy phenotype. IL-10 has been shown to have antiangiogenic properties, as well as inhibitory properties for NF-KB activation. A study testing 282 patients for two candidate cancer-associated SNPs in IL-10 as potential prognostic biomarkers demonstrated that patients with the IL-10 rs3021094 polymorphism had a 3.3 fold higher risk of death (Ting et al., 2013). Treg transfer from IL-10-deficient mice failed to reduce tumor burden in colon cancer-prone $\mathrm{Apc}^{\mathrm{Min}}$ mice, while Treg transfer from healthy wildtype mice did reduce tumor burden through induction of epithelial cell apoptosis and downregulation of Cox-2 in dysplastic epithelium (Erdman et al., 2005). This indicates that IL-10 plays a critical role in CAC. Thus, an established model of CAC using $I L-10^{-/}$mice that develop spontaneous, progressive colitis (Wirtz et al, 2007) was chosen to address this study.

\section{2-3-e. $\mathrm{CD8}^{+}$Th cells}

Other adaptive immune cells also contribute to disease progression in the colon. $\mathrm{CD}^{+}$ Th cells can directly act on tumor cells by a) permeabilization mediated by their production of perforin, granzyme A and granzyme B, b) expression of FasL, which interacts with Fas on dysplastic cells to induce programmed cell death, apoptosis and c) production of IFN- $\gamma$, which can upregulate Fas on tumor cells (Rizzo et al., 2011). In fact, colon cancer cells have an immune system escape mechanism that facilitates the killing of $\mathrm{CD}^{+} \mathrm{T}$ cells through expression of CCL5 and Treg infiltration to the tumor site (Chang et al., 2012). 


\section{2-3-f. NKT cells}

NKT cells can express both Th1 and Th2 cytokines. Activation of NKT cells with alphagalactosylceramide was sufficient to protect mice from DSS-induced colitis, indicating a protective role in IBD (Saubermann et al., 2000). NKT cells may be tumor enhancers or suppressors, depending on the context. Type I NKTs that express V- $\alpha$-14-J $\alpha-18$ TCR- $\alpha$ chain are protective in the gut by promoting IFN- $\gamma$ expression, $\mathrm{CD}^{+}$cell activation and NK cell activation (Kitamura et al., 1999; Yang et al., 2000). Type I NKT cell infiltration into tumors is associated with better prognosis for human patients. However, type II NKT cells that do not express the V-a-14-Ja-18 TCR- $\alpha$ chain function to suppress the immune system and, thus, enhance tumor growth (Rizzo et al., 2011).

\section{2-3-g. NK cells}

Innate immune cells also play a role in inflammation and cancer progression in the colon. Natural Killer (NK) cells have been demonstrated to have a protective effect in DSS-induced colitis, as indicated by increased colonic damage, increased leukocyte infiltration and increased production of pro-inflammatory cytokine production following NK depletion by a polyclonal anti-asialo GM1 antibody, as well as NK cell deficient mice (Hall et al., 2013). Activated NK cells express IFN- $\gamma$, perforin and granzymes that function to induce apoptosis in tumor cells. CRC patients that contain MICA-expressing tumor cells have a better prognosis. MICA is a NKG2D ligand, which functions to activate NK cells (Terabe et al., 2000). Patients with colon cancer were shown to have reduced expression of NKG2D and another NK cell activating ligand, DNAM-1. Inhibition of NKG2D and DNAM-1 resulted in reduced cytotoxicity functions 
of NK cells against tumor cells (Zhang et al., 2012). This demonstrates the anti-cancer role of NK cells in colon cancer.

\section{2-3-h. M1 and M2 macrophages}

Macrophages are tissue-specific mononuclear cells of the innate immune system that are able to uptake non-specific antigens or dying cells through phagocytosis. Activated macrophages have increased expression of MHCII molecules and the co-stimulatory B7 molecule, which function to activate T helper cells. Macrophage activation has been further described as either classical (M1) or alternative (M2). M1 macrophages are generally characterized as promoting inflammation, while M2 macrophages are characterized as suppressing inflammation. IFN- $\gamma$, along with Lipopolysaccharide (LPS) is the primary stimulatory factors for M1 activation. M2 have various stimuli, which can include IL-4, IL-13, glucocorticoids and IL-10 (Martinez et al., 2014).

Polarizing macrophages from an M1 phenotype to an M2 phenotype has been explored to reduce colitis. Lactobacillus plantarum CLP-0611 has been used as a probiotic in experimental mice to not only reduce IL-1beta expression, IL-6 expression and NF- $\square$ B activation, but to also significantly reduce the severe effects of the 2,4,6-trinitrobenzene sulfonic acid (TNBS)-induced colitis in experimental mice through an M1 shift to M2 macrophage activation mechanism (Jang et al., 2014). Likewise, commensal bacteria can potentially cause a shift to M1 macrophages and trigger colitis, as is the case for Enterococcus faecalis (Yang et al., 2013).

In human monocyte-derived macrophages, Wnt signaling pathways have been demonstrated to be activated by M2 polarized cells, but not M1, and were associated with a reduction of the alkaline phosphatase activity and decreased enterocyte differentiation in 
epithelial cells. These results corresponded to analysis of the mucosa in UC patients where M2 macrophages increase in abundance the longer a patient has been diagnosed with the disease and is correlated with activation of epithelial Wnt signaling and reduced enterocyte differentiation, implicating a possible mechanism of these cell types in IBD progression (Cosín-Roger et al., 2013).

However, the lineages of macrophage phenotypes may serve different roles, depending on the disease context. Conditioned media collected from differentiating macrophages to the M1 phenotype (by exposure of IFN-Y and LPS), was sufficient to induce cell cycle arrest and apoptosis in $20 \%$ of the HT-29 colon cancer cell line culture, which indicates that macrophages may have a beneficial anti-cancer role, independent of inflammation (Engström et al., 2014). Understanding how gut microbiota can affect activation of immune cells may be critical to understanding the switch from inflammation to colon cancer, as well as in design of therapeutics utilizing gut microbiota.

\section{Colon cancer etiology in humans}

Benign adenomatous polyps precede many malignant colorectal cancers, although there are colon cancers associated with specific familial syndromes, such as familial adenomatous polyposis (FAP). FAP is well described as being characterized by hundreds of polyps along the colon tissue and as deriving from mutations in the Adenomatous polyposis coli (APC) gene Apc, which encodes the tumor suppressor APC protein. The APC protein has many functions, including cell cycle control, cell attachment and cell migration. APC also functions in the $\beta$ catenin destruction complex . APC has multiple sites for binding to both beta-catenin and axin. Axin is a protein that binds to both GSK3 kinase and $\beta$-catenin within close proximity to each other. This complex results in downstream phosphorylation events of $\beta$-catenin that lead to 
ubiquitination and degradation, which further controls cell division and differentiation. This mechanism of cell cycle control is often dysregulated in colon cancer cells through mutations in Apc (Yang et al., 2006). However, FAP-specific association only accounts for about $1 \%$ of colorectal cancers.

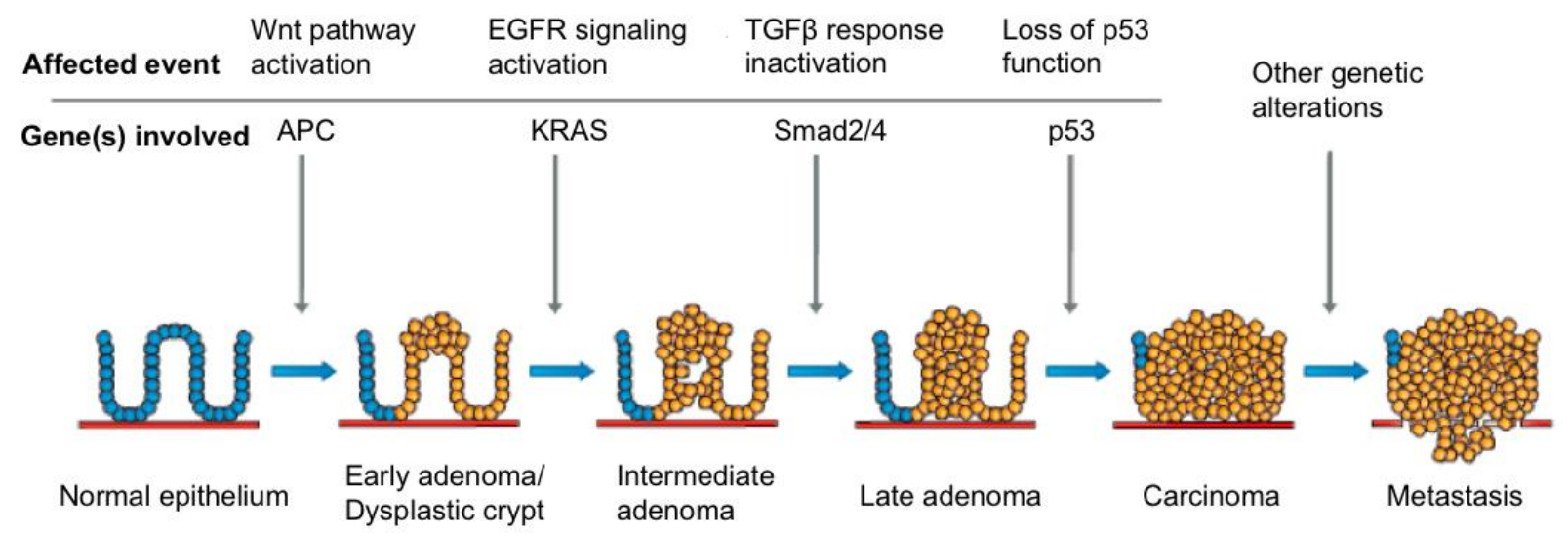

Figure 1.4: Vogelstein model of colon cancer induction

Modified from: http://syscol-project.eu/about-syscol/

The "Vogelstein model" describes the most common genetic mutation sequence over time that is associated with colon cancer as follows: 1) inactivating mutations in the Apc gene,

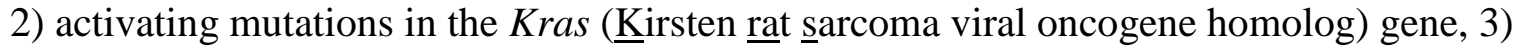
inactivating mutations in chromosome 18 , including the Dcc gene (deleted in colon cancer) and SMAD family members and 4) inactivating mutations in the Tp53 (Tumor protein p53) gene (Johnson et al., 2013 and Fearon et al., 1990). However, dozens of mutations may be detected in a given colon cancer tumor sample, with about 5-12 of the mutations being considered critical "driver" mutations that modulate on average 12-20 pathways (Johnson et al., 2013 and Leary et al., 2008). Furthermore, the Vogelstein model tends to characterize tumors from the descending colon, which accounts for about $80 \%$ of colon cancer.

Colon cancer etiology varies by location with tumors in the ascending colon being characterized more often by microsatellite instability, mutations in B-catenin, Braf (v-raf murine 
sarcoma viral oncogene homolog $\underline{B}$ ), TgfßIIR (transforming growth factor, beta receptor $\underline{\text { II }}$ ) and $\operatorname{Bax}$ (BCL2-associated $\underline{\mathrm{X}}$ protein), as well as often being preceded by poorly differentiated sessile growths, excess mucin production, hyperplastic serrated adenomas and Lynch syndrome. Tumors in the descending colon tend to be characterized by chromosomal instability, mutations in Apc, Kras, Smad and Tp53, as well as being preceded by benign adenomatous polyps, welldifferentiated, pedunculated tubular adenomas and FAP (Johnson et al., 2013). $70 \%$ of sporadic colon cancer is associated with mutations in the Apc gene and occur in the descending colon (Johnson et al., 2013). The sporadic colon cancer in the ascending colon tends to

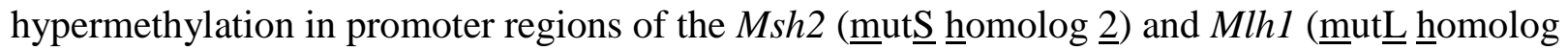
1) genes, which are associated with DNA mismatch repair mechanisms (MMR) (Johnson et al., 2013).

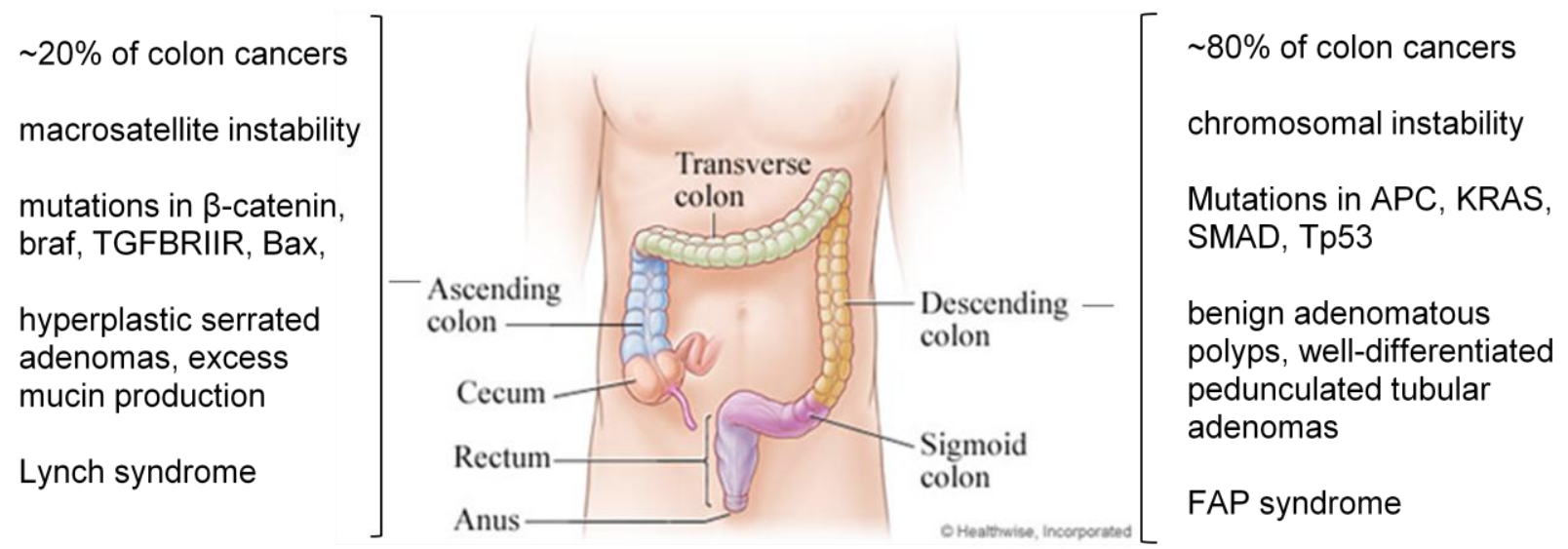

Figure 1.5: Ascending vs. Descending colon cancer

Modified from: http://www.webmd.com/colorectal-cancer/colonoscopy 


\section{Colon Cancer Modifiers and Research Models}

\section{4-1 Non-rodent models of colon cancer}

Cancer in the digestive tract has been detected in canines, primates and sheep. The canine presentation of cancer does closely mimic what has been shown in humans concerning the specific mutations and molecular pathways involved. However, the incidence of spontaneous cancer in dogs, as well as in primates and sheep, is less than $1 \%$ and primarily occurs in the small intestine, instead of the colon, as is seen in human patients (Johnson et al., 2013).

\section{4-2 Rodent models of colon cancer}

Mouse models were considered for the dissertation research, due to the biological similarities in the immune systems from mouse to human, the routine and ease of use, as well as the time efficiency for carcinogenesis models. The entire mouse genome is mapped and genetic manipulation of the mouse genome has become routine. Furthermore, the mouse strains discussed (129 wildtype and $\mathrm{Il}-10^{-/-}$on $129 / \mathrm{SvEv}$ genetic background) are well described and commonly utilized. Mice have much shorter life spans than humans, requiring less time for cancer to develop, or for testing drug efficiency.

\section{4-2-a Diet-associated}

\section{4-2-a-i Western diet}

Diet is an environmental factor closely associated with colon cancer. Although it is difficult to control for in human populations, mechanisms underlying its importance can be explored using rodent models. Although the "Westernized diet" is still being standardized in research publications, different diet preparations share in common trends of increased fat, 
increased sugar and reduced fiber. The AIN76A commercially available diet from Harlan Laboratories, has been modified to a "Western diet" that contains an increase in fat (20\%), a decrease in calcium $(0.05 \%)$ and a decrease in vitamin D (1000 IU/kg diet). Exposing mice and rats to this diet for 12 weeks was enough to induce hyperplasia within colonic crypts, dysplastic crypts and polypoid lesions when fed for 2 years (Newmark et al., 1990; Risio et al., 1996). Furthermore, increasing the calcium and vitamin D was enough to prevent colonic tumors. Increasing fiber and methyl-donor nutrients, however, failed to rescue the mice from colon cancer onset (Richter et al., 1995; Newmark et al., 2009; Johnson et al., 2013). Furthermore, the mRNA transcript profile of Paneth cell markers (normally only found at the bottom of small intestinal crypts) increased in intestinal villi and colon crypts with the addition of the Western diet to that seen in mice with loss of an allele in the $A p c$ gene, which indicates that diet is sufficient to increase risk for colon cancer (Wang et al., 2010). Dietary components can increase risk of colon cancer through affecting bile production and bile components, such as deoxycholic acid (DOC), which causes oxidative and nitrosative stress leading to DNA damage and mutations associated with colorectal cancer (Bernstein et al., 2011). Other associations with diet and human colon cancer include alcohol (increase risk), animal fats (increase risk), milk (reduced risk), Selenium (reduced risk) and vitamin D (reduced risk) (Vargas et al., 2012). This led me to ask the question of whether a dietary supplement of curcumin could effectively be used to limit the progression from chronic inflammation to colon cancer.

\section{4-2-a-ii PhIP (2-amino-1-metyl-6-phenylimidozo [4,5-b] pyridine)}

Another environmental factor associated with colon cancer is PhIP (2-amino-1-metyl-6phenylimidozo [4,5-b] pyridine), a heterocyclic amine found in cigarette smoke, diesel fumes and cooked meat and fish. The risk of exposure and production of PhIP increases as the 
temperature at which meat and fish is cooked increases. Boiling meat and fish and cooking at a lower temperature, even if cooking time is increased, reduces the risk. N-Hydroxylation of PhIP occurs in the liver through phase I hepatic cytochrome P450, mainly by CYP1A2, followed by phase II esterification with $\mathrm{N}$-acetyltransferase and $\mathrm{N}$-sulfotransferase. The resulting arylnitrenium ions react with nucleophilic sites on DNA, typically at guanine bases, and form DNA adducts, such as dG-C8-PhIP, the most common PHIP-associated DNA adduct (Nakagama et al., 2005). The dG-C8-PhIP DNA adduct has been detected in human colon tissue samples, using the 32P-postlabeling, HPLC and an IHC method using an anti-PhIP-adducted DNA polyclonal antibody (Nakagama et al., 2005). PhIP increases the rate of mutation in mammalian cells, such as Chinese hamster fibroblasts, as well as in colonic tissue of rats and mice. PhIP has been shown to be carcinogenic in the colon of rats. PhIP is carcinogenic in the colons of mice when used with either Dextran Sodium Sulfate (DSS) treatment or Apc ${ }^{\mathrm{Min}}$ mice. PhIP-induced tumors occur in the middle to distal regions of the colon tissue in rodents and primarily have mutations in the Cnntbl and $A p c$ genes (Johnson et al., 2013). This indicates that food-borne carcinogens can greatly increase the risk of colon cancer by affecting colonic epithelium directly. Thus, diet is a powerful factor in disease progression. This dissertation research focuses on using the environmental factor of diet as a therapeutic tool to decrease the risk of colon cancer.

\section{$\underline{\text { 4-2-b Genetics-associated (Apc }{ }^{\mathrm{Min}} \text { mouse) }}$}

Mouse model systems also exist that closely mimic the human genetic predisposition to develop colon cancer due to mutations in the $A p c$ gene, which is a commonly mutated gene in colon cancer that is associated with a specific familial syndrome, familial adenomatous polyposis (FAP). FAP characterized by hundreds of polyps along the colon tissue and accounts for about $1 \%$ of colorectal cancers (Johnson et al., 2013). The homozygous phenotype, or mutations in 
both alleles, for the $A p c$ gene results is fatal in embryonic mice. Thus, $\mathrm{Apc}^{\mathrm{Min}}$ mice are heterozygous with "min" standing for multiple intestinal neoplasms and allow for a model system of small intestinal polypoid growths. Tumors form in both the large and small intestines, with the greater burden being in the small intestine. The mutation arises from a T-to-A transversion that truncates the APC protein. This strain is well suited to identify genetic

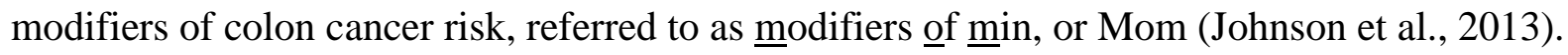
While mutations in the Apc gene are commonly found in sporadic human colon cancers, they do not account for all colon cancer types and our patient population of interest are patients with a history of chronic inflammatory bowel diseases that progress to colon cancer, rather than patients with known genetic predispositions, or known familial disorders that make them higher risk for colon cancer onset. Furthermore, $\mathrm{Apc}^{\mathrm{Min}}$ mice do not live long enough (tend to die by 120 days of age) on average to endure a long-term chronic research study (Johnson et al., 2013). For these reasons, the $129 / \mathrm{SvEv}$ background IL-10 $10^{-/}$mouse strain was chosen, which more closely models the patient population of interest by allowing spontaneous, progressive inflammation to be established before induction of the cancer with the chemical carcinogen AOM.

\section{4-2-c Chemically-induced}

\section{4-2-c-i Nitroso compounds}

Chemical carcinogens, such as N-methyl-N-nitro-N-nitrosoguanidine (MNNG) and Nmethyl-N-nitrosourea (MNU, NMU) can be used to induce colon cancer. Unfortunately, these carcinogens cause widespread cancer in various organs, including stomach, small intestine, large intestine, kidney, skin, lung, thymus, prostate and breast. This can be reduced if administered rectally, but still affects lung and thymus (Johnson et al., 2013). Although dietary treatments, 
such as the 1alpha-hydroxy-24-ethylcholechalciferol vitamin D analogue, have been shown to decrease the effectiveness of nitroso compounds to induce carcinogenesis, utilizing a carcinogen that is specific to the colon tissue would be especially beneficial.

\section{4-2-c-ii Azoxymethane}

$\mathrm{AOM}$ is a well-established chemical carcinogen of colon cancer in mice and rats and only causes tumors in the colon tissue. AOM is a derivative of 1,2-dimethylhydrazine (DMH) and functions as a carcinogen through alkylating DNA. The chemical AOM gets processed in multiple steps and locations. First, it is processed (specifically through hydroxylation to methylazoxymethanol) by cytochrome P450 in the liver. Then, it is excreted in the bile and further processed (into methyldiazonium) by bacteria residing in the colon. This is the most carcinogenic form of AOM. Because the carcinogenic metabolite is processed in the colon, it is active here and causes colon tissue-specific carcinogenesis, with the vast majority of the tumor burden occurring in the distal region of the colon where the bacterial burden is highest. It acts through alkylation of DNA (transfer of an alkyl group to a base - most common form of alkylation is methylation for DNA), causing base pair mismatches. The damage leads to poor repair and a higher likelihood for further mutations, all of which contribute to the cells gaining uncontrolled growth and division properties and, thus, to the onset of cancer (Neufert et al., 2007). AOM-associated tumors have the majority of mutations in the Ctnnb1 gene. These mutations affect the $\mathrm{N}$-terminal amino acids of the $\beta$-catenin protein, which results in stabilization and of the protein and upregulation of the WNT signaling pathway (Johnson et al., 2013). AOM is a well-established and commonly utilized chemical induction of colon cancer that makes it ideal for my research. It can be paired with models that mimic inflammatory bowel 
conditions, such as the dextran sulfate sodium salt (DSS) treatment model system and the $1110^{-1-}$ mice, which have spontaneous, progressive chronic inflammation. This facilitates research concerning colitis-associated colon cancer, which is the disease of interest and focus for my thesis.

AOM is commonly used with DSS, a chemical means of inducing damage to the epithelial lining of the gastrointestinal tract, resulting in an ulcerative-colitis type of colitisassociated colon cancer. Modulations of the AOM/DSS model vary from a single injection to multiple injections and changing the dose and timing of DSS (Neufert et al., 2007). However, this is a harsh treatment of the epithelial lining that recovers when the DSS is removed from the mouse's system. This dissertation research focuses on a patient population that has spontaneous and chronic colitis leading to colon cancer. AOM used with $I l 10^{-/}$mice more closely resembles a Crohn's type of colitis-associated colon cancer and is a well established model system in scientific literature. $I l 10^{-/-}$mice are able to survive long enough for long-term cancer studies and have a spontaneous, progressive inflammation that responds to treatments known to be effective in human patients, such as anti-TNF $\alpha$. For these reasons, the AOM-IL-10-deficient mouse model of colitis-associated colon cancer (Kanneganti et al., 2011; Uronis et al., 2009) was utilized. Below is a schematic describing the processing of azoxymethane, although it should be noted that recent studies suggest that the processing of AOM into the carcinogenic metabolites are not as dependent on microbiota as previously thought, as germ free (GF) mice have a much greater tumor burden than specific pathogen free (SPF)-housed mice given AOM and DSS (Zhan et al., 2013). 
Colonotropic tumor induction

by stepwise activation

Intraperitoneal injection

of azoxymethane

via bloodstream

to the liver

Hydroxylation to

methylazoxymethanol

by cytochromes P450

via bile
to the intestine
Activation to
methyldiazonium promoted
by factors of the bacterial flora
Chemical formula
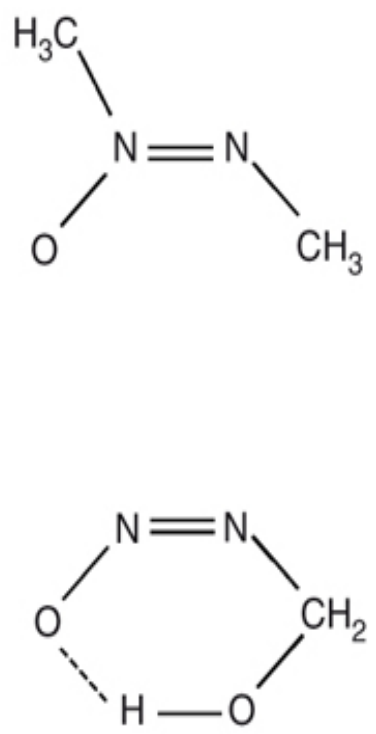

Figure 1.6: Azoxymethane (AOM) processing. From: Neufert et al. 2007. An inducible model of colitis-associated colon cancer. Nature Protocols 2(8):1998-2004.

\section{Chronic inflammation is linked to perturbation of the established gut microbiota}

A long-standing question in CAC research concerns the origin of inflammation. The gastrointestinal tract contains an incredibly complex and symbiotic microecosystem. The microbiota present in the intestines provide essential and non-redundant functions, such as fermentation of otherwise nondigestible dietary components and maintaining homeostasis of the human metabolism and immune system (Zhu et al., 2011 and Flint et al., 2012). However, perturbations of the microbial communities via diet changes or illness, for example, contribute to inflammation that can often become uncontrolled and chronic. The "keystone pathogen" 
hypothesis describes a phenomenon where a species of bacteria may have a disproportionately large impact on the host environment relative to its low abundance (Hajishengallis et al., 2012), as opposed to a single bacterial species becoming the predominant species and initiating tissue damage and disease. The interplay of one or more specific bacterial species with the entire commensal bacterial community to cause dysbiosis is illustrated through a study utilizing the TRUC mouse model system (Garrett et al., 2010). The combination of the bacteria Klebsiella pneumoniae and Proteus mirabilis failed to induce colitis in germ-free animals, while the combination did induce colitis in conventionally housed animals, suggesting a dependence on the interaction of these two bacterial species with the commensal microbiota community to induce disease. This indicates that global changes in microbial composition contribute to inflammation, which can become sustained in the host. The risk for colon cancer increases for patients diagnosed with chronic inflammatory bowel diseases. It is estimated that $18 \%$ of UC patients with a 30-year history of UC will develop colon cancer (American Cancer Society, 2014).

\section{5-1 Assessing Microbial Diversity}

Due to the inability to culture the majority of gut microbiota, culture-independent methods of assessing microbial diversity were explored. A common method is to collect a stool sample and sequence a single marker gene that is ubiquitously expressed and which is conserved over evolutionary time. The most common marker gene currently utilized is the $16 \mathrm{~S}$ ribosomal RNA subunit gene (16S rRNA). This gene has known conserved regions and known variant regions, which have unique sequences for each bacterium. Multiple sequences detected in a single stool sample can be tagged and compared to sequences in a reference database, such as GreenGenes, to get a more complete understanding of the microbial composition of the individual. Some caveats exist, such as the machine platform used for sequencing. Some 
platforms, such as the Illumina, are able to sequence many more sequences for a run than earlier technologies, which makes comparing results among publications using different platforms inappropriate, as there could be a sampling issue that strongly biases the results. Furthermore, there is some leniency to designing the barcodes that identify the variable regions of $16 \mathrm{~S}$ rRNA; tagged sequences that differ by only a few base pairs may really be the same sequence, just with a sequencing/read error. To allow for this, sequence divergence is generally set slightly lower than $100 \%$, typically $97 \%$. These clusters are assumed to be the same Operational Taxonomic Unit (OTU). The alpha diversity can be calculated, which represents the richness (number of taxa) and evenness (distribution of taxa) within each sample. Beta diversity measures the degree of overlap in taxa among samples. Diversity can be assessed by comparing OTUs or by comparing distances of sequences along a reference phylogenetic tree to indicate diversity of microbiota within a sample. Other culture-independent methods involve metagenomics, utilizing whole-metagenome shotgun (WMS) sequencing of genomic DNA fragments, as well as metatranscriptomics to assess RNA transcripts, metaproteomics to assess proteins and metametabolomics to assess small molecule metabolites of microbial communities (Morgan et al., 2014).

Steps of analysis are summarized as follows:

1. Extract DNA and amplify $16 \mathrm{~S}$ rRNA with barcoded primers

2. Pool samples

3. Sequence in 1 run (MiSeq on Illumina)

4. QIIME analysis software

a. Assign reads to samples

b. Assign sequences from the samples to OTUs

c. Compute UniFrac distances on a reference phylogenetic tree

d. Compare alpha diversity: richness (number of taxa) and evenness (distribution of taxa) based on OTUs

e. Compare beta diversity (how much overlap in taxa the samples have) based on UniFrac distances. 


\section{$\underline{5-2}$ Microbiota in healthy individuals}

Colonization of gut microbiota in full-term, naturally-delivered, breastfed, and healthy human newborns has been demonstrated to occur in steps and is critical to establishing healthy immune systems and healthy metabolic programming (Harmsen et al., 2000; Roger et al., 2010; Rautava et al., 2012). Early colonization is by the Firmicutes phylum with aerobic or facultatively anaerobic bacteria, such as Staphlococus and Streptococcus. Bacteria in the Actinobacteria phylum colonize next, along with more anaerobic bacteria, which include the Bifidobacterium genus. Next, the Bacteroidetes phylum and then more anaerobes, such as Clostridia and Eubacteria. The composition is beginning to stabilize at one year of age and proceeds to stabilize to that of an adult profile by 2-3 years of age (Rautava et al., 2012).

The majority of gut microbiota cannot be cultured in a lab. However, of bacteria that can be cultured, many studies consistently show that the most common species in adults include Bacteroides vulgatus, Eubacterium rectale, Faecalibacterium prausnitzii, Colinsella aerofaciens and Ruminococcus bromii (Flint et al., 2012). Yet, there is not a specific profile of bacterial composition identified as "healthy," as there exists an incredibly diverse array of microbial composition profiles among a healthy human population.

Diet is certainly an influential factor. Children raised in rural African communities that have a primarily plant-based diet high in fiber have an enrichment of the Bacteroidetes phylum and a decrease in the Firmicutes phylum, as well as an increased abundance in the Prevotella and Xylanibacter genera, compared to European children. Functionally, this relates to the presence of bacteria that can process cellulose and xylan, which were undetectable in European children. There was also an increase in short chain fatty acid production in African children, which is 
considered protective in the gut and provides energy to colonocytes and liver cells (De Filippo et al., 2010).

While there may not be a core microbial profile that is uniform for all healthy individuals, microbiota have a powerful influence over health, as demonstrated in the emergence of fecal transplants in clinical practice. In a clinical trial feasibility study, fecal microbiota transplant (FMT) therapy was shown to reduce diarrhea and relapses of Clostridium difficile infections in patients that had been poorly responsive to standard of care treatment. Donor stool was pooled from healthy donors and administered either by colonoscopy or nasogastric tube with both methods being effective and neither causing adverse effects (Youngster et al., 2014). Similar findings were demonstrated in a study using an acute colitis DSS model in research mice that were co-housed. The mice differed in their genetic background. One mouse strain was the healthy wildtype and one had a genetic mutation in the $\operatorname{Tm} f$ (Tata element modulatory factor) gene, which encodes a Golgi protein for vesicle tethering to target membranes. When this is mutated, mice produce especially thick mucus and have an altered microbial composition compared to wildtype mice. Additionally, they are resistant to the acute DSS initiation of colitis and can transfer this protection to wildtype mice housed in the same cage (Bel et al., 2014). Mice readily practice coprophagia, or consumption of feces, and can transfer microbiota through that method. Microbiota are a potentially powerful therapeutic tool.

This is an emerging field and what is known is that there are differences from healthy to diseased individuals, even though this is not standardized. A dramatic shift in the microbial communities is associated with triggering inflammation that can become chronic and contribute to sustained diseases. Furthermore, a loss of richness, or number of different microbial taxonomic groups present in an individual, is associated with disease. 


\section{$\underline{5-3 \text { Microbiota and gastrointestinal cancers }}$}

Inflammation has an established partnership with carcinogenesis in the intestines (Schwabe et al., 2013, Arthur et al., 2013, Chiba et al., 2012, Balkwill et al., 2001, Ullman et al., 2011 and Lin et al., 2007). Likewise, microbial pathogens are known to be associated with carcinogenesis in the gastrointestinal tract, such as Helicobacter pylori for gastric cancer, hepatitis C virus for hepatocellular carcinoma and Streptococcus bovis for Colorectal Cancer (Arthur et al., 2013, Chiba et al., 2012, Heidland et al., 2006, Marshall et al., 1995 and Klein et al., 1977). Even microbial products of commensal bacteria, such as CCL5, can contribute to inflammation-associated colorectal cancer by promoting aberrant epithelial cell proliferation $(\mathrm{Hu}$ et al., 2013). The question arises as to what is the link between microbial composition, inflammation and carcinogenesis. The paradigm is that microbial changes trigger inflammation, which, if sustained, leads to carcinogenesis. However, there has been a shift in the scientific dogma due to studies, which indicate that inflammation itself can modulate microbial composition and function, increasing the risk for carcinogenesis (Arthur et al., 2013, Morgan et al., 2012, Sokol et al., 2008 and Arthur et al., 2012). Indeed, it is possible that carcinogenesis itself can alter microbial composition, although it remains mechanistically unclear whether the microbiota affects the carcinogenesis, or the other way around. Microbial composition is altered under cancer conditions versus healthy individuals. Establishing microbiota in completely germfree mice, using a tumor-bearing mouse source, was sufficient to increase their risk of carcinogenesis for the chemical carcinogen utilized (Azoxymethane). Furthermore, this effect was negated with the addition of antibiotics (Zackular et al, 2013). 


\section{5-4 Microbiota and colon cancer}

The microbial composition has been shown to be altered in colorectal cancer patients, compared to healthy individuals (Arthur et al., 2013, Sobhani et al., 2011, Wang et al., 2012, Sanapareddy et al., 2012, Marchesi et al., 2011 and Kostic et al, 2012). The microbial composition has also been shown to differ significantly between healthy mice and mice with colitis. Furthermore, the microbial richness is reduced during colitis in mice, as well as in human patients (Arthur et al., 2013, Uronis et al., 2009, Ott et al., 2004 and Manichanh et al., 2006). These studies were done with mice bred in a completely germ-free (GF) facility and transferred to a specific-pathogen free facility (SPF) for the duration of the studies. Interestingly, although changes in commensal bacteria composition were associated with colitis and carcinogenesis, commensal bacteria also play a significant role in protection from inflammation and carcinogenesis. Using an AOM/DSS model, when mice are bred in an SPF facility, compared to GF, they have fewer and smaller tumors, decreased epithelial proliferation and less delay in intestinal epithelial repair. Recolonization of GF mice with commensal bacteria from SPF-bred mice lessened the severity of the disease (Zhan et al., 2013). The commensal microbiota benefits the host by synthesizing essential vitamins, generating various nutrients from complex dietary carbohydrates, educating the mucosal immune system and competing with invading pathogenic organisms (Arthur et al., 2013, Chiba et al., 2012, Hooper et al., 2001 and Lozupone et al., 2012). While the commensal microbiota serve many protective roles and no single type of bacteria has been absolutely linked to colorectal cancer, it has an undeniable association with disease progression due to changes in the overall composition, which implies that it could, in turn, have an effective role in disease prevention for future therapeutics. 
Table 1.1: Specific changes in microbial composition during colon cancer

\begin{tabular}{|c|c|c|c|}
\hline Gut microbiota & Effect & Model system & Reference \\
\hline B. vulgatus & $\begin{array}{l}\text { increase efficacy of Azoxymethane } \\
\text { (AOM)-induced colon cancer }\end{array}$ & $\begin{array}{l}\text { mice (IL10 deficient), mono- } \\
\text { associated in germ free } \\
\text { facility and compared to SPF- } \\
\text { housed }\end{array}$ & $\begin{array}{l}\text { Uronis et al., } \\
2009\end{array}$ \\
\hline E. coli & $\begin{array}{l}\text { increased abundance in colon cancer } \\
\text { patient biopsies }\end{array}$ & biposies from human patients & $\begin{array}{l}\text { Martin et al., } \\
2004\end{array}$ \\
\hline E.coli & $\begin{array}{l}\text { promote invasive carcinoma during AOM- } \\
\text { induction colon cancer }\end{array}$ & mice (IL10 deficient) & $\begin{array}{l}\text { Arhur et al., } \\
2012\end{array}$ \\
\hline E. faecalis & $\begin{array}{l}\text { induce chromosomal instability } \\
\text { (aneuploidy and tetraploidy) in colonic } \\
\text { epithelial cells }\end{array}$ & $\begin{array}{l}\text { cells: HCT116, RKO and } \\
\text { YAMC }\end{array}$ & $\begin{array}{l}\text { Wang et al., } \\
2008\end{array}$ \\
\hline $\begin{array}{l}\text { enterotoxigenic } \\
\text { B. fragilis }\end{array}$ & $\begin{array}{l}\text { induce colonic tumors, IL-17-dependent } \\
\text { mechanism }\end{array}$ & $\begin{array}{l}\text { mice (Multiple intestinal } \\
\text { neoplasia - Min) }\end{array}$ & $\begin{array}{l}\text { Wu et al., } \\
2009\end{array}$ \\
\hline $\begin{array}{l}\text { Fusobacterium } \\
\text { genus }\end{array}$ & $\begin{array}{l}\text { increased abundance in rectum of colon } \\
\text { cancer patients }\end{array}$ & human rectum tissue biopsies & $\begin{array}{l}\text { McCoy et al., } \\
2013\end{array}$ \\
\hline H. hepaticus & $\begin{array}{l}\text { increase efficacy of Azoxymethane } \\
\text { (AOM)-induced colon cancer }\end{array}$ & mice (BALB/c-IL10 deficient & $\begin{array}{l}\text { Nagamine et } \\
\text { al., } 2008\end{array}$ \\
\hline $\begin{array}{l}\text { L. casei, } L . \\
\text { acidophilus }\end{array}$ & $\begin{array}{l}\text { protective, decrease activity of beta- } \\
\text { glucourinodase, azoreductase and } \\
\text { nitroreductase }\end{array}$ & $\begin{array}{l}\text { rats, measured for free amines } \\
\text { in diet after administration of } \\
\text { probiotics }\end{array}$ & $\begin{array}{l}\text { Goldin et al., } \\
1984\end{array}$ \\
\hline L. acidophilus & $\begin{array}{l}\text { protective, decrease activity of beta- } \\
\text { glucuronidase and nitroreductase }\end{array}$ & humans, dietary supplement & $\begin{array}{l}\text { Goldin et al., } \\
1980\end{array}$ \\
\hline S. bovis & $\begin{array}{l}\text { increased abundance ( } \mathrm{p} \text { value }<0.001 \\
\text { compared to healthy controls) in patients } \\
\text { with carcinoma in the colon }\end{array}$ & $\begin{array}{l}\text { human patients with colon } \\
\text { carcinoma }\end{array}$ & $\begin{array}{l}\text { Klein et al., } \\
1977\end{array}$ \\
\hline $\begin{array}{l}\text { Prevotella genus } \\
\text { (Bacteroidetes } \\
\text { phylum) }\end{array}$ & $\begin{array}{l}\text { increased abundance ( } \mathrm{p} \text { value } 0.009 \text { ) in } \\
\text { human colon cancer patients }\end{array}$ & $\begin{array}{l}\text { stool sample prior to } \\
\text { colonoscopy }\end{array}$ & $\begin{array}{l}\text { Sobhani et al., } \\
2011\end{array}$ \\
\hline $\begin{array}{l}\text { Coriobacteria, } \\
\text { Roseburia, } \\
\text { Fusobacterium, } \\
\text { Faecalibacterium } \\
\text { genera }\end{array}$ & increase in tumors of colon cancer patients & $\begin{array}{l}\text { human, tumor vs. adjacent } \\
\text { tissue }\end{array}$ & $\begin{array}{l}\text { Marchesi et } \\
\text { al., } 2011\end{array}$ \\
\hline $\begin{array}{l}\text { Bacteroides, } \\
\text { Odoribacter, } \\
\text { Akkermansia } \\
\text { genera }\end{array}$ & $\begin{array}{l}\text { increased abundance in mice with tumors, } \\
\text { microbiota from these mice into germ-free } \\
\text { resulted in increased tumor burden }\end{array}$ & $\begin{array}{l}\text { mice }(\mathrm{C} 57 \mathrm{BL} / 6), \mathrm{AOM} / \mathrm{DSS} \\
\text { model }\end{array}$ & $\begin{array}{l}\text { Zackular et al., } \\
2013\end{array}$ \\
\hline $\begin{array}{l}\text { Lactobacillus } \\
\text { S06, E. } \\
\text { aerofaciens }\end{array}$ & $\begin{array}{l}\text { increased abundance in patients with low } \\
\text { risk for colon cancer }\end{array}$ & $\begin{array}{l}\text { humans with colonic polyps } \\
\text { (stool samples) }\end{array}$ & $\begin{array}{l}\text { Moore et al., } \\
1995\end{array}$ \\
\hline $\begin{array}{l}\text { B. vulgatus, } \\
\text { Eubacterium } \\
\text { spp., } \\
\text { Ruminococcus } \\
\text { spp., S. hansenii, } \\
\text { Bifidobacterium } \\
\text { spp., F. } \\
\text { prausnitzii }\end{array}$ & $\begin{array}{l}\text { increased abundance in patients at high } \\
\text { risk for colon cancer }\end{array}$ & $\begin{array}{l}\text { humans with colonic polyps } \\
\text { (stool samples) }\end{array}$ & $\begin{array}{l}\text { Moore et al., } \\
1995\end{array}$ \\
\hline
\end{tabular}




\section{Curcumin: bridging the therapeutic gap between inflammation and colorectal carcinogenesis}

This thesis addresses the potential roles of Curcumin to prevent major perturbations in the microbial communities, as well as to maintain homeostasis of the immune system. Curcumin is a component of the turmeric cooking spice, which is isolated from the rhizome of the Curcuma Longa plant. It is an incredibly promising compound for therapeutic uses, due to its ability to regulate inflammation, oxidation and carcinogenesis. The low toxicity of this compound provides a promising medicinal alternative for patients suffering from colitis-associated colorectal cancer. Curcumin is tolerated well in humans at doses as high as $12 \mathrm{~g} /$ day/adult (Lao et al., 2006).

\section{$\underline{6-1 \quad \text { Structure and components }}$}

Curcumin is the most abundant and most bioactive analogue component of curcuminoids, comprising of about $77 \%$ of the total. Demethoxycurcumin comprises about $17 \%$ and bisdemethoxycurcumin comprises the remaining 3\%. Each curcuminoid shares a common aromatic ring, but differs in the methoxy substitutions of aryl moieties. Curcumin is a hydrophobic polyphenol bis $\alpha, \beta$ unsaturated $\beta$-ketone known as diferuloylmethane, or 1,7-bis-(4hydroxy-3-methoxyphenyl)-1,6-heptadiene-3,5-dione. It is a linear diarylheptanoid with 2-oxysubstituted aryl moieties connected through a 7-carbon chain (Soni et al., 2012). In addition, curcumin has bioactive degradation products with the most common being ferulic acid and vanillin (Ji et al., 2014). 


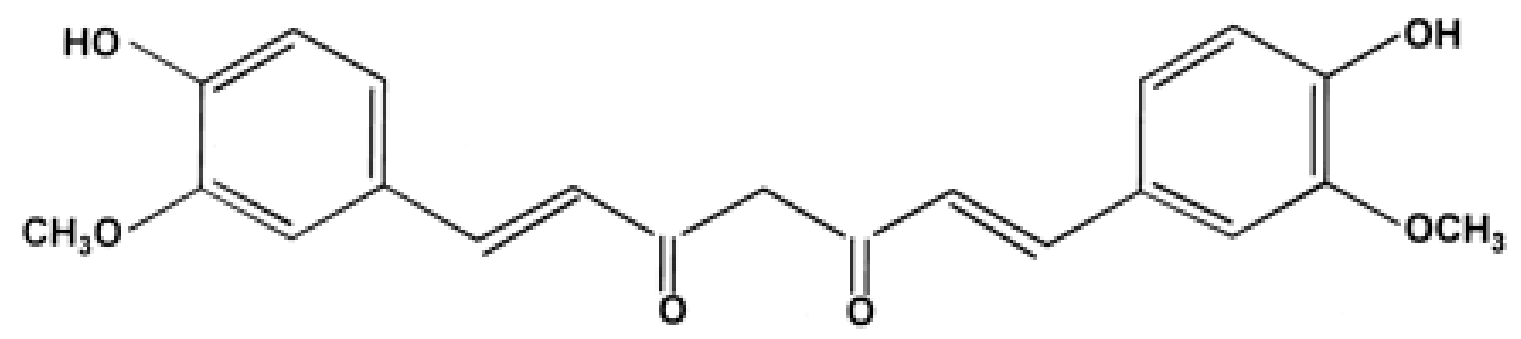

\section{CURCUMIN}

Figure 1.7: Structure of curcumin. From: Kawamori et al. 1999. Chemopreventive Effects of Curcumin, a Naturally Occuring Anti-Inflammatory Agent, during the Promotion/Progression Stages of Colon Cancer. Cancer Research 59:597-601.

\section{6-2 Targets of curcumin}

Curcumin is able to regulate a large array of targets, including tumor suppressor genes (Rb, p53 and PTEN), growth factors (TGF- $\beta$, EGF and p21), kinases (AMPK, Cyclin D and Akt), transcription factors (NF- $\kappa \mathrm{B}, \mathrm{STAT}-3, \beta$-catenin and AP-1), enzymes (COX2, iNOS and MMPs), inflammatory cytokines (IL-6, IL-1 $\beta$, TNF- $\alpha$ and MCP), Apoptotic genes (Bcl-2, Bak, Bax and Caspase 8) and Oncoproteins (c-Myc, Ras and Fas) (Ramamoorthi et al., 2014). Thus, curcumin is an incredibly promising compound for cancer therapeutics, as it can inhibit cell growth cycle and survival mechanisms. 


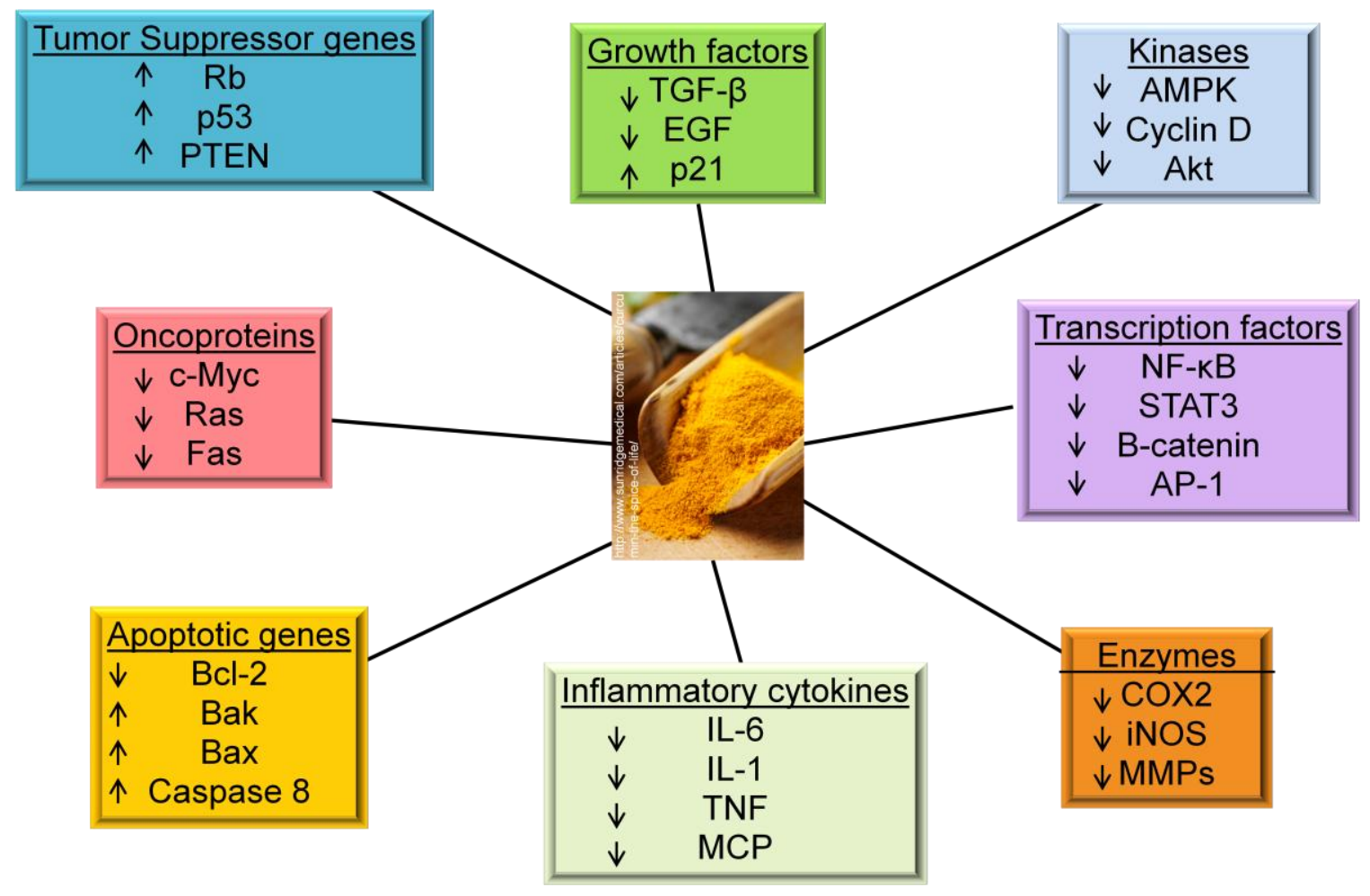

Figure 1.8: Targets of curcumin

Modified from Ramamoorthi, G. and N. Sivalingam. 2014. Molecular mechanism of TGF- $\beta$ signaling pathway in colon carcinogenesis and satus of curcumin as chemopreventive strategy. Tumor Biology ePub ahead of print.

\section{6-3 Functions of curcumin}

Mechanistically, curcumin can limit colon cancer progression through increasing mRNA expression and protein levels of the DNA damage-inducible gene (DDIT3), resulting in induction of chromatin condensation and DNA fragmentation. Furthermore, Curcumin promotes cell cycle growth arrest through regulation of c-myc, cyclin D, Cyclin B and cell division control 2 (CDC2) (Shishodia et al., 2007). Curcumin can induce apoptosis in colorectal cancer cells (Caco2) through inhibition of the Polyisoprenylated methylated protein methyl esterase (PMPMEase) enzyme (Amissah et al., 2013). However, the ability of curcumin to affect the gut microbiota is unknown and, thus, is an exciting frontier of research in colitis-associated colorectal cancer. 


\section{6-4 Bioavailability of curcumin}

Curcumin is considered poorly absorbed, rapidly metabolized and rapidly eliminated with low aqueous solubility (Ji et al., 2014). A study from our lab detected through HPLC analysis significant amounts (ranging from $1.54 \pm 0.2 \mathrm{mM}$ to $7.54 \pm 0.3 \mathrm{mM}$ ) of unmetabolized curcumin in the colon lumen for mice fed curcumin in their diets with doses ranging from $0.1 \%$ to $1 \%$ (Larmonier et al., 2008). Nevertheless, it remains highly effective and much effort has been placed into increasing its bioavailability. Bioavailability increases $154 \%$ when curcumin is administered concomitantly with the adjuvant piperine, an inhibitor of hepatic and intestinal glucouronidation, to human patients and research rodents. Clearance time of curcumin is significantly reduced with piperine and serum concentration is significantly increased, as is the time to maximum serum concentration (Shoba et al., 1998). There is a clinical trial actively recruiting for patients to assess bioavailability of curcumin using plant exosomes as a delivery method (clinicaltrials.gov ID:NCT01294072). Furthermore, curcumin has been explored for use in increasing bioavailability of nanoparticle-based therapeutics against colorectal cancer.

Curcumin was shown to enhance uptake and mucoadhesiveness of the nanoparticles in colorectal cancer cells in an ex vivo study. The curcumin-loaded nanoparticles also promoted cell cycle arrest in the $\mathrm{G}_{2} / \mathrm{M}$ phase and reduced overall cell viability of the cancer cells (Chuah et al., 2014). Apart from muco-adhesiveness, the targeting and drug delivery of curcumin has been explored for colorectal cancer research. Curcumin-loaded lipid-polymer-lecithin hybrid nanoparticles were synthesized with ribonucleic acid Aptamers against the epithelial cell adhesion molecule (Apt-CUR-NP) in order to deliver curcumin to colorectal adenocarcinoma cells. The Apt-CUR-NP bioconjugates demonstrated increased cytotoxicity of the HT29 
colorectal cancer cell line, as well as improved binding of Curcumin to the target when compared to free unbound Curcumin, or particles made with a control Aptamer (Li et al., 2014).

\section{6-5 Curcumin and cancer therapeutics}

Apart from the numerous roles of curcumin to affect specific targets to reduce inflammation, oxidative stress and carcinogenesis, curcumin has been shown to enhance the effectiveness of cancer therapeutics, such as 5-fluorouracil (5-FU). This is especially beneficial because patients can develop a resistance to 5-FU. When cells were treated concomitantly with 5-FU and curcumin, those cultures demonstrated cell cycle growth arrest, increased apoptosis and a decrease in cell surface markers associated with cancer stem cells (Shakibaei et al., 2014). Many clinical trials have been completed, or are ongoing that address the toxicity of curcumin (ClinicalTrials.gov ID: NCT00027495, NCT01859858), as well as its effectiveness when used with other chemotherapeutic agents (NCT01490996) or as a colon cancer preventative agent (NCT00003365, NCT00973869).

\section{6-6 Curcumin effects on bacteria}

Curcumin has been reported to work as an antimicrobial agent. It has been shown to inhibit biofilm formation when administered to K. pneumoniae in vitro (Magesh et al., 2013). The combination of curcumin and cinnamaldehyde also resulted in inhibition of biofilm formation, inhibition of planktonic culture growth and disruption of bacterial membranes of $S$. epidermidis in vitro (Sharma et al., 2014). Through a macrodilution broth susceptibility method, curcumin was shown to reduce bacterial growth of numerous strains, including methicillinsensitive $S$. aureus, methicillin-resistant S. aureus, E. faecalis, B. subtilis, $P$. aeruginosa, E. coli 
and K. pneumoniae (Gunes et al., 2013). Furthermore, curcumin can have an inhibitory effect on pathogenic products of bacteria. Curcumin was shown to inhibit the Sortase A enzyme, which affects the cariogenicity of S. mutans in dental caries (Hu et al., 2013). Besides inhibiting bacterial growth, curcumin has also been shown to limit bacterial adhesion and RTX toxin binding of the bacterial pathogen $V$. vulnificus and protected research mice from septicemia (Na et al., 2011). The effects of curcumin on bacteria in culture are well established, while its effect on gut bacteria, specifically, is understudied and its effect on global microbial composition in the context of colitis-associated colon cancer remains unknown and is the focus of this dissertation. 


\section{Summary}

Curcumin serves an important function in regulation of intestinal inflammation and colorectal carcinogenesis. The use of curcumin as a possible therapeutic and/or preventive agent for colonic inflammation and cancer, is a promising area of research in the context of modulation of the gut microbiota during colitis-associated colon cancer, as this is a novel study in the field. Hypothesis: curcumin will modulate the bacteria of AOM-treated chronically-inflamed $I l 10^{-1-}$ mice to become similar in composition to that of healthy, untreated wildtype mice, thus restoring the health of the mice.

The main goal of the dissertation research is to identify a chemopreventive strategy that restores a healthy microbiota through the dietary addition of curcumin.

The research aims are twofold:

A) To optimize the methodology of colonic microbiota analyses based on Illumina (MiSeq) 16S ribosomal RNA gene sequencing with the goal of adapting this cost-effective next generation sequencing strategy for detailed taxonomic analyses of complex microbial communities in the colon.

B) To evaluate the chemopreventive effects of dietary curcumin on the development and progression of colon cancer and the associated changes in composition of luminal and mucosal colonic microbiota. 


\section{CHAPTER 2: DATA ANALYSIS}

\section{A. METHODS}

\section{$\underline{\text { Curcumin }}$}

98.05\% pure curcumin, free of contaminating curcuminoids (demethoxy-curcumin and bis-demethoxy-curcumin) was obtained from ChromaDex (Irvine, CA). Curcumin was incorporated into NIH-31 modified open formula at $0.05,0.1,0.5$ and $1 \%$ and pelleted by Harlan Teklad (Madison, WI).

\section{$\underline{\text { Experimental animals }}$}

Specific pathogen-free wild type (WT) $129 / \mathrm{SvEv}$ mice and germ-free $I l 10^{-/}$mice on the same genetic background were originally obtained from the National Gnotobiotic Rodent Resource Center at the University of North Carolina, Chapel Hill and transferred to a conventional animal facility at the University of Arizona Health Sciences Center. Sentinel mice were routinely monitored and determined as free from common murine pathogens (MHV, MPV, MVM, TMEV, Mycoplasma pulmonis, Sendai, EDIM, MNV, ecto- and endoparasites). All animal protocols and procedures were approved by the University of Arizona Animal Care and Use Committee. 
$\underline{\mathrm{AOM} / \mathrm{Il1} 0^{-/-} \text {model: }}$

We utilized a well-documented model to study the development of colitis-associated colon cancers in IL-10 deficient mice (Kanneganti et al., 2011; Uronis et al., 2009). This protocol is based on the use of the mutagenic agent, AOM, which exerts colonotropic carcinogenicity. The advantage of using AOM is that that it does not represent by itself the final carcinogenic metabolite. AOM requires further stepwise activation after intraperitoneal injection, which includes a hydroxylation step mediated by cytochrome p450 in the liver and therefore limits personnel exposure to the carcinogen. In addition AOM-induced carcinogenesis includes high potency and reproducibility with a simple mode of application. Tumors induced by AOM are present in the distal colon, which resembles the predominant localization of spontaneous CRC reported in human patients. Repeated intraperitoneal administrations of AOM $(10 \mathrm{mg} / \mathrm{kg})$ were given once per week for six weeks to initiate tumorigenesis. AOM administration began at age 10 weeks to allow for colitis to develop spontaneously in the IL-10 deficient mice.

The analysis of tumor development can be performed by identification of tumor load and histopathological analysis.

\section{Histology and scoring:}

Proximal and distal colons from WT and $1 l 10^{-/-}$mice on different curcumin diets were harvested and fixed in $10 \%$ neutral buffered formalin (Fisher Scientific, Tustin, CA). Fixed tissues were then embedded in paraffin, and 5- $\mu$ m-thick tissue cuts were stained with hematoxylin and eosin (H\&E) for light microscopic examination. Sections were graded by a veterinary pathologist blinded to the study design according to previously published criteria (Kiela 2004). 
Immunohistochemistry:

Sections of proximal and distal colon were prepared as above. Tissues were harvested, fixed in $10 \%$ neutral buffered formalin for 24 hours, processed and embedded in paraffin. Routine hematoxylin and eosin (H\&E) stains were performed on sections of tissue cut to a thickness of 3 microns from the formalin fixed, paraffin embedded (FFPE) blocks. Immunohistochemistry (IHC) of a rabbit monoclonal antibody to Beta Catenin clone E247 (AbCam) was performed using human colon cancer tissues as the positive tissue controls. IHC of Ki67 was performed using a rabbit polyclonal antibody (\#NCL-Ki67p, Leica Biosystems GmbH, Nussloch, Germany), using human tonsil tissue as a positive control. Tissue sections were stained with a Discovery XT Automated Immunostainer (Ventana Medical Systems, Inc., Tucson, AZ; VMSI) using VMSI validated reagents for deparaffinization, cell conditioning (antigen retrieval with a borate-EDTA buffer), primary antibody staining, detection and amplification using a biotinylated-streptavidin-HRP and diaminobenzidine (DAB) system and hematoxylin counterstaining. Following staining, slides were dehydrated through graded alcohols to xylene and coverslipped with mounting medium.

Images were captured using an Olympus BX50 microscope, and an Olympus DP72 camera equipped with CellSens ${ }^{\circledR}$ imaging software. All images were standardized for light intensity and white balance. Microphotographs were taken with a 40x objective for all treatment groups stained with antibodies to Beta Catenin and Ki-67. An experienced clinical pathologist performed the IHC analyses. Analysis of Beta catenin was expressed using pathology long scores. The long scores represent staining intensity ranging from $1+-3+$ and a percentage of 
positively stained cells ranging from 1-100\%. Long scores were calculated by multiplying the intensity by the percentage. The long score minimum is 1 and the long score maximum is 300 .

\section{Real-time RT-PCR:}

Real-time RT-PCR was used to evaluate mucosal expression of TNF- $\alpha$, IFN $\gamma$, IL-6, IL1ß, IL-17, IL-12p40, IL-23 mRNA. Total RNA was isolated from mouse distal colon using TRIzol reagent (Invitrogen, Carlsbad, CA). 250ng of total RNA was reverse-transcribed using iScript cDNA synthesis kit (Bio-Rad, Hercules, CA). Subsequently, $20 \mu 1$ of the PCR reactions were set up in 96-well plates containing $10 \mu 1$ 2x IQ Supermix (Bio-Rad), $1 \mu 1$ TaqMan ${ }^{\circledR}$ primer/probe set (ABI, Foster City, CA), $2 \mu 1$ of the cDNA synthesis reaction (10\% of RT reaction) and $7 \mu l$ of nuclease-free water. Reactions were run and analyzed on a Bio-Rad iCycler iQ real -time PCR detection system. Data were analyzed by using the comparative $\mathrm{C}_{\mathrm{t}}$ method as means of relative quantification, normalized to an endogenous reference (TATA Box Bonding Protein, TBP or glyceraldehyde 3-phosphate dehydrogenase, GAPDH) and relative to a

calibrator (normalized $\mathrm{C}_{\mathrm{t}}$ value obtained from control mice) and expressed as $2^{-\Delta \Delta \mathrm{C}_{\mathrm{t}}}$ (Applied Biosystems User Bulletin \#2: Rev B "Relative Quantification of Gene Expression”).

\section{Bacterial DNA processing:}

Fecal samples were collected fresh once per month from individual mice directly into sterile Eppendorf tubes and stored at $-80^{\circ} \mathrm{C}$ until processing. For processing, frozen stool samples were individually placed into an Eppendorf tube containing autoclaved zirconium beads, lysis buffer $(100 \mathrm{mM} \mathrm{NaCl}, 10 \mathrm{mM}$ Tris, $100 \mathrm{mM}$ EDTA and $0.2 \mathrm{mg} / \mathrm{ml}$ Proteinase $\mathrm{K})$ and a solution of 20\% DNAse-free SDS (Sodium dodecyl sulfate) and incubated for 2 hours. The 
samples were then exposed to 24:24:1 Phenol:Chloroform:IAA (Ph 8.0, lowest phase) and placed into an automatic bead beater machine on high for $2 \mathrm{~min}$, than centrifuged $(8,000 \mathrm{rpm}$ for 3 min.). The aqueous phase was collected and mixed again with 1:1 Phenol:Chloroform and centrifuged (13,000 rpm, $3 \mathrm{~min}$.). The aqueous phase was collected, exposed to $-20^{\circ} \mathrm{C}$ isopropanol with 1:10 3M sodium acetate and incubated at $4{ }^{\circ} \mathrm{C}$ for $20 \mathrm{~min}$. The samples were centrifuged $\left(13,000 \mathrm{rpm}\right.$ for $20 \mathrm{~min}$. at $\left.4^{\circ} \mathrm{C}\right)$ and excess supernatant was discarded. The remaining pelleted material in the tube was washed with cold $\left(4^{\circ} \mathrm{C}\right) 100 \%$ molecular grade ethanol and centrifuged $\left(13,000 \mathrm{rpm}\right.$ for $5 \mathrm{~min}$. at $\left.4^{\circ} \mathrm{C}\right)$. Excess supernatant was discarded and the remaining pelleted material was allowed to dry and then re-suspended in TE (Tris-EDTA, $\mathrm{pH}$ 8.0) buffer.

Generation of $16 \mathrm{~S}$ amplicon library and MiSeq sequencing

The V4 hypervariable region of the 16S rRNA gene was amplified using barcoded PCR with 515F and 806R primers following the Earth Microbiome Project protocol (Caporaso et al., 2012) and quantified using a Nanodrop instrument. Sequencing was performed at Argonne National Laboratories on an Illumina MiSeq (Serial \# M02149) using the MCS (MiSeq Control Software) version 2.2.0. The data generated in this study will be available in the QIIME DB pending publication.

\section{QIIME analysis of microbial diversity:}

The sequence data was analyzed using QIIME 1.7.0-dev (Caporaso et al., 2010). Sequences were assigned to clusters of 97\% similarity using QIIME's uclust-based (Edgar et al., 2010) open-reference OTU picking protocol with the Greengenes 13_5 reference sequence set 
(McDonald et al., 2012). The centroid of each OTU was chosen as the representative sequence for the OTU. The representative sequences were aligned with PyNast (Caporaso et al., 2010) and the trees were constructed with FastTree(4) for phylogenetic calculations. Beta-diversity calculations were performed using weighted and unweighted-unifrac metrics(Lozupone et al., 2005) as implemented in QIIME(Caporaso et al., 2010). Alpha diversity metrics were calculated using whole tree phylogenetic diversity (Faith et al., 1992) and chao1 (Chao et al., 1984) as implemented in QIIME.

\section{$\underline{\text { Statistical Analysis: }}$}

Statistical significance (for non-sequencing data) was determined by the analysis of variance (ANOVA) followed by Fisher PLSD post-hoc test with StatView software package v.4.53 (SAS Institute, Cary, NC). Data were expressed as mean \pm standard error of mean. Nonparametric paired t-tests were done using Excel software.

Statistical significance (sequencing data) was determined by non-parametric paired t-test for the alpha diversity analysis comparing different OTUs in samples, compared using 1000 permutations. Differences among groups within beta diversity were calculated using ANOSIM (Analysis of Similarity) using 1000 permutations for the calculation of R-values. The Bonferroni-corrected test was also used for beta diversity multivariate analysis comparing different taxa associated with OTUs among groups of samples, as well as for PICRUSt-derived data. Taxonomic data was further expressed as mean \pm standard deviation and non-parametric $\mathrm{t}-$ tests were done using Excel software where indicated. 


\section{B. RESULTS}

\section{1. $I I 10^{-/} / \mathrm{AOM}$ Colitis-associated colon cancer mouse model system}

Using a colitis-associated colon cancer mouse model system, $I l 10^{-/-}$mice and the wildtype control mice were allowed to age to 10 weeks by which point the $1110^{-/}$mice develop a spontaneous and progressive colitis (Kühn et al., 1993 and Gomes-Santos et al., 2012). We fed the wildtype and the chronically inflamed $I l 10^{-/-}$mice with curcumin in their pelleted diets (prepared by Harlan Laboratories, Table 2.1) at the following doses: 0\% (control diet), 0.05\%, $0.1 \%, 0.5 \%$ and $1 \%$. These mice were injected with either a carcinogen, Azoxymethane (AOM), or a placebo, Phosphate Buffered Saline (PBS) (Fig. 2.1A). There were six mice in each group with a total of 120 mice (Fig. 2.1B). 


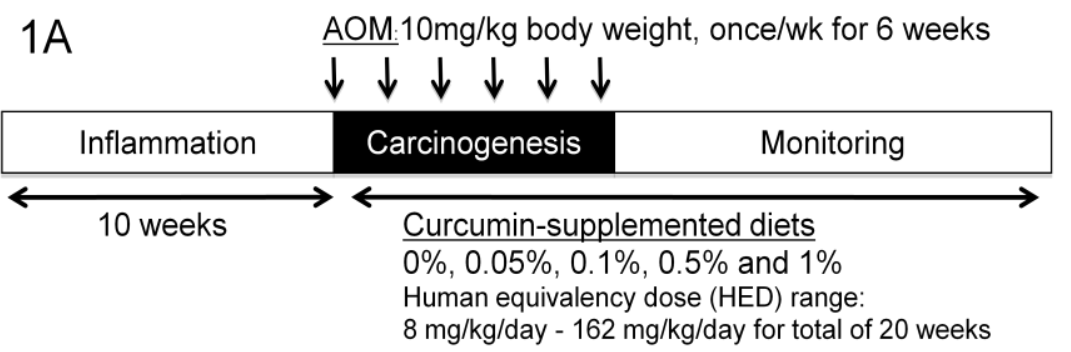

Table 1

Base diet for Curcumin diets

Harlan Laboratories. Tekland diet 7013. NIH-31 for full list

\begin{tabular}{l|l|} 
Macronutrients \\
\hline Crude protein & $18.0 \%$ \\
\hline Fat & $6.2 \%$ \\
\hline Carbohydrate & $45.0 \%$ \\
\hline Crude fiber & $4.0 \%$ \\
\hline Neutral detergent fiber & $13.6 \%$ \\
\hline Minerals \\
\hline Calcium & $1.1 \%$ \\
\hline Phosphorus & $1.0 \%$ \\
\hline Sodium & $0.3 \%$ \\
\hline Amino Acids & $1.1 \%$ \\
\hline Alanine & $1.0 \%$ \\
\hline Glycine & $1.5 \%$ \\
\hline Proline & $1.4 \%$ \\
\hline Leucine & $0.8 \%$ \\
\hline Isoleucine & $1.2 \%$ \\
\hline Fatty Acids & $1.5 \%$ \\
\hline Total Saturated & $2.8 \%$ \\
\hline Total Monounsaturated & \\
\hline Total Polyunsaturated & $24.2 \mathrm{IU} / \mathrm{g}$ \\
\hline Vitamins \\
\hline Vitamin A & $7.2 \mathrm{IU} / \mathrm{g}$ \\
\hline Vitamin D3 \\
\hline Vitamin B1 \\
\hline \multicolumn{2}{|l}{} \\
\hline
\end{tabular}

1B

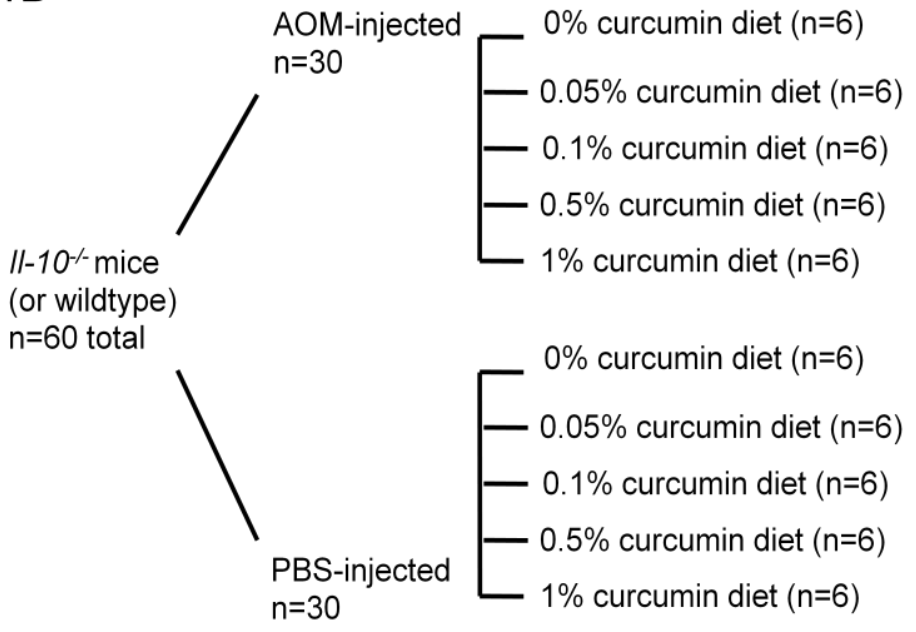

Vitamin B1

Figure 2.1: Experimental setup. $I l 10^{-/}$mice and wildtype control mice were arranged in groups of 6 for each curcumin diet dose: $0 \%, 0.05 \%, 0.1 \%$ and $0.5 \%(1 \mathrm{~B})$ and maintained until 10 weeks of age to allow development of colitis in the $I l 10^{-/-}$mice. Mice were given either a Phosphate buffered saline placebo injection or an Azoxymethane injection once per week for 6 weeks and monitored for an additional 20 weeks to allow induction of tumors (1A).

Table 2.1: Components of base diet. Curcumin diets were produced by Harlan Laboratories, using the standard 7013, NIH-31 diet as a base. The full table is available online through Harlan. 


\section{Curcumin increases survival of $I 110^{-/-}$chronically-inflamed mice, but becomes toxic at very high doses when administered with Azoxymethane carcinogen}

We first assessed whether curcumin negatively affects survival in a non-cancer context. Curcumin has an overall survival benefit for $1 l 10^{-/}$mice on diets $0.05 \%$ to $1 \%$. $I l 10^{-/}$mice on regular control diet had $\sim 83 \%$ survival. However, $1110^{-/}$mice on curcumin diets at doses $0.05 \%$ to $1 \%$ had $100 \%$ survival (Fig. 2.2A), indicating a survival benefit of curcumin on chronicallyinflamed mice.

When mice were injected with the AOM carcinogen, survival decreased for both the wildtype and $I l 10^{-/}$mice on the highest dose (1\%) of curcumin. Two of the six wildtype mice did not survive and none of the $I l 10^{-/}$mice survived on the $1 \%$ curcumin diet when administered with the carcinogen (Fig. 2.2B). Due to the toxicity and poor survival of the animals in the $1 \%$ AOM group, we excluded them from further analysis.

Curcumin is currently used in clinical trials and is not FDA regulated, as it is considered a dietary supplement (ClinicalTrials.gov ID: NCT00027495, NCT01859858, NCT00003365, NCT00973869 and NCT01490996). It has been shown to be well tolerated in large doses in healthy individuals (Lao et al., 2006). Our results in mice correspond to those findings for the placebo (PBS-injected mice) groups. However, the addition of carcinogen and a high dose of curcumin (1\%) drastically reduce survival in both genotypes, particularly for the chronically inflamed mice. This needs to be carefully considered when choosing doses for patients with chronic inflammatory bowel diseases or colitis-associated colon cancer. 

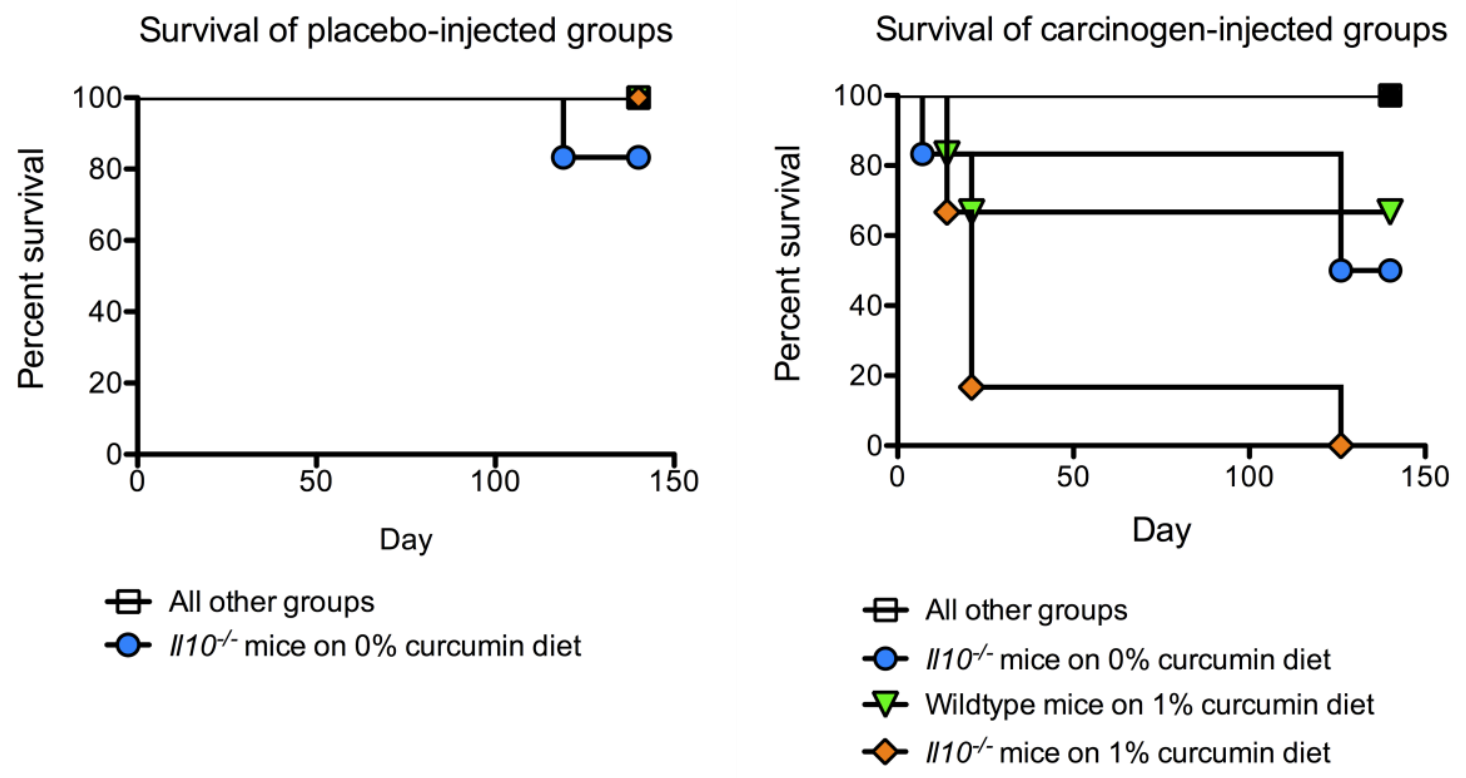

Figure 2.2: Survival assessment. Survival of the $I l 10^{-/}$mice and wildtype control mice was assessed by generating a KaplanMeier curve using the GraphPad Prism software version 5.0a. 1 of 6 placebo-injected $1110^{-/}$mice died in the $0 \%$ curcumin diet group. All other placebo-injected mice in every group had 100\% survival (2A). 3 of 6 carcinogen-injected $I l 10^{-/}$mice died in the $0 \%$ curcumin diet group. 2 of 6 carcinogen-injected wildtype mice and 6 of $61110^{-/}$mice died in the $1 \%$ curcumin diet group. All other carcinogen-injected mice had $100 \%$ survival (2B). 


\section{Curcumin reduces hyperplasia in AOM-treated $I l 10^{-/}$mice}

We assessed the colon at the gross tissue level upon sacrifice of the animals and saw a reduction in weight/length ratios, which are a measure of hyperplasia in colonic tissue that corresponds well to histologic scoring (Ostanin et al., 2009). This reduction increases as the dose of curcumin increases, indicating a beneficial role of curcumin and a dose-dependent mechanism (Fig. 2.3).

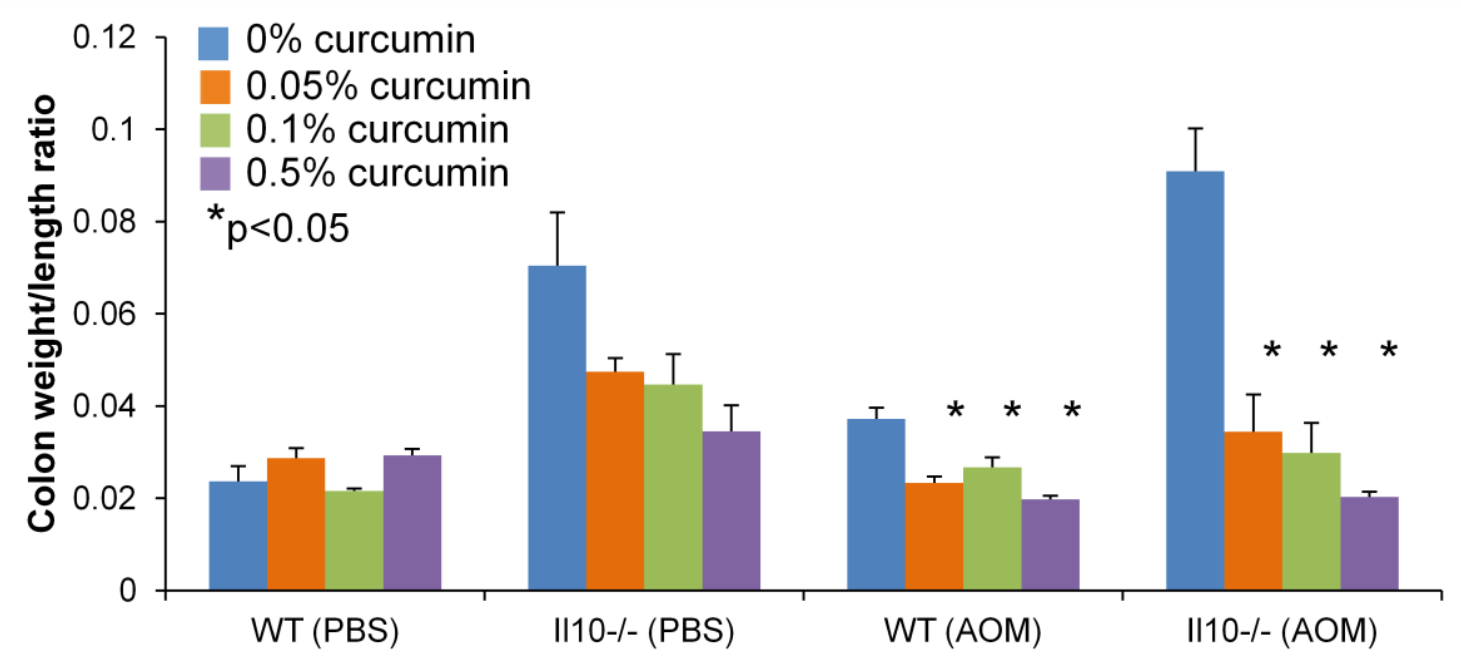

Figure 2.3: Hyperplasia assessment in gross colonic tissue. Colons of mice were removed upon euthanasia at the end of the study (week 20) and flushed with sterile Phosphate Buffered Saline (PBS) to remove excess content in the lumen of the colon. The length $(\mathrm{cm})$ of the colon and the weight $(\mathrm{mg})$ were measured. Ratios represent weight/length. Groups were considered statistically different by a $\mathrm{p}$ value $<0.05$ using the Student's t-test (Excel software) to assess in pairs the $0 \%$ diet to each diet concentration within a group. Exact $\mathrm{p}$ values are as follows. WT(PBS) $0 \%$ to $0.05 \%, \mathrm{p}=0.2218 ; 0 \%$ to $0.1 \%, \mathrm{p}=0.5104 ; 0 \%$ to $0.5 \%, \mathrm{p}=0.1302$. Ill $0^{--}$(PBS) $0 \%$ to $0.05 \%, \mathrm{p}=0.2109 ; 0 \%$ to $0.1 \%, \mathrm{p}=0.2367 ; 0 \%$ to $0.5 \%, \mathrm{p}=0.0673$. WT(AOM) $0 \%$ to $0.05 \%, \mathrm{p}=0.0006 ; 0 \%$ to $0.1 \%, \mathrm{p}=0.0103 ; 0 \%$ to $0.5 \%, \mathrm{p}=0.0001$. $1110^{-/}(\mathrm{AOM}) 0 \%$ to $0.05 \%, \mathrm{p}=0.0064 ; 0 \%$ to $0.1 \%, \mathrm{p}=$ $0.0015 ; 0 \%$ to $0.5 \%, \mathrm{p}=0.0000$. 


\section{Curcumin reduces histological scoring in AOM-treated $I l 10^{-/-}$mice in a dose-dependent manner}

We next wanted to compare the whole tissue hyperplasia assessment to histological scoring. Curcumin reduces the overall histological score (Table 2.2) in the distal region of the colon for the AOM-treated $1 l 10^{-/-}$mice fed the $0.1 \%$ and $0.5 \%$ curcumin diets compared to the AOM-treated $I l 10^{-/}$mice fed the $0 \%$ curcumin control diet. Likewise, curcumin reduces the overall histological score in the distal region of the colon for AOM-treated wildtype mice fed the 0.5\% diet (Fig. 2.4B). We see a similar trend for the proximal region of the colon (Fig. 2.4A). This is demonstrated in representative pictures of the distal colonic tissue Hemotoxylin and Eosin (H\&E) staining of AOM-treated mice (Fig. 2.4C). While the AOM-treated wildtype and ${I I I 0^{-/-}}$mice developed tumors, they also had areas of healthy epithelium. The other curcumin diets for the AOM-treated mice in both the distal and proximal regions of the colon trended towards a reduction compared to the AOM-treated 0\% curcumin control group, but did not reach statistical significance. 


\begin{tabular}{|c|c|c|c|c|c|}
\hline Score & Cancer & Inflammation & Colitis Description & Infiltrates & $\begin{array}{c}\text { Crypt } \\
\text { Hyperplasia }\end{array}$ \\
\hline 0 & none & none & none & none & none \\
\hline 1 & none & mild & multifocal infiltrates & lymphocytes, plasma cells & none \\
\hline 2 & none & mild & subacute multifocal & $\begin{array}{l}\text { predominantly } \\
\text { lymphocytic }\end{array}$ & none \\
\hline 3 & none & mild & subacute multifocal to coalescing & $\begin{array}{l}\text { predominantly } \\
\text { lymphocytic }\end{array}$ & mild \\
\hline 4 & none & mild & subacute multifocal to coalescing & $\begin{array}{l}\text { mixed lymphocytic and } \\
\text { neutrophilic }\end{array}$ & mild \\
\hline 5 & none & moderate & subacute multifocal to coalescing & $\begin{array}{l}\text { mixed lymphocytic and } \\
\text { neutrophilic }\end{array}$ & moderate \\
\hline 6 & none & moderate & $\begin{array}{l}\text { subacute multifocal to coalescing, } \\
\text { ulcerations }\end{array}$ & $\begin{array}{l}\text { mixed lymphocytic and } \\
\text { neutrophilic }\end{array}$ & moderate \\
\hline 7 & none & moderate & subacute multifocal to coalescing & $\begin{array}{l}\text { mixed lymphocytic and } \\
\text { neutrophilic }\end{array}$ & moderate \\
\hline 8 & none & severe & $\begin{array}{l}\text { subacute multifocal to coalescing, } \\
\text { ulcerations }\end{array}$ & $\begin{array}{l}\text { mixed lymphocytic and } \\
\text { neutrophilic }\end{array}$ & severe \\
\hline 9 & none & severe & subacute multifocal to coalescing & $\begin{array}{l}\text { mixed lymphocytic and } \\
\text { neutrophilic }\end{array}$ & severe \\
\hline 10 & present & mild & subacute multifocal to coalescing & $\begin{array}{l}\text { mixed lymphocytic and } \\
\text { neutrophilic }\end{array}$ & mild \\
\hline 11 & present & moderate & subacute multifocal to coalescing & $\begin{array}{l}\text { mixed lymphocytic and } \\
\text { neutrophilic }\end{array}$ & moderate \\
\hline 12 & present & severe & subacute multifocal to coalescing & $\begin{array}{l}\text { mixed lymphocytic and } \\
\text { neutrophilic }\end{array}$ & severe \\
\hline
\end{tabular}

Table 2.2: Histological scoring key. A description of histological scores is shown with a higher score representing increasing severity of hyperplasia, colitis and/or cancer. 

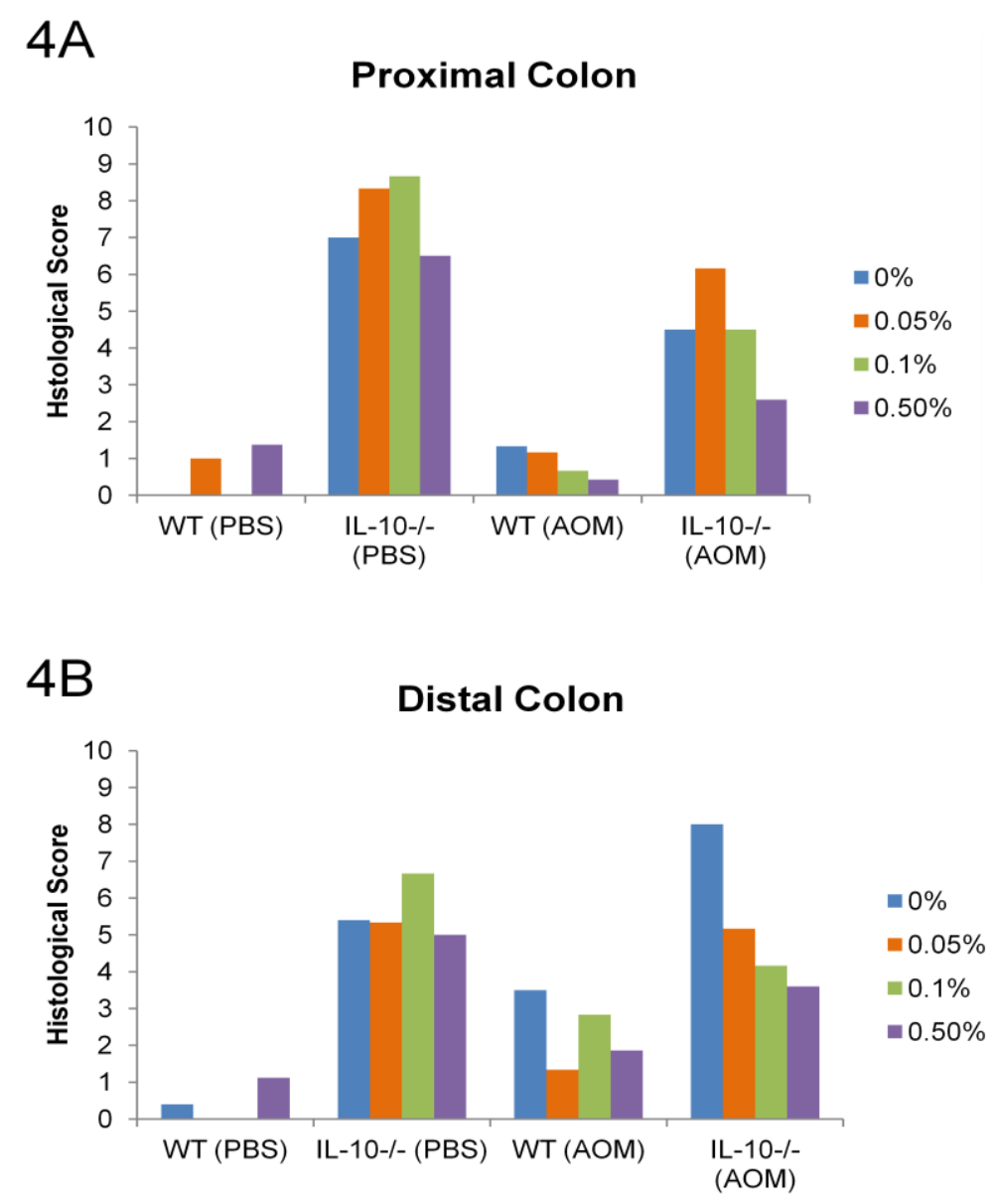
Wildtype + AOM
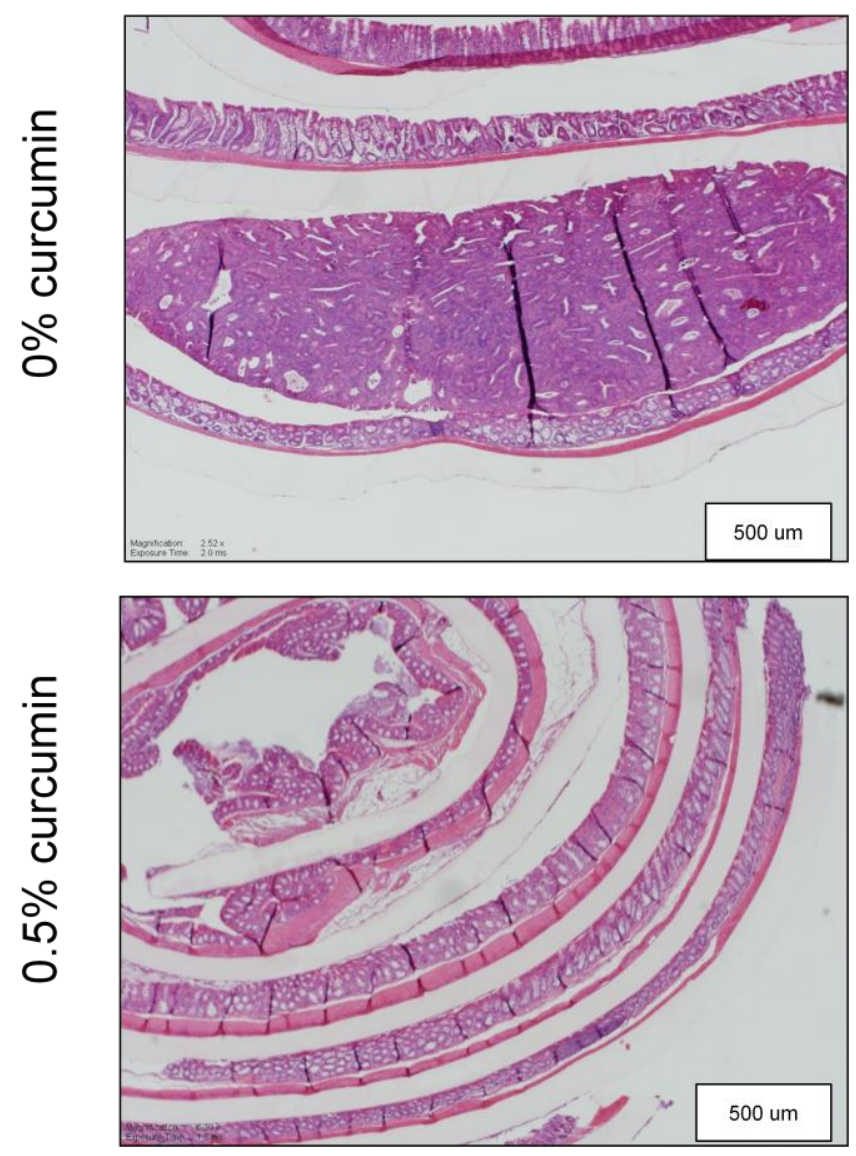

$1 / 10^{--}+\mathrm{AOM}$
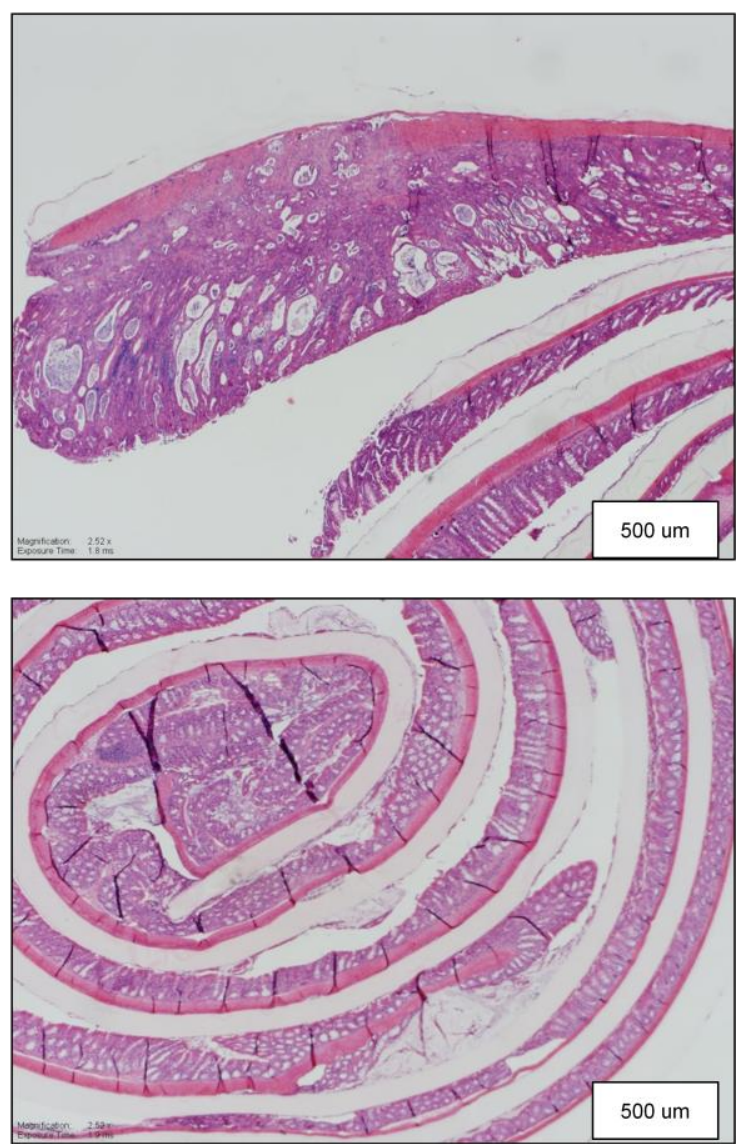

Figure 2.4: Histological scoring. Colons of mice were removed upon euthanasia at the end of the study (week 20) and flushed with sterile Phosphate Buffered Saline (PBS) to remove excess content in the lumen of the colon, cut longitudinally and rolled with the nitrocellulose paper into a "swiss roll," fixed in $10 \%$ neutral buffered formalin for 24 hours and processed for embedding in paraffin. Hematoxylin and eosin (H\&E) stains were performed on sections of tissue cut with a width of 3 microns from the formalin fixed, paraffin embedded (FFPE) blocks. The histological assessment and scoring was performed by a pathologist (blinded to the study groups) and scores are represented for proximal colon (4A) and distal colon (4B). Representative pictures of the stained sections used for scoring are shown for the distal colon (4C). 


\section{Curcumin reduces tumor burden in AOM-treated $1110^{-/-}$mice}

We assessed the mice for tumor burden and saw a reduction for the AOM-treated $1110^{-/}$ mice, as well as for the wildtype control mice (Fig. 2.5A and 2.5B). Macroscopically, we could not visually detect tumors in the PBS-treated $1110^{-/-}$mice, although histological assessment detected spontaneous tumors within the colonic tissue. Wildtype mice had no spontaneous tumors.

The use of AOM to induce colon cancer is a well-described method that promotes tumors primarily in the distal region (Neufert et al., 2007). Tumors of the AOM-treated $1 l 10^{-/-}$mice were primarily in the distal region of the colon, while spontaneous tumors of the PBS-treated $I l 10^{-/-}$mice were exclusively in the proximal region of the colon. AOM-treated wildtype mice had tumors exclusively in the distal region of the colon.

Curcumin did not reduce the likelihood of $1110^{-/}$mice to spontaneously develop tumors (2.5B). This suggests that the efficacy of this treatment may depend on the mechanism of carcinogenesis, as well as the genetic background of the host. 
$5 \mathrm{~A}$
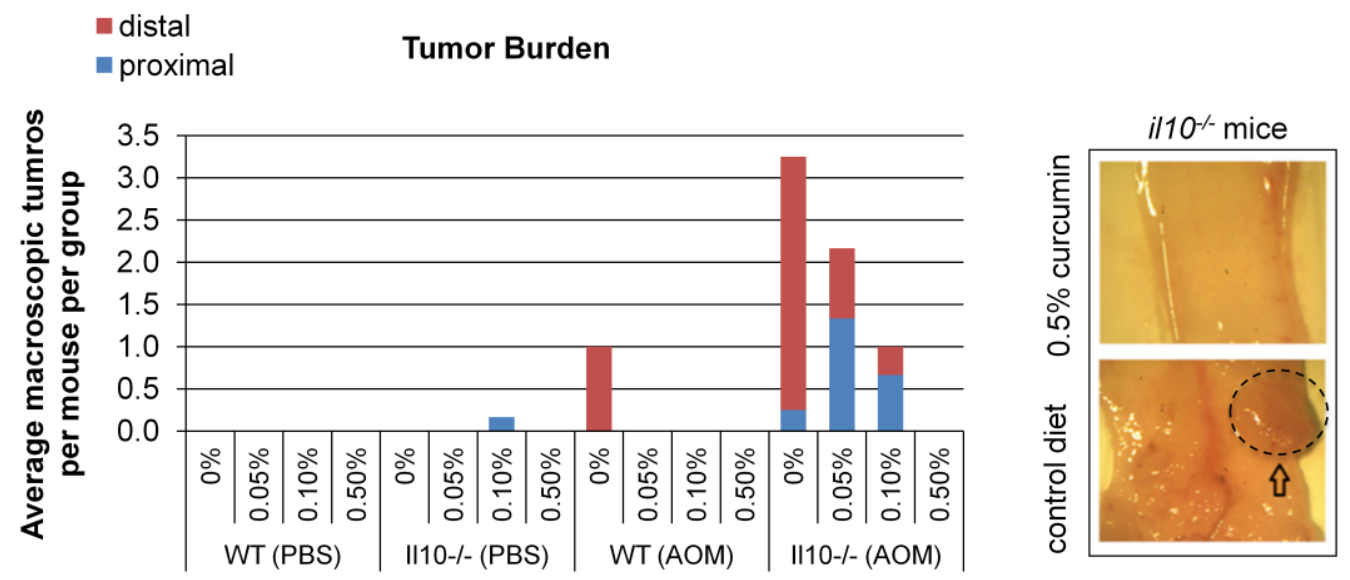

$5 B$

\section{Histological Tumor Assessment}

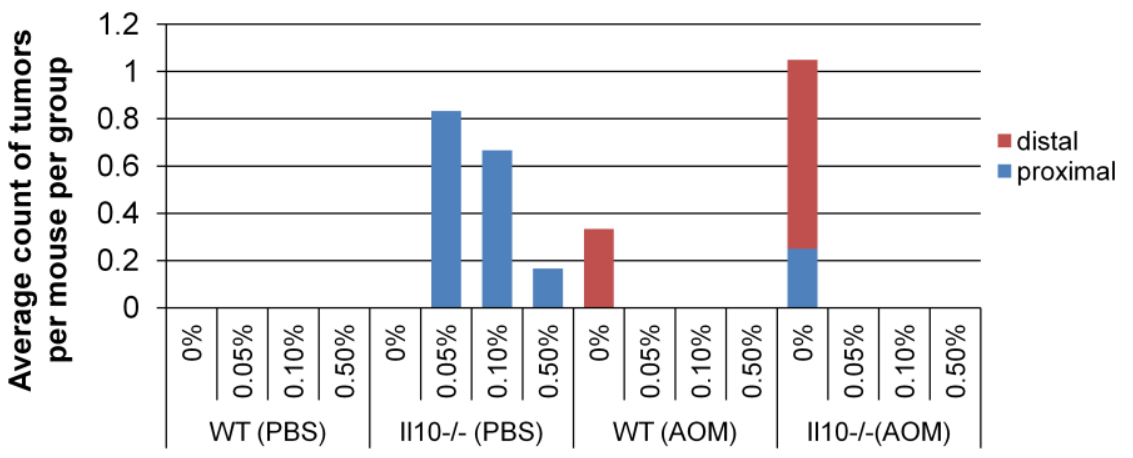

Figure 2.5: Tumor burden. Colons of mice were removed upon euthanasia at the end of the study (week 20) and flushed with sterile Phosphate Buffered Saline (PBS) to remove excess content in the lumen of the colon, cut longitudinally and any tumors present were recorded for area, distance from proximal end, and abundance. Average numbers of macroscopic tumors per mouse in a group are represented with an insert giving an example of what was considered a tumor (5A). A pathologist, blinded to the study groups, determined presence of tumors histologically on $\mathrm{H} \& \mathrm{E}$ stained tissue sections (5B). It is important to note that the average number of macroscopic tumors per mouse for the AOM-treated $\mathrm{Il}-10^{-/}$mice is an underestimate as this group had two mice with tumor burden classified as "too many to count" (above 10 ten tumors, numerous and tiny) and were assigned an arbitrary number of " 10 " for the purposes of calculation. Numbers of mice with macroscopic tumors are as follows: PBS-treated $I l 10^{-/}$mice $+0.1 \%$ (1 of 6); AOM-treated WT mice $+0 \%$ ( 2 of 6 ); AOM-treated $1110^{-/}$mice $+0 \%$ (3 of 6), $0.05 \%$ (5 of 6), $0.1 \%$ (4 of 6) and $0.5 \%$ ( 0 of 6 ). Numbers of mice with tumors assessed histologically are as follows: PBS-treated $1110^{-/-}$mice $+0.05 \%$ ( 5 of 6 ), $0.1 \%$ (4 of 6 ) and $0.5 \%$ (1 of 6); AOM-treated WT mice $+0 \%$ (2 of 6); AOM-treated $1110^{-/}$mice $+0 \%(4$ of 5$)$. 


\section{Curcumin reduces aberrant localization of beta-catenin in AOM-treated $\mathrm{Il1O}^{-/-}$mice}

We next assessed the general expression and localization of beta-catenin, a protein that functions in cell-cell adhesion, gene transcription, cell division and differentiation and which is commonly mutated in colon cancer (Miyaki et al., 1999). We chose the $0.5 \%$ diet for analysis, as it was the most effective dose in tumor reduction. AOM-treated $I l 10^{-/-}$mice without curcumin in the diet had tumors and increased expression of beta-catenin and localization was much more varied, being located at the nucleus, cytoplasm and membrane (Fig. 2.6A). Compared to the control diet ( $0 \%$ curcumin), the $1110^{-/}$mice on the $0.5 \%$ curcumin diet showed increased localization of beta-catenin to the membrane, as we see in healthy tissue and the PBS-treated animals that did not produce spontaneous tumors (Fig. 2.6B). The histological long scores are reported (Table 2.3). While curcumin did not reduce the incidence of spontaneous tumors, beta catenin is localized to the membrane in the epithelium of the tumor in the only PBS-treated + $0.5 \%$ curcumin $I l 10^{-/-}$mouse that developed a spontaneous tumor (Fig. 2.6C). Some areas of that sample also expressed beta-catenin in cytoplasmic or nuclear regions. However, the membrane localization in $\mathbf{2 . 6 C}$ demonstrates a very different morphology than the AOM-induced tumors shown in 2.6A. This indicates a beneficial effect of curcumin on beta-catenin localization. 

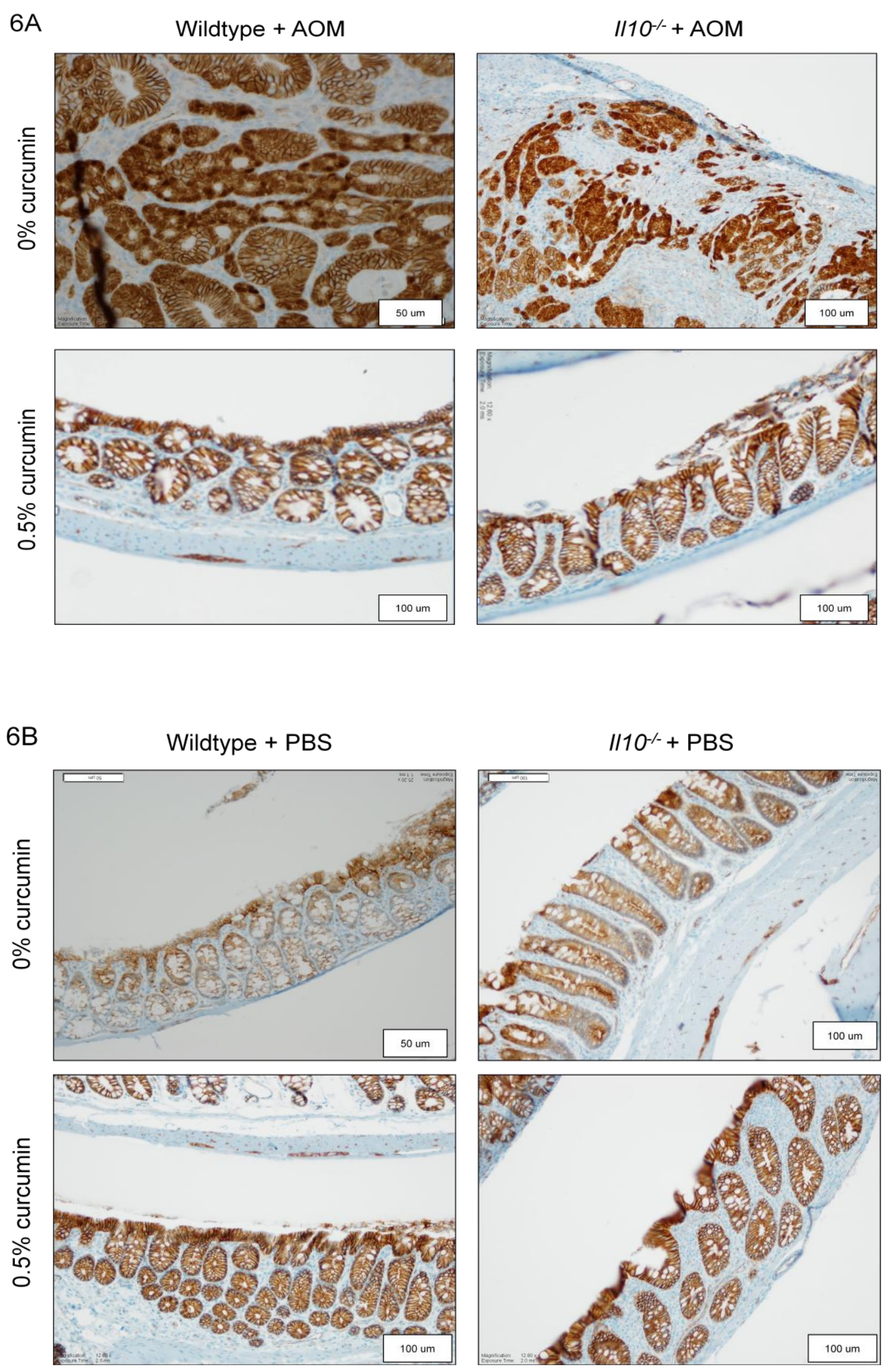


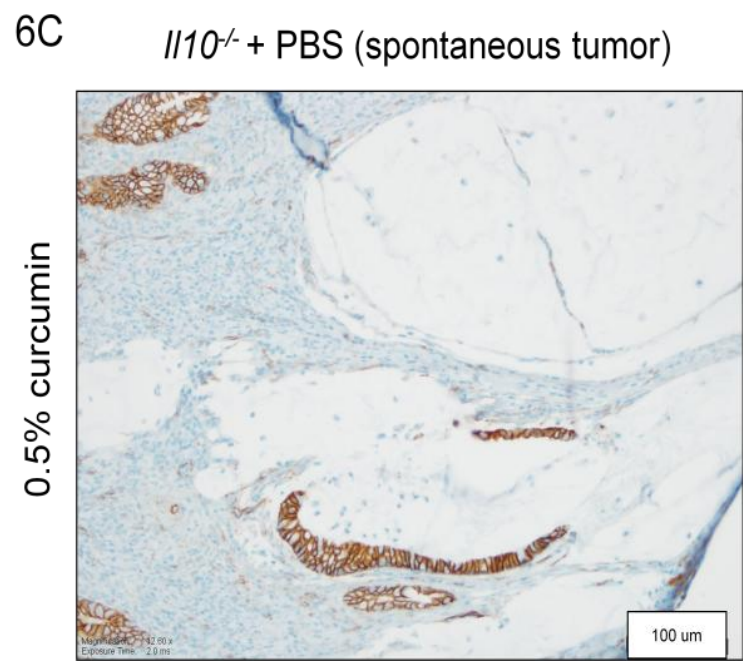


Table 2.3

Beta-catenin IHC scoring (Long Scores)

\begin{tabular}{|l|l|l|}
\cline { 2 - 3 } \multicolumn{1}{c|}{} & Score & Tumor(s) \\
\cline { 2 - 3 } \multicolumn{1}{c|}{$0 \%$ w AOM-WT } & 300 & Tumor \\
\hline $0 \%$ w PBS-WT & 100 & No Tumor \\
\hline $0 \%$ w AOM (IL10) & 300 & Tumor \\
\hline $0 \%$ w PBS (IL10) & 200 & No Tumor \\
\hline $.5 \%$ w AOM -WT & 200 & No Tumor \\
\hline $.5 \%$ w PBS-WT & 200 & No Tumor \\
\hline $.5 \%$ w AOM (IL10) & 200 & No Tumor \\
\hline $.5 \%$ w PBS (IL10) & 200 & No Tumor \\
\hline $\begin{array}{l}.5 \% \text { w PBS (IL10) } \\
\text { spontaneous tumor }\end{array}$ & 200 & $\begin{array}{l}\text { Some } \\
\text { Tumor }\end{array}$ \\
\hline
\end{tabular}

Figure 2.6: beta-catenin localization in colonic tissue. Immunohistochemistry (IHC) of a rabbit monoclonal antibody to Beta Catenin clone E247 (AbCam) was performed using human colon cancer tissues used as the positive tissue controls. Tissue sections were stained with a Discovery XT Automated Immunostainer (Ventana Medical Systems, Inc., Tucson, AZ; VMSI). AOM-treated $I l 10^{-/}$mice and wildtype mice had tumors with increased staining intensity for beta-catenin and localization to the membrane, nucleus and cytoplasm (6A). AOM-treated $I l 10^{-/}$mice and wildtype mice $+0.5 \%$ have normal colon morphology and beta-catenin localized primarily to the membrane, as did all PBS-treated mice (6B) with the exception of the one PBS-treated $\mathrm{Il}-10^{-/}$mouse $+0.5 \%$ curcumin diet, which had a spontaneous tumor and beta-catenin localized the membrane $(6 \mathrm{C})$.

Table 2.3: beta-catenin IHC Histological scoring. Immunohistochemistry (IHC) of a rabbit monoclonal antibody to Beta Catenin clone E247 (AbCam) was performed using human colon cancer tissues used as the positive tissue controls. Tissue sections were stained with a Discovery XT Automated Immunostainer (Ventana Medical Systems, Inc., Tucson, AZ; VMSI). Scoring (long scores) was done by a pathologist with a specialty in GI cancers who was blinded to the experimental groups. 300 is the maximum score, representing the most severe disease phenotype and a score of 100 was the lowest score for this set of samples, representing a healthy individual. 


\section{Curcumin's role in reducing tumorigenesis is independent of anti-inflammatory functions}

Because of curcumin's well-documented role as an anti-inflammatory agent, we next assessed that function in this mouse model system, where it is administered to individuals who already have established inflammation. While the expression of mRNA that transcribes proinflammatory cytokines is generally higher in $1110^{-/-}$mice than in wildtype mice, we do not see a statistically significant overall trend in curcumin doses to reduce the expression compared to the mice on the $0 \%$ curcumin control diet (Fig. 2.7). Of all the doses, the $0.1 \%$ curcumin diet is the most effective at reducing inflammation, as shown in AOM-treated wildtype mice (for TNF- $\alpha$, proximal and distal regions; IFN $\square$, proximal region), AOM-treated $I l 10^{-/}$mice (IL-1ß, distal region) and PBS-treated wildtype mice (IL-17, proximal region). This corresponds with published studies from our lab, where we previously showed that colon morphology was improved and pro-inflammatory cytokine production inhibited only at the $0.1 \%$ curcumin dose when testing a range from $0.1 \%$ to $1 \%$. For that study, curcumin was used as a preventative agent in germ-free $I l 10^{-/-}$mice and germ-free $\mathrm{IllO}^{--}$mice given microbiota from mice housed in a non germ-free, specific-pathogen free facility (Larmonier et al., 2008). However, the data thus far has shown the $0.5 \%$ dose to be the most effective for tumor reduction. This indicates, that curcumin's ability to reduce tumorigenesis is independent of its ability to reduce inflammation and that both functions are, respectively, dose-dependent. 

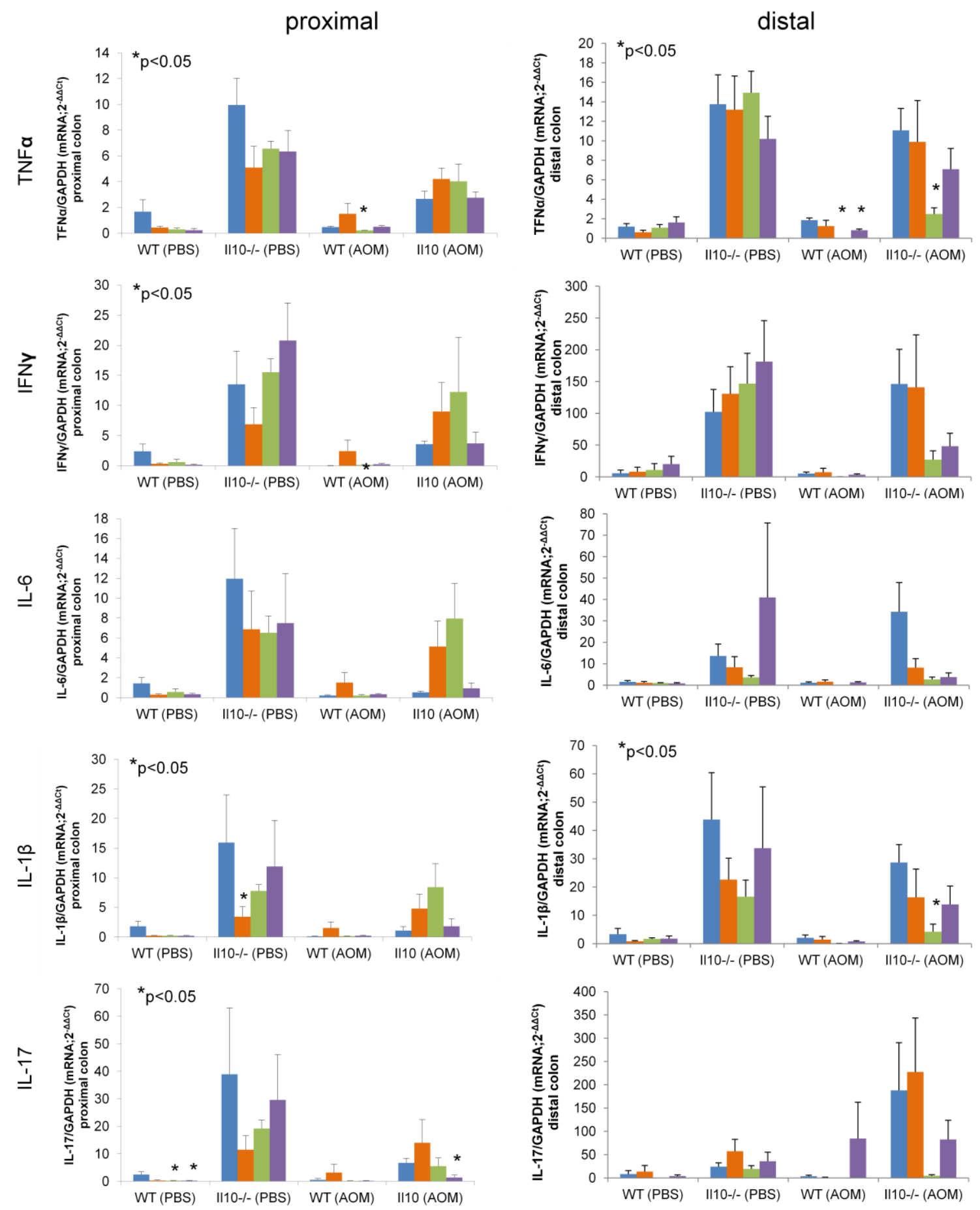
Figure 2.7: mRNA expression of colitis-associated cytokines within colonic tissue. Relative quantification of mRNA expression of TNF- $\alpha$, IFN $\gamma$, IL-6, IL-1ß and IL17 are shown as a change in expression of the target gene relative to untreated WT on control diet. Each sample was normalized to GAPDH expression. Bars represent means and SEM. Groups were considered statistically different by a p value $<0.05$ using the Student's t-test (Excel software) to assess in pairs the $2^{\wedge}-\Delta \Delta$ Ct scores of the $0 \%$ diet to each diet concentration within a group. Exact $\mathrm{p}$ values for the statistically significant values are as follows. Proximal TNF- $\alpha$ : WT(AOM) $0 \%$ to $0.1 \%, p=0.0107$. Distal TNF- $\alpha$ : WT(AOM) $0 \%$ to $0.1 \%, p=0.0101 ; 0 \%$ to $0.5 \%, p=0.0061 . I l 10^{-1}$ (AOM) $0 \%$ to $0.1 \%, \mathrm{p}=0.0111$. Proximal IFN $\gamma$ : WT(AOM) $0 \%$ to $0.1 \%, \mathrm{p}=0.0421$. Proximal IL- $1 \beta \mathrm{Il} 10^{-/}$(PBS) $0 \%$ to $0.05 \%$, $\mathrm{p}=0.0448$. Distal IL-1 $\beta$ Illo ${ }^{--}(\mathrm{AOM}) 0 \%$ to $0.1 \%, \mathrm{p}=0.0067$. Proximal IL-17 WT(PBS) $0 \%$ to $0.1 \%, \mathrm{p}=0.0480 ; 0 \%$ to $0.5 \%$, $\mathrm{p}=0.0473$ and $I l 10^{--}(\mathrm{AOM}) 0 \%$ to $0.5 \%, \mathrm{p}=0.0281$. 


\section{Baseline Gut Microbial Composition Patterns between WT and Il10 $^{-/-}$mice}

Because the anti-cancer effect of curcumin does not mechanistically function through the well-described anti-inflammatory role in this model system, we wanted to explore other possible targets of curcumin. Gut microbiota can be affected by diet and contribute to human health in a variety of ways, including providing essential and non-redundant functions, such as fermentation of otherwise non-digestible dietary components and maintaining homeostasis of the human metabolism and immune system (Zhu et al., 2011 and Flint et al., 2012). We designed an experiment to determine whether or not curcumin given in the diet affects the luminal microbial composition during the course of disease and treatment. In order to assess those changes, we first determined whether there are any inherent differences in the microbial composition between WT and $I l 10^{-/}$mice and, indeed, we do see a difference in microbial composition patterns (Fig. 2.8). Previous work by Arthur et al., 2012, has shown this finding, which provides a verification of our microbial diversity analysis and model system, as well as a baseline to determine effects of curcumin. I am extending this work to include a detailed analysis of the microbial composition profiles in relation to curcumin supplementation in the diet.

Alpha diversity is a measure of how many (observed species, OS) and how many different types (Phylogenetic Diversity, PD) of bacteria are present in one group of samples. The type of bacteria present are determined from unique variations in the genetic sequence of an ecologically conserved gene, 16S rRNA (amplified from bacterial DNA extracted from stool samples). Those unique sequences (in reality, sets of highly similar sequences to take into account possible misreads), are assigned to Operational Taxonomic Units (OTU) and each OTU is associated with a specific bacteria. Here, we show that PD varies between WT and $I l 10^{-/-}$mice with the richness being greater in the WT mice, as indicated by the higher mean value (Fig. 
2.8A). Although not shown on the graph, the OS values do correspond with these findings (p < 0.05, mean WT: 707.2; mean $I l 10^{-/-}$mice: 542.1).

Beta diversity, which takes into account similarities of microbial composition among groups of samples, also demonstrates a difference in microbial diversity between WT and $I l 10^{-/-}$ mice, as indicated by the separation pattern in the principal coordinate of analysis (pcoa) plot and the associated Analysis of Similarity (ANOSIM) (Fig. 2.8B). Instead of OTU comparisons, beta diversity calculations compare distances (unweighted UniFrac distance) along a reference phylogenetic tree of microbiota between groups of samples.

We next wanted to determine which bacteria, specifically, are different between the WT and $I l 10^{-/-}$mice. Taxa bar charts allow for a quick visual overview of patterns to identify if there are differences among groups, as indicated by the colored blocks present (each block represents a different microbial taxa) and the size of those blocks in the chart (size corresponds to abundance). Here we show that there are differences between WT and $I l 10^{-/}$mice in taxonomic patterns at the Phyla level and the genera level (Fig. 2.8C). Specific changes are described below (Table 2.4). Microbial taxa that were significantly different between WT and $\mathrm{Il} 10^{-/-}$mice were primarily in the Bacteroidetes and Firmicutes phyla, which comprise over $90 \%$ of the total phyla (2.8C). However, the $I l 10^{-/}$mice also had an increase in the Bifidobacterium genus within the Actinobacteria phyla and a decrease, compared to WT, of two members of the Clostridia class, one from the Lachnospiraceae genus and one from an unknown genus. Some microbial taxa, such as the S24-7 genus of the Bacteroidetes phyla were found to sometimes increase in $I l 10^{-/-}$mice compared to WT and sometimes decrease, although the same taxonomic hierarchy is listed. This indicates that there are differences at deeper levels than we are currently able to detect for that genus, e.g. at the species level. 
Predicted bacterial metabolic changes associated with the microbial composition pattern were generated using PICRUSt (phylogenetic investigation of communities by reconstruction of unobserved states) (Langille et al., 2013) are described below (Table 2.5). Functionally, the microbial composition profiles indicate that $1110^{-/}$mice, compared to $\mathrm{WT}$, are predicted to have increases in the following pathways: general metabolism category, carbohydrate metabolism in particular and the phosphotransferase system (PTS). Parallel increase in the carbohydrate metabolism is logical, as the PTS allows for carbohydrate transport into the bacterial cells. PTS also has a role in biofilm formation and is necessary for initial colonization in germ free animals, as well as abiotic surfaces in the environment (Houot et al., 2010). The $1110^{-/-}$mice have predicted decreases in the following pathways: cell motility, membrane transport, flagellar assembly, bacterial motility and the general transporter category. 
$8 \mathrm{~A}$

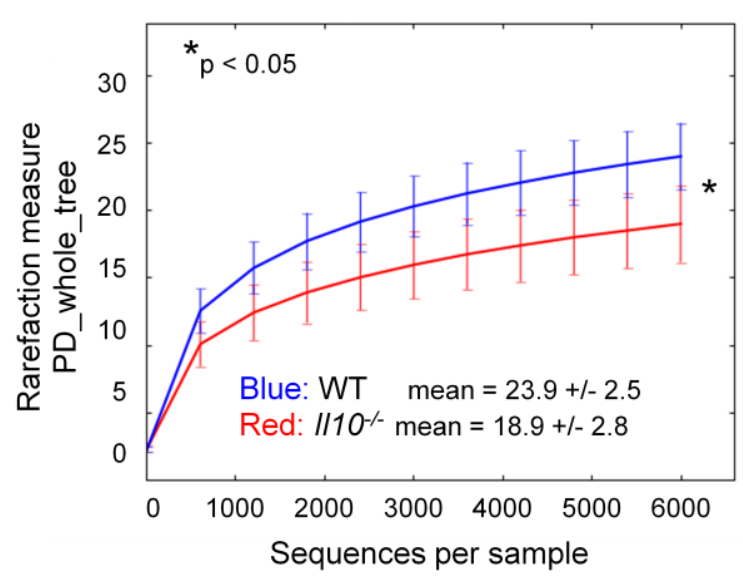

$8 \mathrm{~B}$

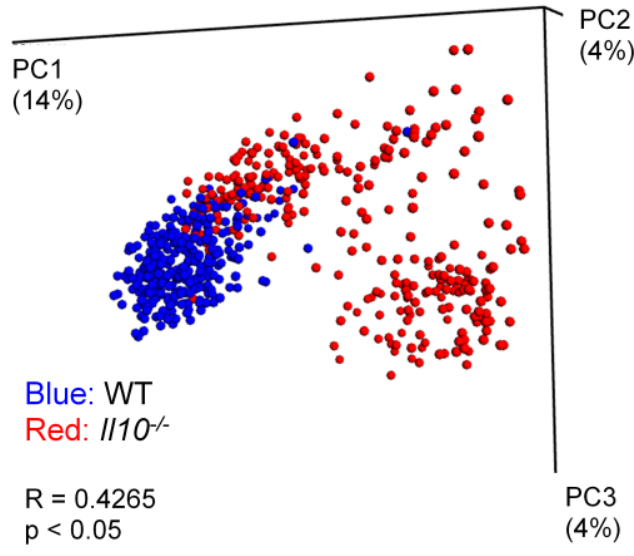

\section{$8 \mathrm{C}$}

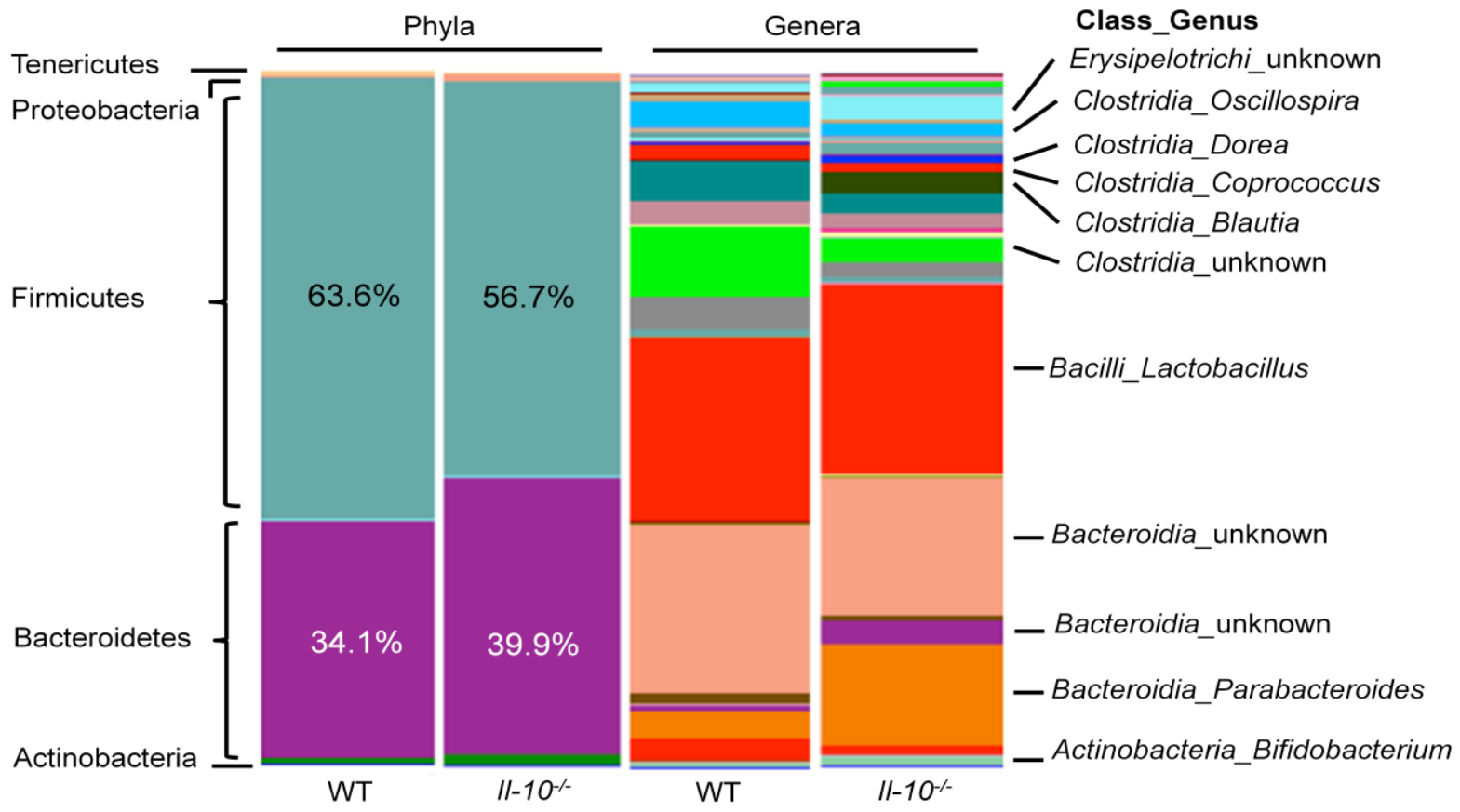

Figure 2.8: Microbial diversity analysis of WT and $\mathrm{IllO}^{-/-}$mice

Alpha diversity was calculated as phylogenetic diversity using the QIIME software, which utilizes a non-parametric t-test. The $\mathrm{p}$-value $=0.003(8 \mathrm{~A})$. Beta diversity pcoa plots were generated in QIIME and analyzed using Analysis of Similarity. The pvalue $=0.001(8 \mathrm{~B})$. The taxonomic grouping bar chart was also generated in QIIME and modified to include $\%$ abundance and labels in Microsoft Powerpoint (8C) 
Differences in microbial composition of $I l 10^{-/-}$compared to WT

\begin{tabular}{|c|c|c|c|c|c|c|c|c|}
\hline OTU & $\begin{array}{c}\text { mean } \\
\text { WT }\end{array}$ & $\begin{array}{l}\text { mean } \\
I l 10^{-/-}\end{array}$ & Pattern & Phyla & Class & Order & Family & $\begin{array}{l}\text { Genus/ } \\
\text { Species }\end{array}$ \\
\hline 559527 & 0.0040 & 0.0125 & higher & Actinobacteria & Actinobacteria & Bifidobacteriales & Bifidobacteriaceae & $\begin{array}{l}\text { Bifidobact- } \\
\text { erium }\end{array}$ \\
\hline 535375 & 0.0309 & 0.1214 & higher & Bacteroidetes & Bacteroidia & Bacteroidales & Bacteroidaceae & B. ovatus \\
\hline 291090 & 0.0016 & 0.0106 & higher & Bacteroidetes & Bacteroidia & Bacteroidales & Porphyromonadaceae & P. distasonis \\
\hline 585914 & 0.0010 & 0.0069 & higher & Bacteroidetes & Bacteroidia & Bacteroidales & Porphyromonadaceae & P. distasonis \\
\hline 276149 & 0.0036 & 0.0096 & higher & Bacteroidetes & Bacteroidia & Bacteroidales & Porphyromonadaceae & P. gordonii \\
\hline 384555 & 0.0056 & 0.0110 & higher & Bacteroidetes & Bacteroidia & Bacteroidales & $\mathrm{S} 24-7$ & \\
\hline 348038 & 0.0244 & 0.0507 & higher & Bacteroidetes & Bacteroidia & Bacteroidales & S24-7 & \\
\hline 356760 & 0.0001 & 0.0112 & higher & Firmicutes & Erysipelotrichi & Erysipelotrichales & Erysipelotrichaceae & \\
\hline 3013444 & 0.0322 & 0.0107 & lower & Bacteroidetes & Bacteroidia & Bacteroidales & & \\
\hline 162539 & 0.0073 & 0.0011 & lower & Bacteroidetes & Bacteroidia & Bacteroidales & Rikenellaceae & \\
\hline 276802 & 0.0076 & 0.0020 & lower & Bacteroidetes & Bacteroidia & Bacteroidales & S24-7 & \\
\hline 196645 & 0.0064 & 0.0011 & lower & Bacteroidetes & Bacteroidia & Bacteroidales & S24-7 & \\
\hline 272850 & 0.0366 & 0.0146 & lower & Bacteroidetes & Bacteroidia & Bacteroidales & S24-7 & \\
\hline 331043 & 0.0148 & 0.0077 & lower & Bacteroidetes & Bacteroidia & Bacteroidales & S24-7 & \\
\hline 372368 & 0.0068 & 0.0042 & lower & Bacteroidetes & Bacteroidia & Bacteroidales & S24-7 & \\
\hline 199532 & 0.0089 & 0.0017 & lower & Firmicutes & Clostridia & Clostridiales & & \\
\hline 1105981 & 0.0079 & 0.0018 & lower & Firmicutes & Clostridia & Clostridiales & Lachnospiraceae & \\
\hline
\end{tabular}

Table 2.4: Specific changes in microbial composition of $I l 10^{-/}$mice compared to WT

This is a summary of changes in microbial composition generated using the QIIME software, which utilizes the Bonferroni-corrected method of multivariate analysis. OTUs and their associated bacteria taxa were considered "different" if the p-value $<0.05$. Comparison of the means determined the abundance trend pattern. All p-values $=0.0000$, except OTU\#559527 where the $\mathrm{p}$-value $=0.0002$ 
cted Pathway - overall

Metabolism

Cellular Processes

Environmental Information Processing

Predicted Pathway - type

Carbohydrate Metabolism

Cell Motility

Membrane Transport

\section{Predicted Pathway - specific}

General function prediction only

Phosphotransferase system (PTS)

Flagellar assembly

Bacterial motility proteins

Transporters

\begin{tabular}{|c|c|c|}
\hline mean WT & mean $\mathrm{IlIO}^{-/-}$ & Pattern \\
\hline 0.4754 & 0.4851 & higher \\
\hline 0.0336 & 0.0255 & lower \\
\hline 0.1405 & 0.1328 & lower \\
\hline 0.1085 & 0.1129 & higher \\
\hline 0.0242 & 0.0159 & lower \\
\hline 0.1229 & 0.1168 & lower \\
\hline 0.0345 & 0.0358 & higher \\
\hline 0.0045 & 0.0060 & higher \\
\hline 0.0055 & 0.0030 & lower \\
\hline 0.0103 & 0.0061 & lower \\
\hline 0.0720 & 0.0664 & lower \\
\hline
\end{tabular}

Table 2.5: Predictions of microbial metagenome and function based on microbial composition of $1110^{-/}$mice and WT mice

9 Predictions of pathways were generated by the PICRUSt software, which uses the 16S rRNA sequences present in a sample and an ancestral-state reconstruction algorithm to predict gene families and estimate the composite metagenome. PICRUSt results were analyzed using QIIME. This table represents statistically significant differences as calculated by the Bonferroni-corrected multivariate analysis in predicted pathways associated with abundance(s) of OTUs. Differences were considered significant if the $\mathrm{p}<0.05$. All p-values $=0.0000$. 


\section{Microbial analysis of the effect of curcumin-supplemented diet}

Because of the striking reduction of tumor burden in mice receiving the $0.5 \%$ curcumin diet, we wanted to further investigate whether this effect was associated with a change in microbial diversity (Fig. 2.9). We observed a separation in the clustering pattern in the beta diversity principal coordinate of analysis (pcoa) plots by the Diet-Gene-Treatment groups which was maintained over the course of the study (2.9A). Indeed, the taxonomic profiling of mice receiving the $0.5 \%$ diet vs. the $0 \%$ control diet showed a different microbial composition pattern as shown visually by the taxonomic bar charts $(\mathbf{2 . 9 B})$. Although the profiles did visually vary between the $1110^{--}$(PBS and AOM groups) mice on the start date of the study, these were not statistically significant and, for clarity of purposes, only the PBS-injected $I l 10^{-/}$mouse group is shown in the taxa bar chart representing week 0 samples from that genotype.

Because our hypothesis was that curcumin would modulate the microbial ecology of AOM-treated chronically-inflamed $I l 10^{-/}$mice to become similar in composition to that of healthy, untreated wildtype mice, thus restoring the gut homeostasis of those mice, we next compared the microbial composition profiles of the AOM-injected $I l 10^{-/}$mice on the control diet $(0 \%)$ to the untreated WT mice on control diet (Table 2.6) and the AOM-injected $I l 10^{-/}$mice on the $0.5 \%$ curcumin diet to the untreated WT mice on the control diet (Table 2.6). Of the OTUs that are significantly different from WT mice, thirteen are shared among the $1 l 10^{-/}$mice (OTU\# 276149, 384555, 535375, 214919, 352049, 262095, 359809, 196645, 272850, 1107027, 337494, 588197 and 592160). 11 of these OTUs have the same trend (higher or lower) compared to the healthy WT mice and only 2 have different trends based on diet. These two OTUs (588197 and 592160) are both in the Firmicutes phyla and Lactobacillus genus. Both of these OTUs are lower in the AOM-injected $I l 10^{-/}$mice on the control diet ( $0 \%$ curcumin) and higher in the 
AOM-injected $1 l 10^{-/}$mice on the $0.5 \%$ curcumin diet. This is intriguing because the AOMtreated $1 l 10^{-/}$mice on the $0.5 \%$ had such a striking improvement in reduction of tumors and the Lactobacillus genus is associated with cell cycle arrest and induction of apoptosis in colon cancer cell lines (Wan et al., 2014 and Wang et al., 2014). While the Clostridium genus stands out on the taxa charts, it failed to reach significance by Bonferroni-corrected multivariate analysis or nonparametric t-tests ( $\mathrm{p}$-value $=0.2548$ ) for the groups of interest, most likely due to the variation of its abundance within the individual $1110^{-/}$mice.

Statistically significant differences in microbial composition OTUs unique to the AOMinjected $I l 10^{-/}$mice on the control diet, or AOM-injected $I l 10^{-/}$mice on the $0.5 \%$ curcumin diet, respectively, compared to healthy untreated WT are reported (Table 2.7 and Table 2.8). As with the $I l 10^{-/}$mice on the control diet, the $1110^{-/}$mice given $0.5 \%$ curcumin diets showed changes, compared to untreated WT control mice, primarily in the Bacteroidetes and Firmicutes phyla, although $1110^{-/-}$mice given $0.5 \%$ curcumin diet also had an increase in Bifidobacterium from the Actinobacteria phylum. Bifidobacteria are associated with a healthy state in the colon, are used in probiotics and have been shown to reduce aberrant crypt foci in mice receiving a chemical carcinogen, dimethylhyrazine (Liboredo et al., 2013). Bifidobacteria, along with Lactobacillus genus (Bacteroidetes phyla) and Sutterella genus (Proteobacteria phyla) also produce esterases, which can liberate ester-linked nutrient sources that the human host would otherwise be unable to utilize (Mukhopadhya et al., 2011). Sutterella is also increased in $I l 10^{-/}$mice given the $0.5 \%$ curcumin diet. Lactobacillus and S24-7 is found to both increase and decrease, which indicates that there are differences in those OTUs at deeper levels, such as species, that we are currently unable to detect. 
The predicted function pathways based on these microbial composition profiles are reported (Table 2.9). The "healthier" $I l 10^{-/-}$mice receiving the $0.5 \%$ curcumin diet that had the reduction in tumor burden compared to the $1110^{-/}$mice on the control ( $0 \%$ curcumin) diet, had decreases in the following: general cellular processes, environmental processing, cell motility, transcription, membrane transport, 2-component system, transcription factors and transporters. They had increases in the following pathways: general metabolism, genetic information processing, translation, oxidation phosphorylation, aminoacyl-tRNA biosynthesis, purine metabolism, pyrimidine metabolism and DNA repair and recombination proteins. The $1110^{-/-}$ mice on the control diet have, by comparison, a decrease in DNA repair mechanisms, which may contribute to the increased risk for colon cancer onset, as well as a decrease in metabolism pathways, which may make that group more prone to microbial nutrient deficiencies. 


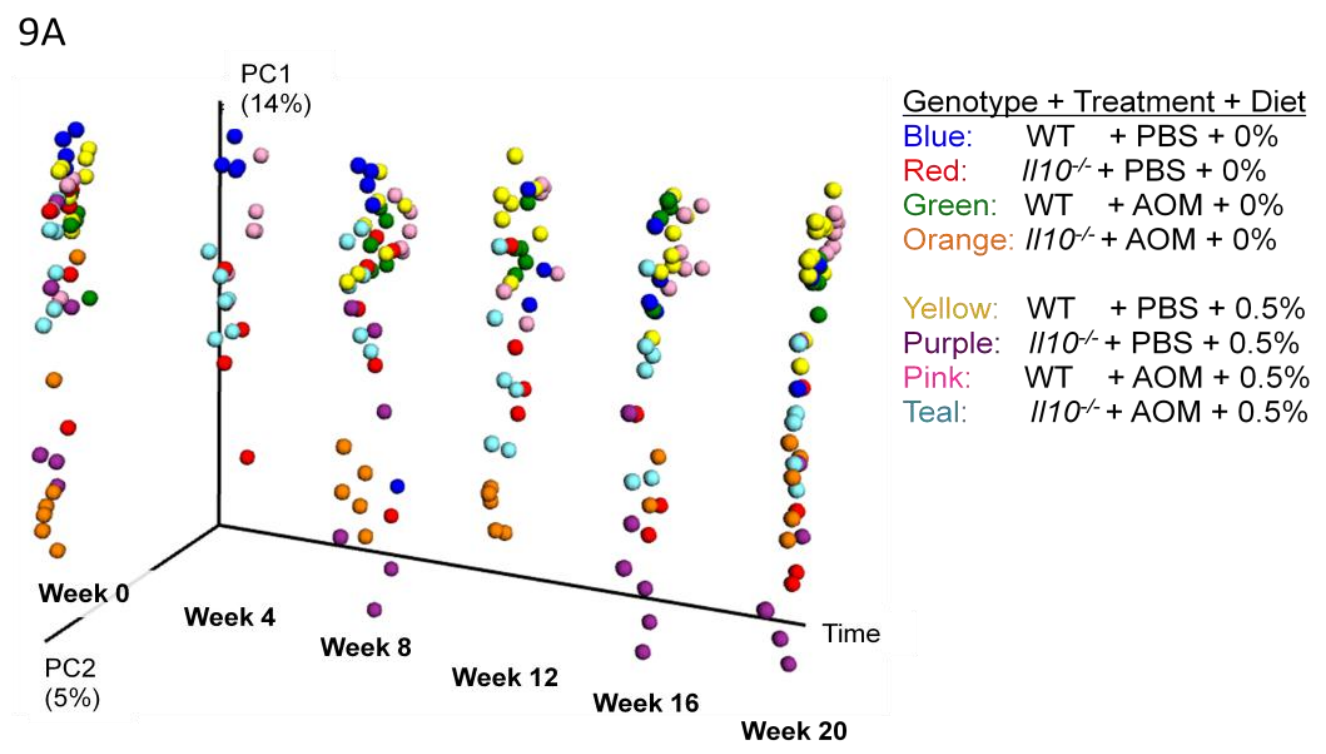

9B

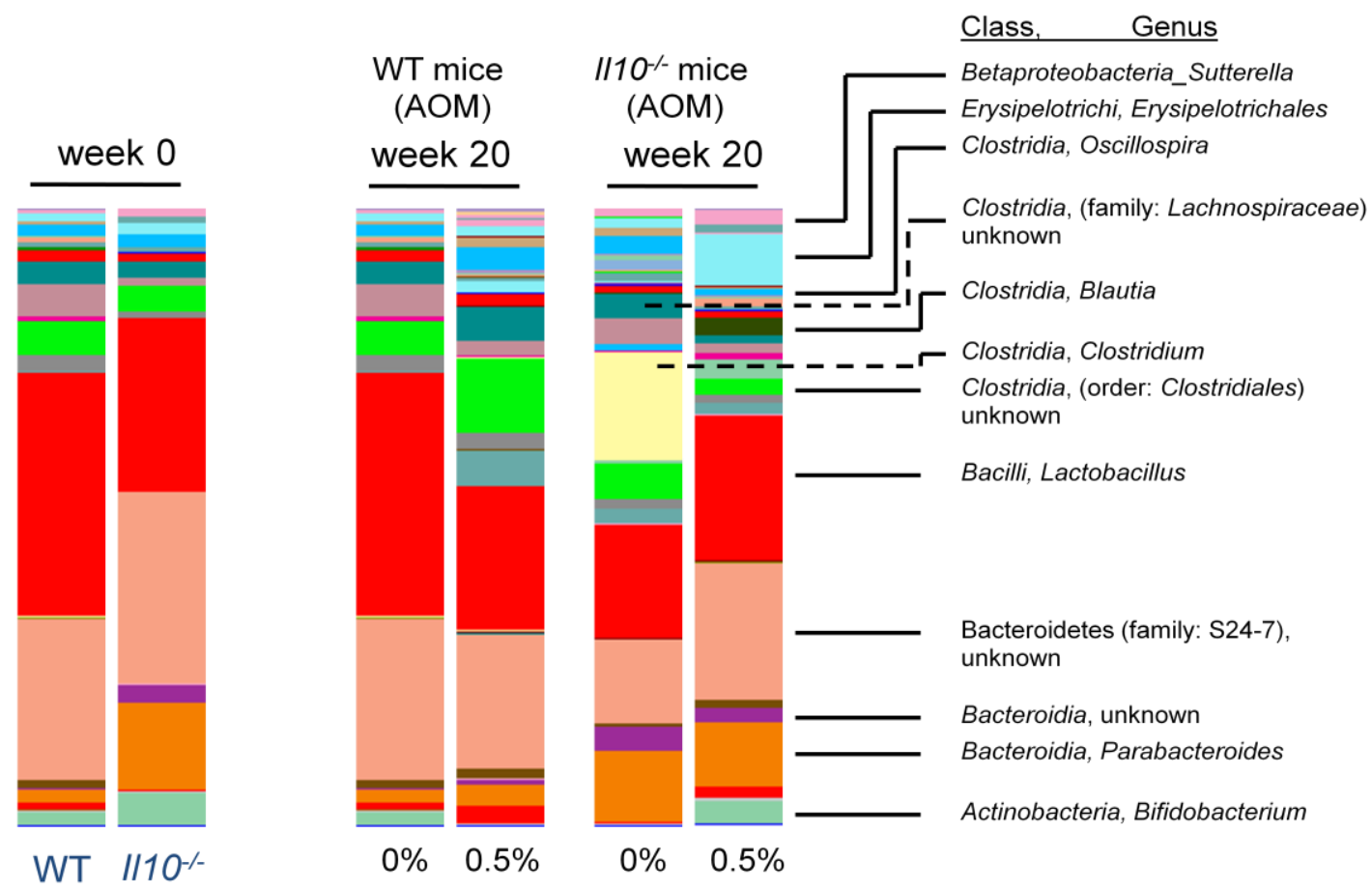

Figure 2.9: Microbial diversity analysis of WT and $I l 10^{-/-}$mice

Beta diversity pcoa plots were generated in Qiime and analyzed using Analysis of Similarity (9A). The p-value was 0.0010 and the R-value $=0.5156$. The taxonomic grouping bar chart was also generated in Qiime and modified to include \% abundance and labels in Microsoft Powerpoint (9B) 
Abundance of OTUs of AOM-Il10 $0^{--}+0 \%$ curcumin compared to PBS-WT + 0\% curcumin (week 20)

\begin{tabular}{|c|c|c|c|c|c|c|c|c|}
\hline OTU & $\begin{array}{l}\text { mean } \\
(\mathrm{WT})\end{array}$ & $\begin{array}{c}\text { mean } \\
\left(I l 10^{-/-}\right)\end{array}$ & Pattern & Phyla & Class & Order & Family & Genus/ species \\
\hline 535375 & 0.0147 & 0.0995 & higher & Bacteroidetes & Bacteroidia & Bacteroidales & Bacteroidaceae & B. ovatus \\
\hline 291090 & 0.0014 & 0.0120 & higher & Bacteroidetes & Bacteroidia & Bacteroidales & Porphyromonada-ceae & P. distasonis \\
\hline 276149 & 0.0015 & 0.0144 & higher & Bacteroidetes & Bacteroidia & Bacteroidales & Porphyromonada-ceae & P. gordonii \\
\hline 384555 & 0.0028 & 0.0208 & higher & Bacteroidetes & Bacteroidia & Bacteroidales & S24-7 & \\
\hline 214919 & 0.0009 & 0.0157 & higher & Firmicutes & Bacilli & Turicibacterales & Turicibacteraceae & Turicibacter \\
\hline 352049 & 0.0000 & 0.0283 & higher & Firmicutes & Clostridia & Clostridiales & & \\
\hline 262095 & 0.0000 & 0.0126 & higher & Firmicutes & $\begin{array}{l}\text { Erysipelot- } \\
\text { richi }\end{array}$ & Erysipelotrichales & Erysipelotrichace-ae & \\
\hline 359809 & 0.0013 & 0.0134 & higher & Proteobacteria & $\begin{array}{l}\text { Betaproteoba } \\
\text { cteria }\end{array}$ & Burkholderiales & Alcaligenaceae & Sutterella \\
\hline 272850 & 0.0406 & 0.0025 & lower & Bacteroidetes & Bacteroidia & Bacteroidales & S24-7 & \\
\hline 196645 & 0.0115 & 0.0000 & lower & Bacteroidetes & Bacteroidia & Bacteroidales & $\mathrm{S} 24-7$ & \\
\hline 356226 & 0.0254 & 0.0129 & lower & Bacteroidetes & Bacteroidia & Bacteroidales & S24-7 & \\
\hline 1107027 & 0.3083 & 0.1476 & lower & Firmicutes & Bacilli & Lactobacillaceae & Lactobacillaceae & Lactobacillus \\
\hline 592160 & 0.0130 & 0.0085 & lower & Firmicutes & Bacilli & Lactobacillaceae & Lactobacillaceae & Lactobacillus \\
\hline 588197 & 0.0120 & 0.0087 & lower & Firmicutes & Bacilli & Lactobacillaceae & Lactobacillaceae & L. reuteri \\
\hline 337494 & 0.0475 & 0.0007 & lower & Firmicutes & Clostridia & Clostridiales & & \\
\hline
\end{tabular}

Table 2.6: microbial composition profile of the AOM-injected $I l 10^{-/-}$mice on the control diet $(0 \%)$ compared to the untreated WT mice on control diet.

This is a summary of changes in microbial composition generated using the QIIME software, which utilizes the Bonferroni-corrected method of multivariate analysis. OTUs and their associated bacteria taxa were considered "different" if the p-value $<0.05$. Comparison of the means determined the abundance trend pattern. All p-values were 0.0000, except OTU\# $352049(\mathrm{p}=0.0001)$ and OTU\# $588197(\mathrm{p}=0.0010)$ 
Abundance of OTUs between AOM-Il10 ${ }^{-/}+0.5 \%$ curcumin and PBS-WT + 0\% curcumin (week 20)

\begin{tabular}{|c|c|c|c|c|c|c|c|c|}
\hline OTU & $\begin{array}{l}\text { mean } \\
(W T)\end{array}$ & $\begin{array}{c}\text { mean } \\
\left(I 110^{-/-}\right)\end{array}$ & Pattern & Phyla & Class & Order & Family & Genus/ Species \\
\hline 559527 & 0.0008 & 0.0349 & higher & Actinobacteria & $\begin{array}{l}\text { Actinobac- } \\
\text { teria }\end{array}$ & Bifidobacteriales & Bifidobacteriaceae & Bifidobacteri-um \\
\hline 3013444 & 0.0063 & 0.0180 & higher & Bacteroidetes & Bacteroidia & Bacteroidales & & \\
\hline 535375 & 0.0147 & 0.0800 & higher & Bacteroidetes & Bacteroidia & Bacteroidales & Bacteroidaceae & B. ovatus \\
\hline 276149 & 0.0015 & 0.0104 & higher & Bacteroidetes & Bacteroidia & Bacteroidales & Porphyromonadaceae & P. gordonii \\
\hline 271131 & 0.0025 & 0.0162 & higher & Bacteroidetes & Bacteroidia & Bacteroidales & $\mathrm{S} 24-7$ & \\
\hline 175706 & 0.0000 & 0.0140 & higher & Bacteroidetes & Bacteroidia & Bacteroidales & $\mathrm{S} 24-7$ & \\
\hline 384555 & 0.0028 & 0.0118 & higher & Bacteroidetes & Bacteroidia & Bacteroidales & $\mathrm{S} 24-7$ & \\
\hline 337724 & 0.0034 & 0.0119 & higher & Bacteroidetes & Bacteroidia & Bacteroidales & $\mathrm{S} 24-7$ & \\
\hline 592160 & 0.0130 & 0.0871 & higher & Firmicutes & Bacilli & Lactobacillales & Lactobacillaceae & Lactobacillus \\
\hline 588197 & 0.0120 & 0.0219 & higher & Firmicutes & Bacilli & Lactobacillales & Lactobacillaceae & L. reuteri \\
\hline 214919 & 0.0009 & 0.0175 & higher & Firmicutes & Bacilli & Turicibacterales & Turicibacteraceae & Turicibacter \\
\hline 352049 & 0.0000 & 0.0118 & higher & Firmicutes & Clostridia & Clostridiales & & \\
\hline 276478 & 0.0007 & 0.0116 & higher & Firmicutes & Clostridia & Clostridiales & Peptostreptococcaceae & \\
\hline 262095 & 0.0000 & 0.0238 & higher & Firmicutes & $\begin{array}{l}\text { Erysipelot- } \\
\text { richi }\end{array}$ & Erysipelotrichales & Erysipelotrichaceae & \\
\hline 356760 & 0.0001 & 0.0278 & higher & Firmicutes & $\begin{array}{l}\text { Erysipelot- } \\
\text { richi }\end{array}$ & Erysipelotrichales & Erysipelotrichaceae & \\
\hline 180869 & 0.0028 & 0.0236 & higher & Firmicutes & $\begin{array}{l}\text { Erysipelot- } \\
\text { richi }\end{array}$ & Erysipelotrichales & Erysipelotrichaceae & \\
\hline 4407703 & 0.0000 & 0.0129 & higher & Firmicutes & $\begin{array}{l}\text { Erysipelot- } \\
\text { richi }\end{array}$ & Erysipelotrichales & Erysipelotrichaceae & Coprobacillus \\
\hline 359809 & 0.0013 & 0.0226 & higher & Proteobacteria & $\begin{array}{l}\text { Betaprote- } \\
\text { obacteria }\end{array}$ & Burkholderiales & Alcaligenaceae & Sutterella \\
\hline 272850 & 0.0406 & 0.0110 & lower & Bacteroidetes & Bacteroidia & Bacteroidales & & \\
\hline 276802 & 0.0103 & 0.0043 & lower & Bacteroidetes & Bacteroidia & Bacteroidales & & \\
\hline 196645 & 0.0115 & 0.0013 & lower & Bacteroidetes & Bacteroidia & Bacteroidales & & \\
\hline 261350 & 0.0188 & 0.0039 & lower & Bacteroidetes & Bacteroidia & Bacteroidales & & \\
\hline 348038 & 0.0698 & 0.0335 & lower & Bacteroidetes & Bacteroidia & Bacteroidales & & \\
\hline 1107027 & 0.3083 & 0.1014 & lower & Firmicutes & Bacilli & Lactobacillales & Lactobacillaceae & Lactobacillus \\
\hline 337494 & 0.0475 & 0.0000 & lower & Firmicutes & Clostridia & Clostridiales & & \\
\hline
\end{tabular}


Table 2.7: microbial composition profile of the AOM-injected $I l 10^{-/}$mice on the $0.5 \%$ curcumin diet compared to the untreated WT mice on the control diet. This is a summary of changes in microbial composition generated using the QIIME software, which utilizes the Bonferroni-corrected method of multivariate analysis. OTUs and their associated bacteria taxa were considered "different" if the $\mathrm{p}$-value $<0.05$. Comparison of the means determined the abundance trend pattern. All $\mathrm{p}$ values $=0.0000$, except OTU\# $337724(\mathrm{p}=0.0003)$, OTU\# $588197(\mathrm{p}=0.0010)$ and OTU\# $352049(\mathrm{p}=0.0001)$. 
Microbial composition patterns unique to 0\% AOM-Il10 ${ }^{-/-}$compared to 0\% PBS-WT

\begin{tabular}{|c|c|c|c|c|c|c|l|l|}
\hline OTU & $\begin{array}{c}\text { mean } \\
\text { (WT) }\end{array}$ & $\begin{array}{c}\text { mean } \\
\text { Illo- } \\
\text { /-) }\end{array}$ & Pattern & Phyla & Class & \multicolumn{2}{|c|}{ Order } & \multicolumn{2}{c|}{ Family } & Genus/ species \\
\hline 291090 & 0.0014 & 0.0120 & higher & Bacteroidetes & Bacteroidia & Bacteroidales & Porphyromonadaceae & P. distasonis \\
\hline 356226 & 0.0254 & 0.0129 & lower & Bacteroidetes & Bacteroidia & Bacteroidales & S24-7 & \\
\hline
\end{tabular}

Microbial composition patterns unique to 0.5\% AOM- $1110^{-/-}$compared to 0\% PBS-WT

\begin{tabular}{|c|c|c|c|c|c|c|c|c|}
\hline OTU & $\begin{array}{l}\text { mean } \\
(\mathrm{WT})\end{array}$ & $\begin{array}{c}\text { mean } \\
(I l 10- \\
/-)\end{array}$ & Pattern & Phyla & Class & Order & Family & Genus/ species \\
\hline 559527 & 0.0008 & 0.0349 & higher & Actinobacteria & Actinobacteria & Bifidobacteriales & Bifidobacteriaceae & Bifidobacterium \\
\hline 175706 & 0.0000 & 0.0140 & higher & Bacteroidetes & Bacteroidia & Bacteroidales & S24-7 & \\
\hline 271131 & 0.0025 & 0.0162 & higher & Bacteroidetes & Bacteroidia & Bacteroidales & S24-7 & \\
\hline 337724 & 0.0034 & 0.0119 & higher & Bacteroidetes & Bacteroidia & Bacteroidales & S24-7 & \\
\hline 3013444 & 0.0063 & 0.0180 & higher & Bacteroidetes & Bacteroidia & Bacteroidales & & \\
\hline 276478 & 0.0007 & 0.0116 & higher & Firmicutes & Clostridia & Clostridiales & Peptostreptococcaceae & \\
\hline 180869 & 0.0028 & 0.0236 & higher & Firmicutes & Erysipelotrichi & Erysipelotrichales & Erysipelotrichaceae & \\
\hline 356760 & 0.0001 & 0.0278 & higher & Firmicutes & Erysipelotrichi & Erysipelotrichales & Erysipelotrichaceae & \\
\hline 4407703 & 0.0000 & 0.0129 & higher & Firmicutes & Erysipelotrichi & Erysipelotrichales & Erysipelotrichaceae & Coprobacillus \\
\hline 261350 & 0.0188 & 0.0039 & lower & Bacteroidetes & Bacteroidia & Bacteroidales & & \\
\hline 276802 & 0.0103 & 0.0043 & lower & Bacteroidetes & Bacteroidia & Bacteroidales & & \\
\hline 348038 & 0.0698 & 0.0335 & lower & Bacteroidetes & Bacteroidia & Bacteroidales & & \\
\hline
\end{tabular}

Table 2.8: microbial composition profiles of the AOM-injected $I l 10^{-/-}$mice on their respective diets, $0 \%$ or $0.5 \%$ compared to the untreated WT mice on the control diet. This is a summary of changes in microbial composition generated using the QIIME software, which utilizes the Bonferroni-corrected method of multivariate analysis. OTUs and their associated bacteria taxa were considered "different" if the $\mathrm{p}$-value $<0.05$. Comparison of the means determined the abundance trend pattern. All $\mathrm{p}$-values $=0.0000$, except OTU\# $337724(\mathrm{p}=0.0003)$. 


\begin{tabular}{|c|c|c|c|c|c|c|c|c|}
\hline Predicted pathway - overall & $\begin{array}{c}\text { mean } \\
\text { PBS-WT } \\
0 \%\end{array}$ & $\begin{array}{cc}c & \text { mean } \\
\text { AOM-Il10 } \\
\text { /. } \quad 0 \%\end{array}$ & $\begin{array}{c}\begin{array}{c}\text { Pattern } \\
\text { than }\end{array} \\
\text { WT }\end{array}$ & $\begin{array}{c}\text { mean } \\
\text { AOM- } \\
I l 10^{-/-} \\
0.5 \% \\
\end{array}$ & $\begin{array}{c}\begin{array}{c}\text { Pattern } \\
\text { than }\end{array} \\
\text { WT }\end{array}$ & $\begin{array}{c}\text { mean } \\
\text { AOM-- } \\
I l 10^{--} \\
0 \% \\
\end{array}$ & $\begin{array}{l}\text { mean } \\
\text { AOM- } \\
I 110^{--} \\
0.5 \% \\
\end{array}$ & $\begin{array}{l}\text { Trend } \\
\text { than AOM- } \\
\text { Il10-/- 0\% }\end{array}$ \\
\hline Unclassified & 0.1329 & 0.1403 & higher & 0.1383 & higher & 0.1403 & 0.1383 & lower \\
\hline Cellular Processes & 0.0333 & 0.0301 & lower & 0.0243 & lower & 0.0301 & 0.0243 & lower \\
\hline Metabolism & 0.4773 & 0.4711 & lower & 0.4843 & higher & 0.4711 & 0.4843 & higher \\
\hline Genetic Information Processing & 0.1999 & 0.1979 & lower & 0.2058 & higher & 0.1979 & 0.2058 & higher \\
\hline $\begin{array}{l}\text { Environmental Information } \\
\text { Processing }\end{array}$ & 0.1418 & 0.1452 & higher & 0.1313 & lower & 0.1452 & 0.1313 & lower \\
\hline \multicolumn{6}{|l|}{ Predicted pathway - type } & & & \\
\hline Cellular Processes and Signaling & 0.0353 & 0.0402 & higher & 0.0387 & n.s. & 0.0402 & 0.0387 & n.s. \\
\hline Cell Motility & 0.0236 & 0.0213 & n.s. & 0.0146 & lower & 0.0213 & 0.0146 & lower \\
\hline Transcription & 0.0269 & 0.0299 & n.s. & 0.0263 & n.s. & 0.0299 & 0.0263 & lower \\
\hline Glycan Biosynthesis and Metabolism & 0.0276 & 0.0233 & lower & 0.0270 & n.s. & 0.0233 & 0.0270 & n.s. \\
\hline Membrane Transport & 0.1245 & 0.1282 & n.s. & 0.1151 & lower & 0.1282 & 0.1151 & lower \\
\hline Translation & 0.0579 & 0.0553 & n.s. & 0.0610 & higher & 0.0553 & 0.0610 & higher \\
\hline \multicolumn{6}{|l|}{ Predicted pathway - specific } & & & \\
\hline Other ion-coupled transporters & 0.0116 & 0.0126 & higher & 0.0129 & higher & 0.0126 & 0.0129 & n.s. \\
\hline General function prediction only & 0.0337 & 0.0361 & higher & 0.0358 & higher & 0.0361 & 0.0358 & n.s. \\
\hline Two-component system & 0.0141 & 0.0136 & n.s. & 0.0125 & lower & 0.0136 & 0.0125 & lower \\
\hline Purine metabolism & 0.0236 & 0.0223 & lower & 0.0232 & n.s. & 0.0223 & 0.0232 & higher \\
\hline Oxidative phosphorylation & 0.0112 & 0.0106 & n.s. & 0.0121 & higher & 0.0106 & 0.0121 & higher \\
\hline Aminoacyl-tRNA biosynthesis & 0.0123 & 0.0115 & n.s. & 0.0125 & n.s. & 0.0115 & 0.0125 & higher \\
\hline Transcription factors & 0.0163 & 0.0184 & higher & 0.0148 & lower & 0.0184 & 0.0148 & lower \\
\hline $\begin{array}{l}\text { DNA repair and recombination } \\
\text { proteins }\end{array}$ & 0.0289 & 0.0282 & lower & 0.0297 & higher & 0.0282 & 0.0297 & higher \\
\hline Transporters & 0.0737 & 0.0727 & lower & 0.0642 & lower & 0.0727 & 0.0642 & lower \\
\hline Pyrimidine metabolism & 0.0197 & 0.0188 & lower & 0.0196 & n.s. & 0.0188 & 0.0196 & higher \\
\hline
\end{tabular}

Table 2.9: Predicted pathways based on microbial composition profiles of the AOM-injected $I l 10^{-/}$mice on their respective diets, $0 \%$ or $0.5 \%$ compared to the untreated WT mice on the control diet. Predictions of pathways were generated by the PICRUSt software, which uses the 16S rRNA sequences present in a sample and an ancestral-state reconstruction algorithm to predict gene families and estimate the composite metagenome. PICRUSt results were analyzd using QIIME. This table represents statistically significant differences as calculated by the Bonferroni-corrected multivariate analysis in predicted pathways associated with abundance(s) of OTUs. Differences were 
considered significant if the $\mathrm{p}>0.05$. All $\mathrm{p}$-values $=0.0000$, except Genetic Information Processing $(\mathrm{p}=0.0003)$, Environmental Information Processing ( $\mathrm{p}=0.0017)$, Aminoacyl-tRNA biosynthesis $(\mathrm{p}=0.0006)$, Transcription factors $(\mathrm{p}=0.0051)$ and Pyrimidine metabolism $(\mathrm{p}=0.0384)$. 


\section{Microbial composition patterns associated with colon cancer induction}

We next wanted to further explore the association of microbial composition profiles in relation to carcinogenesis in the colon (Fig. 2.10). We found that there is a statistically significant difference in the microbial composition profiles between mice without tumors and mice with tumors (2.10A-B). Furthermore, there are differences in microbial composition when we differentiate samples based on spontaneity or chemical induction (2.10C-D). The majority of mice with tumors are $1110^{-/-}$mice (as described in Fig. 2.5). Separation can not be based primarily on genotype because they would all cluster together. Instead, the clustering pattern is associated with presence of tumor and what type of tumor induction. Taxa bar charts allow for a quick visual overview in patterns to see if there are differences among groups, defined as mice without tumors vs. mice with tumors $(\mathbf{2 . 1 0 E})$ and PBS-injected mice with spontaneous tumors versus AOM-injected mice with tumors (2.10F). It is important to note that all microbial DNA samples from tumor-bearing mice in the AOM-injected groups were treated as "induced." Specific changes in microbial composition are reported (Table 2.10). There are relatively few differences in abundance of OTUs between samples with tumor and samples without. The microbial composition profile from samples with spontaneous tumors and from samples with induced tumors both have an increase in B. ovatus compared to samples from mice without tumors. However, they differ in all other identified OTUs compared to samples without tumor. The microbial composition profile of the samples from mice with spontaneous tumors have a higher abundance of OTUs within the Bacteroidetes phyla, compared to samples from mice without tumors. The microbial composition profile of the samples from mice with induced tumors have higher abundance of OTUs within the Firmicutes phyla, compared to samples from mice without tumors. This same pattern is maintained when the groups of samples from mice 
with tumors are compared to each other. The induced tumor samples have higher abundance in Firmicutes than the spontaneous tumor samples.

The predicted pathways associated with these microbial composition profiles are reported in Table 2.11. The predicted pathways based on the microbial composition are the same for both groups of samples from mice with spontaneous or induced tumors, respectively. However, the predicted function of those pathways is opposite. In comparison to samples from mice with no tumors, microbiota within mice that have spontaneous tumors are predicted to have a decrease in environmental processing, membrane transport and transporters, while having an increase in general metabolism pathways. The opposite is predicted for the microbiota within mice that have induced tumors, compared to mice with no tumors. When the groups are compared to each other, microbiota from mice with induced tumors are predicted to have pathways less active for metabolism, but more active for environmental processing, membrane transport and transporters. 

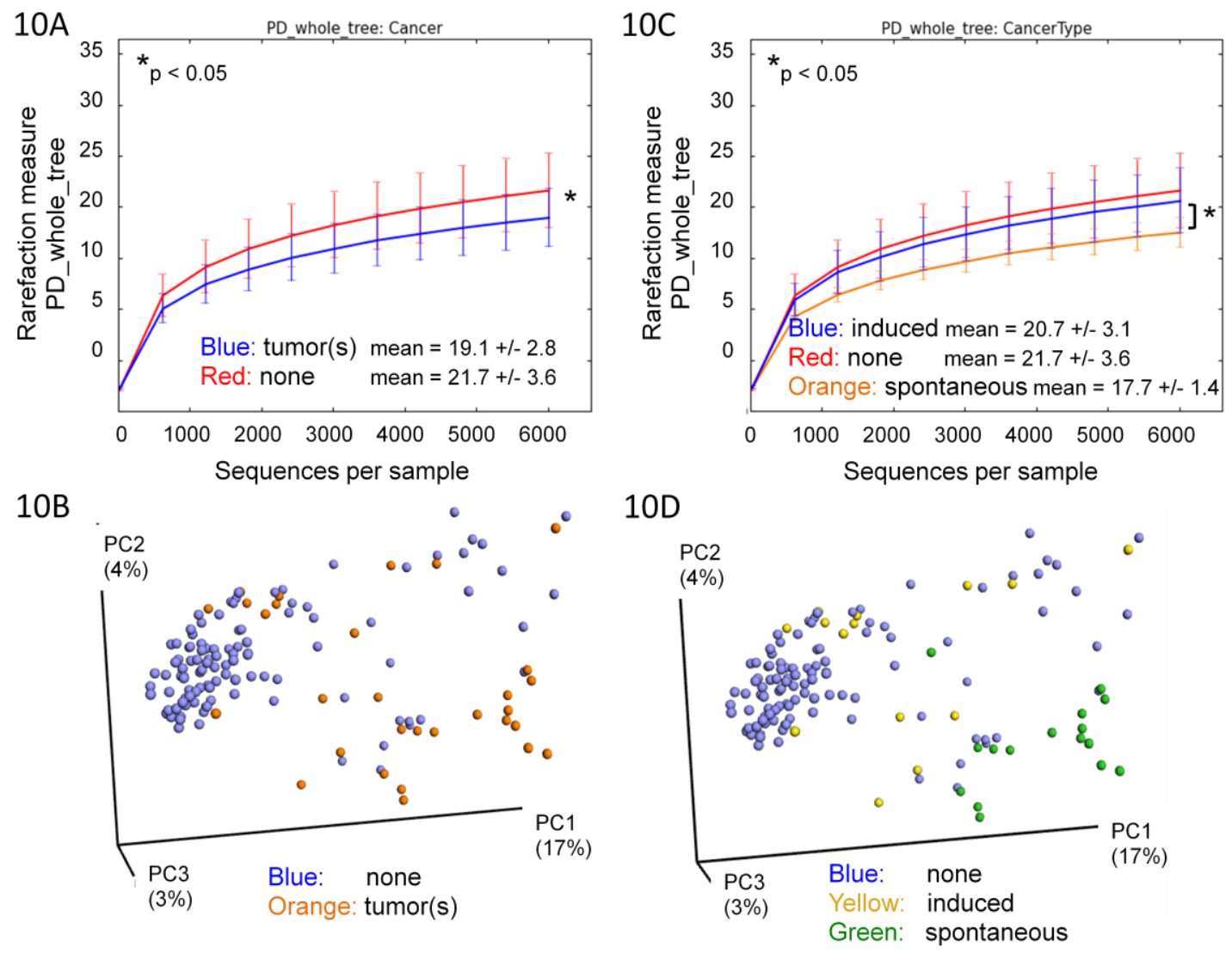

10E

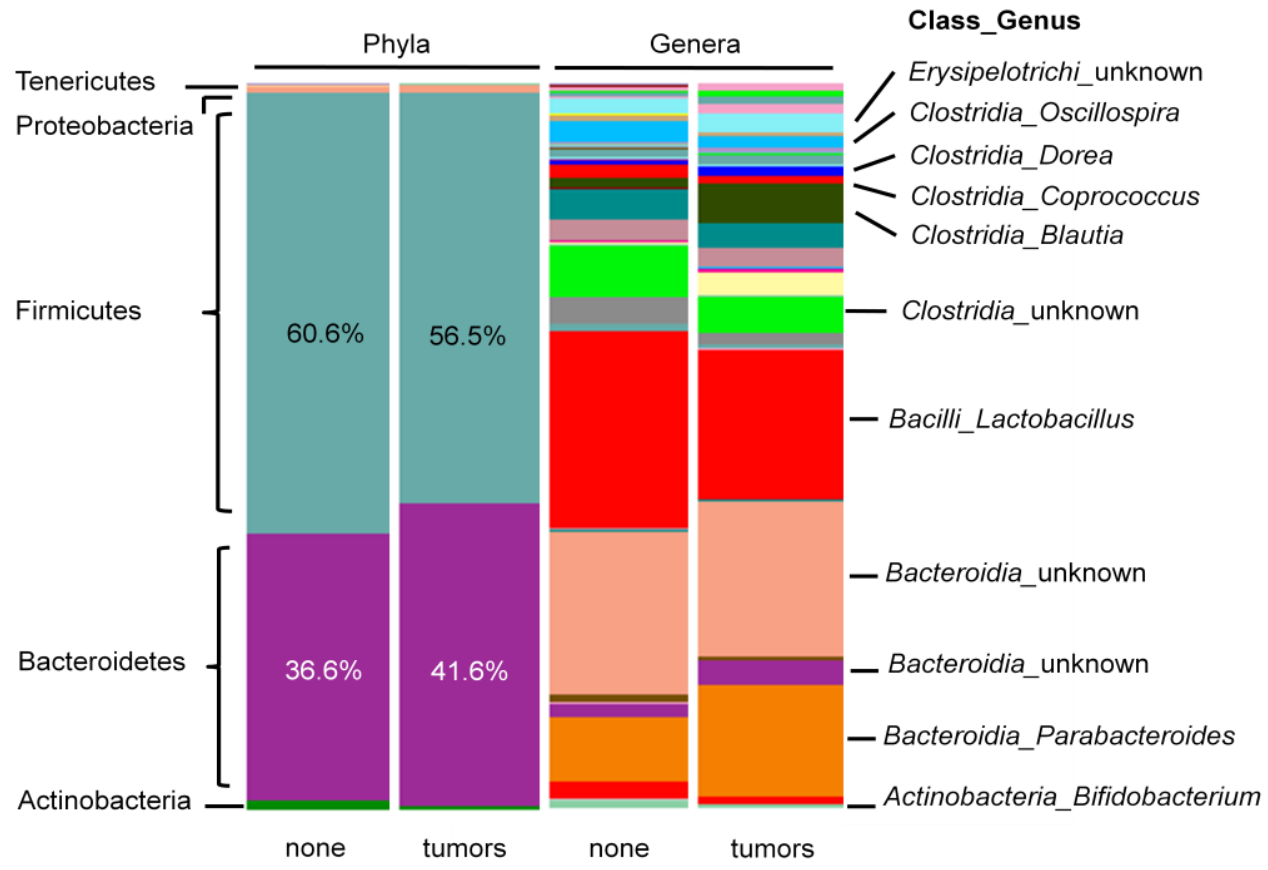


$10 \mathrm{~F}$

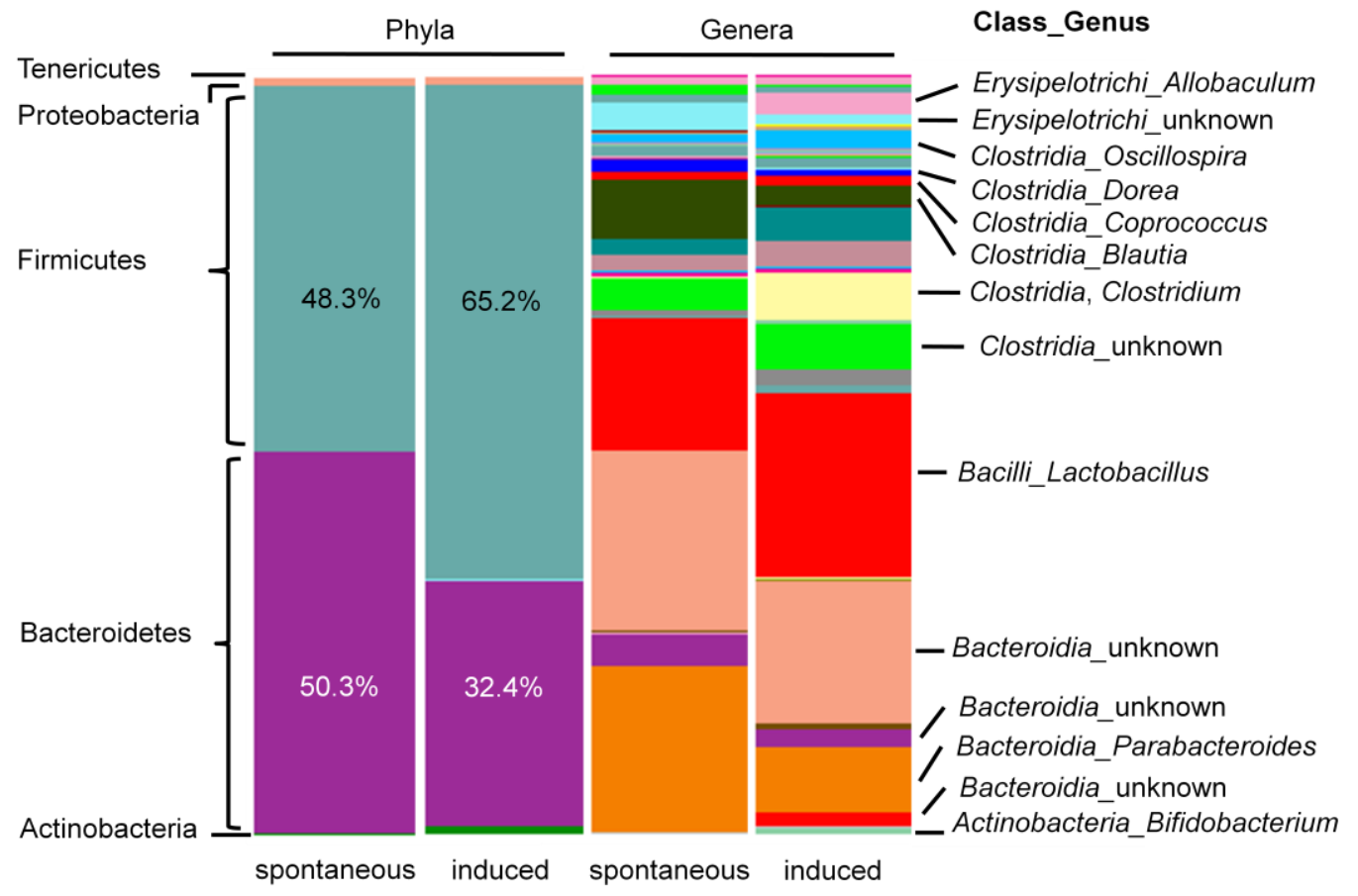

Figure 2.10: Microbial composition patterns associated with colon cancer induction

Alpha diversity was calculated as phylogenetic diversity using the QIIME software, which utilizes a non-parametric t-test (10A, 10C). The alpha diversity $\mathrm{p}$-value for samples from mice with tumors vs. mice without tumors was 0.0060 . The alpha diversity p-value for samples from mice with spontaneous tumors vs. from mice with induced tumors was 0.024 . Beta diversity pcoa plots were generated in QIIME and analyzed using Analysis of Similarity (10B, 10D). The p-value for the ANOSIM analysis for samples from mice with tumors vs. mice without tumors was 0.001 and the R-value was 0.3797 . The p-value for the ANOSIM analysis for samples from mice with spontaneous tumors vs. from mice with induced tumors was 0.001 and the R-value was 0.3821). The taxonomic grouping bar chart was also generated in QIIME and modified to include \% abundance and labels in Microsoft Powerpoint for mice with no tumor and mice with tumors (10E), as well as for mice with spontaneous vs. AOMinduced tumors $(10 \mathrm{~F})$. 
A

Microbial composition patterns of spontaneous tumors samples compared to samples without tumor

\begin{tabular}{|c|c|c|c|c|c|c|c|c|}
\hline OTU & $\begin{array}{c}\text { mean } \\
\text { none }\end{array}$ & $\begin{array}{c}\text { mean } \\
\text { spon. }\end{array}$ & Pattern & Phyla & Class & Order & Family & Genus/ Species \\
\hline 343853 & 0.0012 & 0.0057 & higher & Bacteroidetes & Bacteroidia & Bacteroidles & S24-7 & \\
\hline 589277 & 0.0014 & 0.0093 & higher & Bacteroidetes & Bacteroidia & Bacteroidles & Bacteroidaceae & Bacteroides \\
\hline 535375 & 0.0712 & 0.1796 & higher & Bacteroidetes & Bacteroidia & Bacteroidles & Bacteroidaceae & B. ovatus \\
\hline 291090 & 0.0056 & 0.0154 & higher & Bacteroidetes & Bacteroidia & Bacteroidles & Porphyromonadaceae & P. distasonis \\
\hline
\end{tabular}

B

Microbial composition patterns of induced tumors samples compared to samples without tumor

\begin{tabular}{|c|c|c|c|c|c|c|c|c|}
\hline OTU & $\begin{array}{c}\text { mean } \\
\text { none }\end{array}$ & $\begin{array}{c}\text { mean } \\
\text { induced }\end{array}$ & $\begin{array}{c}\text { Patter } \\
\mathbf{n}\end{array}$ & Phyla & Class & Order & Family & Genus/ Species \\
\hline 535375 & 0.0712 & 0.0728 & higher & Bacteroidetes & Bacteroidia & Bacteroidales & Bacteroidaceae & B. ovatus \\
\hline 337494 & 0.0040 & 0.0226 & higher & Firmicutes & Clostridia & Clostridiales & & \\
\hline 277143 & 0.0017 & 0.0225 & higher & Firmicutes & Erysipelotrichales & $\begin{array}{c}\text { Eysipelotric- } \\
\text { hales }\end{array}$ & Erysipelotrichaceae & Allobaculum \\
\hline
\end{tabular}

C

microbial composition patterns of samples from mice with induced tumors compared to spontaneous tumors

\begin{tabular}{|c|c|c|c|c|c|c|c|c|}
\hline OTU & $\begin{array}{l}\text { mean } \\
\text { spon. }\end{array}$ & $\begin{array}{c}\text { mean } \\
\text { induced }\end{array}$ & Pattern & Phyla & Class & Order & Family & $\begin{array}{l}\text { Genus/ } \\
\text { Species }\end{array}$ \\
\hline 589277 & 0.0093 & 0.0002 & lower & Bacteroidetes & Bacteroidia & Bacteroidales & Bacteroidaceae & Bacteroides \\
\hline 535375 & 0.1796 & 0.0728 & lower & Bacteroidetes & Bacteroidia & Bacteroidales & Bacteroidaceae & Bacteroides \\
\hline 585914 & 0.0101 & 0.0046 & lower & Bacteroidetes & Bacteroidia & Bacteroidales & Porphyromonadaceae & P. distansonis \\
\hline 291090 & 0.0154 & 0.0069 & lower & Bacteroidetes & Bacteroidia & Bacteroidales & Porphyromonadaceae & P. distansonis \\
\hline 337494 & 0.0000 & 0.0226 & higher & Firmicutes & Clostridia & Clostridiales & & \\
\hline 277143 & 0.0001 & 0.0225 & higher & Firmicutes & Erysipelotric-hi & Erysipelotricha-les & Eryipelotrichaceae & Allobacul-um \\
\hline
\end{tabular}

Table 2.10: Microbial Composition Profiles of samples from mice with spontaneous tumors, induced tumors and no tumors.

This is a summary of changes in microbial composition generated using the QIIME software, which utilizes the Bonferroni-corrected method of multivariate analysis. OTUs and their associated bacteria taxa were considered "different" if the p-value $<0.05$. Comparison of the means determined the abundance trend pattern. The p-values $=0.0000$, except OTU\# 291090 ( $\mathrm{p}=0.0167)$, OTU\# $337494(\mathrm{p}=0.0062)$ and OTU\# $585914(\mathrm{p}=0.0136)$. 


\begin{tabular}{|c|c|c|c|c|c|c|c|c|}
\hline $\begin{array}{l}\text { Predicted pathway - } \\
\text { overall }\end{array}$ & $\begin{array}{l}\text { mean } \\
\text { none }\end{array}$ & $\begin{array}{l}\text { mean } \\
\text { spontaneous }\end{array}$ & $\begin{array}{l}\text { Pattern } \\
\text { than } \\
\text { none }\end{array}$ & $\begin{array}{l}\text { mean } \\
\text { induced }\end{array}$ & $\begin{array}{l}\text { Pattern } \\
\text { than } \\
\text { none }\end{array}$ & $\begin{array}{l}\text { mean } \\
\text { spontaneous }\end{array}$ & $\begin{array}{l}\text { mean } \\
\text { induced }\end{array}$ & $\begin{array}{l}\text { Pattern - } \\
\text { than } \\
\text { spontaneous }\end{array}$ \\
\hline Unclassified & 0.1366 & 0.1413 & higher & 0.1370 & n.s. & 0.1413 & 0.1370 & lower \\
\hline $\begin{array}{l}\text { Environmental Information } \\
\text { Processing }\end{array}$ & 0.1370 & 0.1296 & lower & 0.1381 & higher & 0.1296 & 0.1381 & higher \\
\hline Metabolism & 0.4797 & 0.4911 & higher & 0.4838 & lower & 0.4911 & 0.4838 & lower \\
\hline \multicolumn{6}{|l|}{ Predicted pathway - type } & & & \\
\hline Membrane Transport & 0.1200 & 0.1143 & lower & 0.1220 & higher & 0.1143 & 0.1220 & higher \\
\hline \multicolumn{6}{|l|}{$\begin{array}{l}\text { Predicted pathway - } \\
\text { specific }\end{array}$} & & & \\
\hline Transporters & 0.0694 & 0.0659 & lower & 0.0708 & higher & 0.0659 & 0.0708 & higher \\
\hline
\end{tabular}

Table 2.11: Predictions of pathways in mice (spontaneous tumors vs induced tumors) based on microbial composition profiles

Predictions of pathways were generated by the PICRUSt software, which uses the 16S rRNA sequences present in a sample and an ancestral-state reconstruction algorithm to predict gene families and estimate the composite metagenome. PICRUSt results were analyzed using QIIME. This table represents statistically significant differences as calculated by the Bonferroni-corrected multivariate analysis in predicted pathways associated with abundance(s) of OTUs. Differences were considered significant if the $\mathrm{p}>0.05$.

The $p$-values were as follows: Unclassified $(p=0.0000)$, Environmental Information Processing $(p=0.0131)$, Metabolism $(p=0.0300)$, Membrane Transport $(p=0.0155)$ and

Transporters $(\mathrm{p}=0.0251)$. 


\section{CHAPTER 3: DISCUSSION}

A. Effects of microbiota on progression and incidence of colon cancer

\section{$\underline{\text { Review and verification of mouse model of CAC }}$}

Using a colitis-associated colon cancer mouse model system, $I l 10^{-/-}$mice and the wildtype control mice were allowed to age to 10 weeks by which point the $I l 10^{-/}$mice develop a spontaneous and progressive colitis (Kühn et al., 1993 and Gomes-Santos et al., 2012). We fed the wildtype and the chronically inflamed $I l 10^{-/}$mice with curcumin in their pelleted diets at the following doses: $0 \%$ (control diet), $0.05 \%, 0.1 \%, 0.5 \%$ and $1 \%$. These mice were injected with either a carcinogen, azoxymethane (AOM), or a placebo, Phosphate Buffered Saline (PBS) once per week for six weeks total (Figure 2.1). We were able to induce tumors through the use of $\mathrm{AOM}$ and tumor burden was increased for $1110^{-/}$mice receiving AOM, compared to WT mice receiving AOM and compared to $I l 10^{-/}$mice that did not receive AOM (Figure 2.5).

1. How this data fits in with current research in the field

This research adds to the field by describing differences in microbial populations based on induction of tumors, whether in mice exposed to AOM, or in mice with no AOM exposure (spontaneous). The microbial composition profile differs by tumor induction, whether spontaneous or AOM-induced, among mice that have tumors compared to mice that did not develop tumors. Of the bacteria found to statistically differ from those within mice with no 
tumors, the Bacteroidetes phyla dominate the microbial composition profile of mice with spontaneous tumors, while Firmicutes dominate the microbial composition profile of mice with AOM-induced tumors (Table 2.10).

Because Bifidobacteria and Lactobacilli were found to be statistically different among curcumin treated vs. control diet groups, we wanted to compare abundance of Bifidobacteria and Lactobacilli between mice with tumor vs. no tumor or between mice with spontaneous vs. AOMinduced tumors. However, differences in these were not found to be statistically significant in the context of cancer. It is interesting to note that previous studies have seen a correlation of increased abundance of Lactobacillus in patients with low risk for colon cancer, vs. patients at high risk for colon cancer. Risk assessments were based on number of polyps and a history of chronic inflammatory bowel diseases (Moore et al., 1995). I would like to explore this upon repeating the studies and increasing the number of mice per group in both spontaneous vs. chemically-induced cancer populations.

We discovered that differences in predicted bacterial pathways, namely bacterial transporters, vary based on spontaneous vs. induced tumors, which is novel to the field. The expression of transporters of gut microbiota is predicted to vary by development of spontaneous vs. AOM-induced tumors (Table 2.11). Bacterial transporters were predicted to be lower in mice with spontaneous tumors compared to the mice that do not have tumors, while the opposite was predicted for bacterial transporters in mice with induced tumors compared to mice without tumors. I would like to extend this finding to explore if certain host transporters associated with colon cancer, such as SLC5A8, are decreased in $I l 10^{-/-}$mice, making them higher risk to develop colon cancer, or if expression of transporters varies depending on spontaneous or AOM-induced colon cancer. SLC5A8 is a sodium-coupled transporter that not only transports beneficial short 
chain fatty acids (SCFAs), but also functions as a tumor suppressor that is commonly mutated in colon cancer (Ganapathy et al., 2013). Characterizing changes in transporters may allow for better biomarkers for colon cancer, as well as indicate function within the colon epithelium.

2. Future directions of influences of microbiota on colon cancer

The numbers of mice in this study, though over 100 animals total, resulted in few mice per diet/treatment group $(n=6)$. Now, that we have a clearer understanding of effective dose on reduction of tumor burden, there are many avenues for which to explore.

\section{- Evaluate effects of curcumin to reduce severity/score of spontaneous vs. induced colon cancer in the AOM/IIIO-/- mouse model}

A. We would characterize the differences in spontaneous vs. induced colon cancer with and without $0.1 \%$ curcumin treatment for: a) microbial composition patterns by $16 \mathrm{~S}$ rRNA sequencing and Qiime analysis, b) genetic mutations present by microarray c) gene expression and local production within Mesenteric Lymph Nodes of pro-inflammatory cytokines/chemokines produced of tumor tissue and adjacent non-tumor tissue, d) inflammatory cell infiltration characterization, d) beta-catenin, NF-KB, Ki67 expression by IHC.

B. We would further explore the necessity of microbiota in curcumin's mechanism of action by a) co-housing mice on the same diet with and without the AOM carcinogen to observe any changes in tumor burden and characterization of the tumors due to changes in microbial composition within a shared environment. 
- Evaluate curcumin as an effective agent in reducing tumor burden and likelihood of progressing to colon cancer from a state of chronic inflammation

We would repeat the studies, focusing on the $0.5 \%$ diet to increase the statistical power of the analysis. We would characterize as above to identify other potential mechanisms of action of curcumin in tumor reduction.

- Microbial colonization of tumor tissue during development and progression of colon cancer

The predicted metabolic pathways indicated an increase in PTS for the $1110^{-/}$mice compared to WT. This system is associated with early colonization of bacteria in GF mice, as well as on abiotic surfaces (Houot et al., 2010). This finding suggests a stepwise colonization of tumor tissue that is currently poorly understood. The metabolic needs of bacteria for survival in a tumor context may be very different than in a tumor-free epithelium, given that the tumor-burdened epithelium may no longer be bringing in nutrients and the mucus layer may not be being produced continuously in these regions. So, the physical environment for colonization and the available nutrients may change in the context of cancer.

The tumor may also be producing anti-inflammatory factors, which could potentially shield the bacteria from immune system surveillance in the local environment, which may affect which specific bacteria can flourish without that limiting factor.

It would be intriguing to set up a study to explore microbial colonization of a tumor. Endoscopy could allow for detection of tumor development during a mouse study and stool samples could be collected throughout the study for analysis of the overall composition. Ideally, biopsy samples could be obtained during endoscopy, although this may not be an 
option, currently for the technology available for mice. However, tissue samples from the tumor and adjacent non-tumor tissue could be collected from mice upon euthanasia where some mice are taken for tissues early in the study and some are allowed to develop the colon cancer for months and taken for tissue analysis at a later time. This can be compared to human biopsy samples from tumor and adjacent non-tumor tissue.

We could further compare tissue samples from spontaneous vs. induced tumors in the proposed mouse studies above to investigate the effect of curcumin on epithelium barrier properties in the context of microbial invasion. An additional question I would like to answer is how microbial biofilm production potentially affects metastasis potential of a colonic tumor.

Other possible mechanisms to explore that were not addressed in this investigation include exploring the effect of curcumin on colon cancer metastasis (Radhakrishnan et al., 2014) and the role of curcumin to inhibit NFKB (Larmonier et al., 2008), which would potentially allow cells to be more susceptible to TNF- $\alpha$-mediated apoptosis.

\section{B. Curcumin functions as an effective anti-colon cancer agent}

1. How this data fits in with current research in the field

Larmonier, et al. (2008) demonstrated that increasing curcumin does not necessarily equate to increasing effectiveness and we have verified those findings. The toxicity of large doses when administered with AOM and given to the chronically inflamed $\mathrm{IllO}^{-/}$mice indicates that dose is an important factor to consider. Curcumin has been observed to be well tolerated in healthy adult humans (Lao et al., 2006). However, this tolerance to large amounts of curcumin 
has not been reported in patients with active disease. This dissertation research adds to the field by exploring the appropriate dose of curcumin in chronically inflamed mice. It also adds to the field by suggesting in which patient populations this treatment will be most effective, as it is possible that curcumin may be most effective in patient populations where patients with polymorphisms in IL10, or the receptor for IL10, are excluded from this treatment strategy.

Although our original hypothesis tested whether or not curcumin could be used to influence microbial composition patterns to shift in inflamed mice closer to that of healthy individuals, we did not see a strong effect at any of the doses tested. However, this is a benefit as it could potentially be used concomitantly with other colon cancer treatments without the concern of shifting the microbial composition and initiating further inflammatory response events. The gut microbiota appears especially sensitive to dietary environmental factors. Thus, having a treatment option that does not cause dramatic shifts in the microbiota is useful in the medicinal field and would also be less invasive and potentially less expensive and facilitate FDA approval, as it can be administered as a dietary supplement. In addition to microbial compositional changes, functional analyses of the microbiome using transcriptomics will be beneficial.

Concerning the effects of curcumin on microbial profiles, data indicates a shift towards bacteria associated with gut health. Bifidobacteria is associated with health in the colon (Liboredo et al., 2013) and yet it was identified as increased overall in the chronically inflamed $I l 10^{-/}$compared to the wildtype (WT) mice. (Table 2.4), which was unexpected. However, when we investigate the microbial composition of $I l 10^{-/}$mice in relation to the curcumin diet group, we see a pattern emerge. The $1110^{-/-}$mice fed the $0.5 \%$ curcumin diet have an increase in Bifidobacteria (Table 2.7 and Table 2.8), while the $I l 10^{-/-}$mice on the control ( $0 \%$ curcumin) 
diet are not statistically different from the healthy WT mice on control diet. This pattern holds true for Lactobacillus, another bacteria which is considered beneficial to the health of the colon. Both Bifidobacteria and Lactobacilli are used as probiotics and function to produce esterase's, which can liberate ester-linked nutrient sources that the host would otherwise be unable to utilize (Mukhopadhya et al., 2011). This research adds to the field by indicating that curcumin has an advantageous effect to shift the microbial composition towards bacteria that are known to be beneficial to the health of the colon.

\section{Metabolism}

The increase in Bacteroidetes in $I l 10^{-/-}$mice, compared to WT, corresponds with an increase in carbohydrate metabolism (Table 2.5), which suggests utilization of the Bacteroidetes' carbohydrate fermentation pathway as an energy source in the inflamed mice. This further corresponds to an increase in the phosphotransferase system (PTS) pathway, which allows for carbohydrate transport into bacterial cells (Table 2.5). The purine and pyrimidine metabolism was decreased compared to WT. Purines and pyrimidines are critical for DNA replication and survival. The metabolism pathways allow for do novo synthesis, as well as harvesting them from nucleic acid turnover or from food, which allows the bacteria flexibility in the sources of nucleotides, especially if unable to acquire them from the environment. Addition of curcumin in the diet at a dose of $0.5 \%$ resulted in an increase in purine and pyrimidine metabolism pathways to be similar to that of healthy WT mice on the control diet (Table 2.9), which suggests a beneficial effect of curcumin on microbial metabolism stability and homeostasis in the gut. 


\section{Transporters}

The predicted pathways based on the microbial composition profiles showed that bacterial transporters are predicted to decrease in the $I l 10^{-/}$mice, as opposed to the healthy WT mice on control diet (Table 2.5). The addition of the curcumin-supplemented diet did not alter this prediction (Table 2.9). However, the finding that "other ion-coupled transporters" are predicted to be higher in $I l 10^{-/-}$mice compared to WT mice (Table 2.9) indicates that not all bacterial transporters will be reduced in the context of chronic inflammation.

It would be advantageous to know which bacterial transporters are potentially decreased, as this may be an indicator about what could be taken up in to the bacterial cell as an energy source, especially if transporters change over the course of the disease progression or during the switch from inflammation to cancer.

\section{Two-component systems}

PICRUSt analysis indicated that bacterial two-component systems are decreased in $1110^{-/}$ mice given the $0.5 \%$ curcumin-supplemented diet compared to $1110^{-/}$mice on the control $(0 \%$ curcumin) diet (Table 2.9). It was not identified as statistically different between tumor types or presence/absence of tumors. Yet, this is intriguing, as the $1 l 10^{-/-}$mice given $0.5 \%$ curcumin had a striking reduction in tumor development for both spontaneous and AOM-induced tumors with no $\mathrm{IlIO}^{-/-}$mice on the $0.5 \%$ curcumin diet developing tumors (Figure 2.5). The two-component system is associated with the bacteria's ability to sporulate, gain antibiotic resistance, become competent (take in DNA) and to transition to a static phase (Mitrophanov et al., 2008). Sporulation was not predicted by PICRUSt to be different between the $1110^{-/-}$mice and the WT 
mice, or between the $1110^{-/-}$mice on the control vs. on the $0.5 \%$ curcumin diet. PICRUSt does not predict competence or antibiotic resistance. However, $I l 10^{-/-}$mice fed the $0.5 \%$ curcumin diet were predicted to have reduced cell motility (Table 2.9). Curcumin has been observed to inhibit bacterial motility and cytotoxicity of Vibrio vulnificus (Na et al., 2011), to arrest Helicobacter pylori growth during infections (De et al., 2009), as well as inhibit biofilm formation in Pseudomonas aeruginosa (Rudrappa et al., 2008). This suggests that the protective effect of $0.5 \%$ curcumin diet shifts the microbial composition to be more stationary, which may contribute to a decrease in microbial invasiveness and a decrease in overall disease severity.

\section{Future directions of curcumin as an anti-cancer agent}

There are many future directions in which to explore. Increasing the bioavailability of curcumin may make the therapeutic outcome of this treatment even more effective. Curcumin is considered poorly absorbed, quickly metabolized and quickly eliminated with low aqueous solubility (Ji et al., 2014). A study from our lab using mice housed in specific pathogen free (SPF) conditions detected through HPLC analysis significant amounts (ranging from $1.54 \pm 0.2$ $\mathrm{mM}$ to $7.54 \pm 0.3 \mathrm{mM}$ ) of unmetabolized curcumin in the colon lumen for mice fed curcumin in their diets with doses ranging from $0.1 \%$ to $1 \%$ (Larmonier et al., 2008). Nevertheless, it remains highly effective and much effort has been placed into increasing its bioavailability to the intestinal epithelium. Increasing the bioavailability through the use of nanoparticles (Chuah et al., 2014 and Li et al., 2014), using plant exosomes as a delivery method (clinicaltrials.gov ID:NCT01294072)) and administering concomitantly with compounds, such as piperine (Shoba et al., 1998), are current strategies used to increase bioavailability of curcumin that we could explore in the laboratory or through collaboration. 
Another avenue of research was suggested by Dr. Dirk Haller, who described his findings (unpublished) that using standard mouse chow for dietary supplements causes variation in microbial composition. He recommends trying synthetic component based diet, as his research team has found this to cause less variability in the microbial composition, which made it easier to understand how their dietary supplementation was truly affecting the microbiota.

A question arises as to how our research can contribute directly to human healthcare. I propose consideration of the following clinical trials.

\section{- Clinical trial for use of curcumin in patients with IL10 polymorphisms}

Curcumin is tolerated well in healthy patients, but it is concerning that it may become toxic in the context of chronic inflammation. There are many clinical trials that explore the tolerability of curcumin in healthy humans, but this needs to be explored with IBD patients, especially if it can be an effective prevention of the progression to colon cancer in high-risk patients with a long history of IBD, particularly Ulcerative Colitis. I propose not only to test this in IBD patients, but to have two groups of patients recruited, one that tests positive for IL10 polymorphism and one that does not. This will allow for a refinement of selecting patients that will most benefit from curcumin treatment. 


\section{- Clinical trial for use of curcumin in patients with colon cancer in the ascending vs. descending colon}

There are differences in the genetic mechanisms of colon cancer spatially between ascending and descending colon locations. Furthermore, the microbial burden varies spatially within the colon, with the greater abundance being located in the distal regions of the colon. If the bacteria are playing a large role in the initiation of cancer in the colon, this is also a promising therapeutic target that warrants more investigation. The $1 l 10^{-/}$mouse model system allows for a unique model system where mice spontaneously develop tumors in the proximal region, which corresponds to the ascending colon. The $I l 10^{-/}$mice can be given AOM to promote tumors primarily in the distal region, which corresponds to the descending colon. Even if curcumin did not reduce spontaneous tumors, it may reduce the severity, as demonstrated by the localization of beta catenin in the membrane of tumor tissue from mice given $0.5 \%$ curcumin, as it would be in healthy animals. Conversely, the mice that were not given curcumin had aberrant beta catenin localization. If curcumin can function by keeping tumors from progressing to malignancy or limiting the malignant potential of tumors, this would be very beneficial treatment. I propose a clinical trial were patients would be selected for having either ascending or descending tumors and given curcumin. This would also allow for refinement of selecting patients that will most benefit from curcumin treatment. 


\section{Summary and Conclusion}

Inflammatory bowel diseases are a major risk factor for colon cancer and intestinal microbiota have been identified as a trigger of inflammatory responses that affects the progression of colitis-associated colorectal cancer (CAC). With diet being a key determinant of the gut microbial ecology, dietary interventions, such as curcumin, are an attractive avenue for the prevention of CAC. I hypothesized that curcumin would modulate the bacteria of AOMtreated chronically-inflamed $I l 10^{-/}$mice to become similar in composition to that of healthy, untreated wildtype mice, thus restoring the colon homeostasis of the mice.

Curcumin is effective in reducing the carcinogenicity of the chemical carcinogen azoxymethane (AOM) in a dose-dependent manner (Figure 2.5). We explored whether or not it can modulate the microbiota on a global scale within the colon tissue and if that could be a potential mechanism of action. We did not see a dramatic shift in microbial composition based solely on this treatment, although there were moderate differences in composition profiles at the most effective dose $\left(0.5 \%\right.$ curcumin in $I l 10^{-/}$mice treated with and without AOM compared to healthy untreated WT and the $I l 10^{-/}$mice on the $0 \%$ curcumin control diet)(Figure 2.9).

Curcumin's role as an anti-cancer agent is independent of its anti-inflammatory role. We do not see a statistically significant reduction in the pro-inflammatory cytokine gene expression compared to the mice on the $0 \%$ curcumin control diet (Fig. 2.7). Of all the doses, the $0.1 \%$ curcumin diet is the most effective at reducing inflammation, as shown in AOM-treated wildtype mice (for TNF- $\alpha$, proximal and distal regions; IFN $\square$, proximal region), AOM-treated $I l 10^{-/-}$mice (IL-1ß, distal region) and PBS-treated wildtype mice (IL-17, proximal region). This corresponds with published studies from our lab, where we previously showed that colon morphology was improved and pro-inflammatory cytokine production inhibited only at the $0.1 \%$ curcumin dose 
when testing a range from $0.1 \%$ to $1 \%$. For that study, curcumin was used as a preventative agent in germ-free $I l 10^{-/-}$mice and germ-free $\mathrm{IllO}^{-/}$mice given microbiota from mice housed in a non germ-free, specific-pathogen free facility (Larmonier et al., 2008). This indicates, that curcumin's role to reduce tumorigenesis is independent of its role to reduce inflammation and that both roles are, respectively, dose-dependent.

Results from this study suggest that curcumin may reduce the severity and score of the tumors that form (Figure 2.6). Furthermore, we did observe a striking difference in the microbial composition based on the tumor type of the sources of the samples, whether spontaneous or AOM-induced (Figure 2.10).

This is a promising study that opens many avenues for future research to advance the fields of both microbial analysis in the gut environment and in colon cancer research.

Curcumin was observed to have a beneficial effect as a modulator of microbial composition and as an anti-cancer agent in WT vs. $1110^{-/-}$mice, as well as in mice with spontaneous vs. AOM-induced tumors. Microbial composition profiles of $1110^{-/-}$mice treated with curcumin corresponded with specific microbes associated with tumor-free colon tissue, namely Bifidobacterium and Lactobacillus. Genotype is a strong driving factor behind statistically significant shifts in bacteria. Tumor-free wildtype animals have greater microbial diversity than chronically inflamed $I l 10^{-/}$mice. Functionally, untreated $1 l 10^{-/-}$mice have a shift in their microbial composition profile towards carbohydrate metabolism and a decrease in purine and pyrimidine metabolism, compared to WT, as well as a decrease in general bacterial transporters. Curcumin treatment results in purine and pyrimidine metabolism being indistinguishable from that of WT mice, rather than lower. Curcumin also is associated with predicted decreases in bacterial motility and the two-component system. 


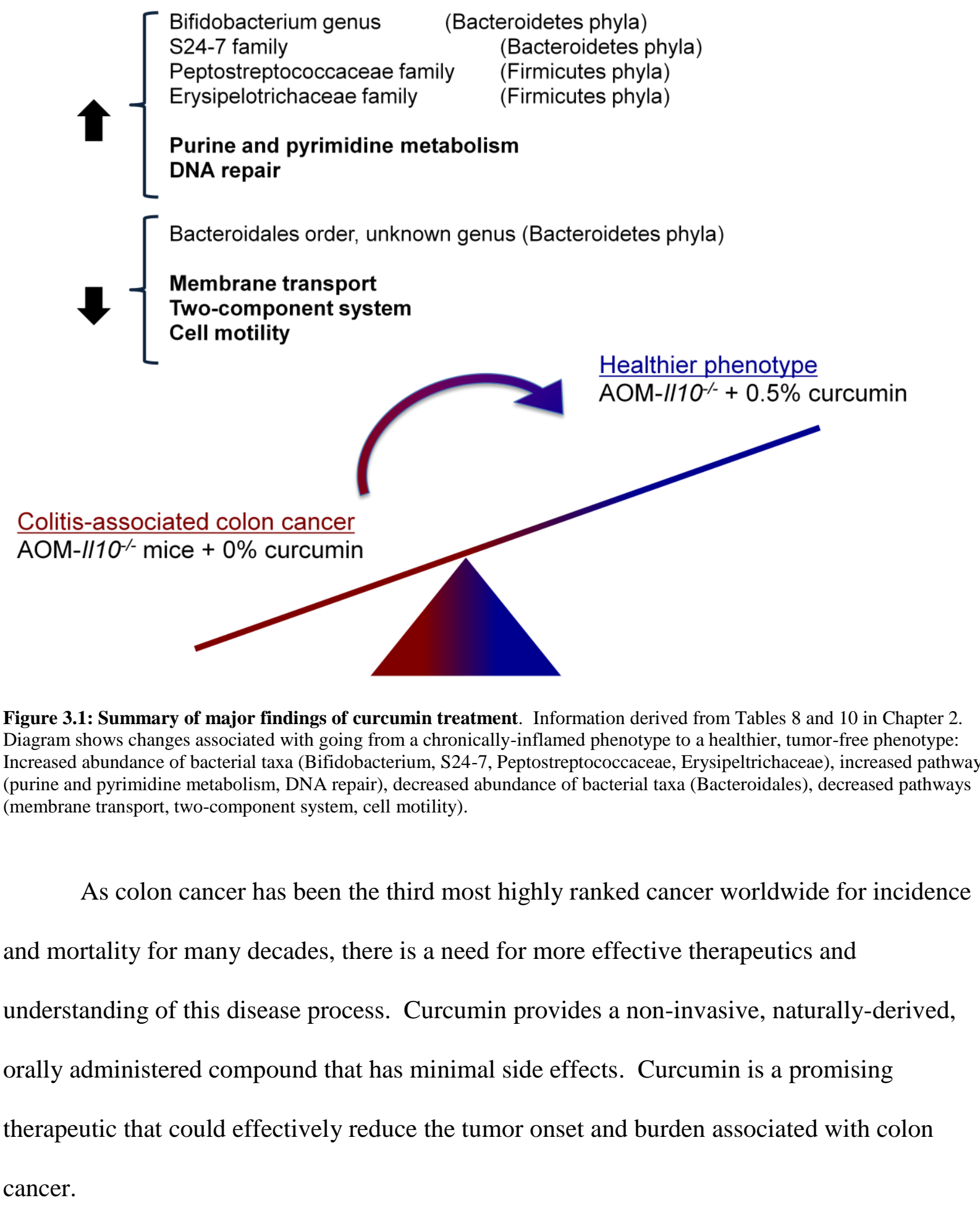




\section{ADDENDUM}

\section{$\underline{\text { Publications }}$}

Radhakrishnan VM, Ramalingam R, Larmonier CB, Thurston RD, Laubitz D, Midura-Kiela MT, McFadden R-M T., Kuro-O M, Kiela PR, Ghishan FK. Post-Translational Loss of Renal TRVP5 Calcium Channel Expression, $\mathrm{Ca}(2+)$ Wasting and Bone Loss in Experimental Colitis. Gastroenterology. 2013. In press.

Larmonier CB, Laubitz D, Hill FM, Shehab KW, Lipinski L, Midura-Kiela MT, McFadden RM T., Ramalingam R, Hassan KA, Golebiewski M, Besselsen DG, Ghishan FK, Kiela PR. Reduced Colonic Microbial Diversity is Associated with Colitis in NHE3-deficient mice. American Journal of Physiology, Gastrointestinal and Liver Physiology. 2013. Epub ahead of print.

Larmonier CB, McFadden R-M T., Hill FM, Schreiner R, Ramalingam R, Besselsen DG, Ghishan FK, Kiela PR. High Vitamin D diet Administered During Active Colitis Negatively Affects Bone Metabolism in Adoptive T-cell Transfer Model. American Journal of Physiology, Gastrointestinal and Liver Physiology. 2013. 305(1):G35-46.

Navath S, Rao V, Woodford R-M T., Midura-Kiela M, Ahad A, Alleti R, Kiela P, Mash E. Design, Synthesis and Testing of a Molecular Truck for Colonic Delivery of 5-Aminosalicylic Acid. ACS Medicinal Chemistry Letters. 2012. 3:710-14.

Allen IC, Wilson JE, Schneider M, Lich JD, Roberts RA, Arthur JC, Woodford R-M T., Davis BK, Uronis JM, Herfarth HH, Jobin C, Rogers AB, Ting JP. NLRP12 suppresses colon inflammation and tumorigenesis through the negative regulation of noncanonical NF-kB signaling. Immunity. 2012. 36(5):742-54.

Allen IC, TeKippe EM, Woodford R-M T., Uronis JM, Holl EK, Rogers AB, Herfarth HH, Jobin C, Ting JP. The NLRP3 inflammasome functions as a negative regulator of tumorigenesis during colitis-associated cancer. Journal of Experimental Medicine. 2010. 207(5):1045-56.

Van Deventer HW*, Burgents JE*, Wu QP, Woodford R-M T., Brickey WJ, Allen IC, McElvania-Tekippe E, Serody JS, Ting JP. The inflammasome component NLRP3 impairs antitumor vaccine by enhancing the accumulation of tumor-associated myeloid-derived suppressor cells. Cancer Research. 2010. 15;70(24):10161-9.

*co-first authors

\section{$\underline{\text { Presentations }}$}

2014 The Role of Curcumin in Modulating Colonic Microbiota During Inflammation and Carcinogenesis

$>$ Digestive Disease Week International Conference, lecture 
Emory University STEM Research and Career Symposium, poster

2013 Design, Synthesis and Testing of a Molecular Truck for Colonic Delivery of 5-Aminosalicylic Acid: Translational Medicine Symposium at the University of North Carolina in Chapel Hill, poster presentation

Antagonism of TGF- $\beta$ pathway in dendritic cells by TLR stimulation is TRIF dependent, poster presentations:

$>$ University of Arizona in Tucson, Frontiers in Immunobiology \& Immunopathogenesis Symposium

Digestive Disease Week (international conference: Orlando, FL)

2011

Inflammasome Deficiency Increases Anti-Cancer Vaccine Efficacy:

$>$ UNC Dental Research and Review Day oral presentation

$>$ UNC Translational Medicine Symposium poster presentation

2010 Role of NLRX1 in colitis-associated colon cancer: UNC

Center for Gastrointestinal Biology and Disease research competition, oral presentation

2009

T cell Expression of Coronin 1A has a role in induction of Graft-versushost disease. UNC Dental Research and Review Day poster presentation.

\section{Training Opportunities}

2010- $\quad$ Howard Hughes Medical Institute Med to Grad training initiative certificate program in Translational Medicine

\section{Accolades}

2013

$2^{\text {nd }}$ place for poster presentation "Design, Synthesis and Testing of a Molecular Truck for Colonic Delivery of 5-Aminosalicylic Acid."

Translational Medicine Symposium at University of North Carolina in Chapel Hill, co-sponsored by Howard Hughes Medical Institute Program in Translational Medicine and the Cancer Cell Biology Training Program

2011 Turner Award: American Association for Dental Research for UNC DRRD 2011 oral presentation "Inflammasome Deficiency Increases Anti-Cancer Vaccine Efficacy."

\section{Teaching/Mentorship/Outreach}

2013

Graduate Research Mentor for Summer Institute for Medical Ignorance (SIMI) program to advance education beyond the classroom, primarily for students from disadvantaged environments - train and prepare two high school students to complete independent 
projects with an emphasis on understanding the techniques and assays used for the research. Students prepared oral presentations on techniques learned and experimental findings. This year, the students assisted with extraction of bacterial DNA, running PCRs and understanding the microbial contribution to inflammation during the course of disease from stool samples of research mice undergoing treatment for colon cancer.

$>$ Volunteer for BIOTECH genetics outreach program at University of Arizona, Tucson Book Festival with the Bio5 Institute. Volunteers help children understand and work through various educational activities about DNA structure, such as extraction and interpreting electrophoresis gels (mini "crime" scene investigation, paternity testing, construct candy DNA structure, etc.).

2012

> Graduate Research Mentor for Keep Engaging Youth in Science (KEYS) Program for highly achieving Arizona high school interns. Research mentor for 5 weeks - train and prepare student to become independent with their own experiments and to display their findings at the KEYS Student Research Showcase. This year, the student (Bob and Nancy Clark sponsored intern) helped with my graduate research project and presented, "The Role of Curcumin in Modulating Colonic Microbiota During Inflammation and Carcinogenesis."

Preceptor: teach a laboratory section with a fellow graduate student TA (Adiv Johnson) of an undergraduate level Anatomy and Physiology class PSIO 202 Spring semester (2012) at the University of Arizona in Tucson. The Course Director is Dr. Eric Price.

2011

> Judge for North Carolina Student Academy of Science's statewide science competition for Middle and High School students: review submitted research papers for assigned section and give verbal and written comments teaching them how to improve their scientific writing and oral presentation skills. Rank and select students for awards.

Student guest lecturer "Scientist Ambassador" for North Carolina DNA Day. Volunteer for one day in April 2011 to teach a high school class with a fellow graduate student promoting Biological Sciences. Powerpoint and science demonstration materials are provided and commemorate the Human Genome Project.

> Teaching Assistant: teach a laboratory section of an undergraduate level Anatomy and Physiology class BIOL252 Summer Session I (2011) at the University of North Carolina in Chapel Hill. The Course Director is Dr. James Fiordalisi.

> Preceptor: teach a laboratory section with a fellow graduate student TA (Kate Smith) of an undergraduate level Anatomy and Physiology class PSIO201 Fall semester (2011) at the University of Arizona in Tucson. The Course Director is Dr. Eric Price. 


\section{REFERENCES}

Abbas, A.K., A.H. Lichtman and S. Pillai. Cellular and molecular immunology. Philadelphia: Saunders Elsevier, 2007. Print.

Abreu, M.T. and R.M. Peek Jr. 2014. Gastrointestinal Malignancy and the Microbiome. Gastroenterology 146:1534-1546.

American Cancer Society. 2014. Colorectal Cancer Facts \& Figures 2014-2016.

Amissah, F., R. Duverna, B.J. Aguilar, R.A. Poku and N.S. Lamango. 2013. Polyisoprenylated methylated protein methyl esterase is both sensitive to curcumin and overexpressed in colorectal cancer: implications for chemoprevention and treatment. BioMed research international 2013:416534.

Arthur, J.C. and C. Jobin. 2013. The complex interplay between inflammation, the microbiota and colorectal cancer. Gut Microbes 4(3):253-258.

Arthur, J.C., E. Perez-Chanona, M. Mühlbauer, S. Tomkovich, J.M. Uronis, T.-J. Fan, B.J. Campbell, T. Abujamel, B. Dogan, A.B. Rogers, J.M. Rhodes, A. Stintzi, K.W. Simpson, J.J. Hansen, T.O. Keku, A.A. Fodor and C. Jobin. 2012. Intestinal Inflammation Targets CancerInducing Activity of the Microbiota. Science 338(6103):120-123.

Balkwill, F. and A. Mantovani. 2001. Inflammation and cancer: back to Virchow? Lancet 357:539-545.

Bel, S., Y. Elkis, H. Elifantz, O. Koren, R. Ben-Hamo, T. Lerer-Goldchtein, R. Rahimi, S.B. Horin, A. Nyska, S. Shpungin and U. Nir. 2014. Reprogrammed and transmissible intestinal microbiota confer diminished susceptibility to induced colitis in $\mathrm{TMF}^{-/-}$mice. Proceedings of the National Academy of Sciences 111(13):4964-4969.

Bernstein, C., H. Halubec, A.K. Bhattacharyya, H. Nguyen, C.M. Payne, B. Zaitlin and H. Bernstein. 2011. Carcinogenicity of deoxycholate, a secondary bile acid. Archives of toxicology 85:863-871.

Billerey-Larmonier, C., J.K. Uno, N Larmonier, A.J. Midura, B. Timmermann, F.K. Ghishan and P.R. Kiela. 2008. Inflammatory bowel disease 14(6):780-793.

Caporaso J.G., J. Kuczynski, J. Stombaugh, K. Bittinger, F.D. Bushman, et al. 2010. QIIME allows analysis of high-throughput community sequencing data. Nature Methods 7: 335-336.

Caporaso, J.G., K. Bittinger, F.D. Bushman, T.Z. DeSantis, G.L. Andersen and R. Knight. 2010. PyNAST: a flexible tool for aligning sequences to a template alignment. Bioinformatics 26: 266267. 
Caporaso J.G., C.L. Lauber, W.A. Walters, D. Berg-Lyons, J. Huntley, N. Fierer, S.M. Owens, J. Betley, L. Fraser, M. Bauer, N. Gormley, J.A. Gilbert, G. Smith and R. Knight. 2012. Ultra-highthroughput microbial community analysis on the Illumina HiSeq and MiSeq platforms. ISME Journal: Multidisciplinary Journal of Microbial Ecology 6: 1621-1624.

CDC. 2014. Inflammatory Bowel Disease (IBD). http://www.cdc.gov/ibd/ May19, 2014.

Chang, L.Y., Y.C. Lin, J. Mahalingam, C.T. Huang, T.W. Chen, C.W. Kang, H.M. Peng, Y.Y. Chu, J.M. Chiang, A. Dutta, Y.J. Day, T.C. Chen, C.T. Yeh and CY. Lin. 2012. Tumor-derived chemokine CCL5 enhances TGF-beta-mediated killing of CD8(+) T cells in colon cancer by Tregulatory cells. Cancer Research 72(5):1092-1102.

Chao, A. 1984. Nonparametric estimation of the number of classes in a population. Scandinavian Journal of Statistics 11, 265-270.

Chiba, T., H. Mausawa and T. Ushijima. 2012. Inflammation-associated cancer development in digestive organs: mechanisms and roles for genetic and epigenetic modulation. Gastroenterolgy 143:550-563.

Chuah, L.H., C.J. Roberts, N. Billa, S. Abdullah and R. Rosli. 2014. Cellular uptake and anticancer effects of mucoadhesive curcumin-containing chitosan nanoparticles. Colloids and Surfaces. B, Biointerfaces 116:228-236.

Cosín-Roger, J., D. Ortiz-Masiá, S. Calatayud, C. Hernández, A. Álvarez, J. Hinojosa, J.V. Esplugues and M.D. Barrachina. 2013. M2 Macrophages Activate WNT Signaling Pathway in Epithelial Cells: Relevance in Ulcerative Colitis. PLoS One 8(10):e78128.

Crohn's and Colitis Foundation of America. 2014. What are Crohn's \& Colitis? http://www.ccfa.org/what-are-crohns-and-colitis/July 11, 2014.

Dai, Y., H. Jiao, G. Teng, W. Wang, R Zhang, Y. Wang, L. Hebbard, J. George and L. Qiao. 2014. Embelin Reduces Colitis-Associated Tumorigenesis through Limiting IL-6/STAT3 Signaling. Molecular cancer therapeutics 13(5):1206-1216.

De, R., P. Kundu, S. Swarnakar, T. Ramamurthy, A. Chowdhury, G.B. Nair and A.K. Mukhopadhyay. 2009. Antimicrobial activity of curcumin against Helicobacter pylori isolates from India and during infections in mice. Antimicrobial agents and chemotherapy 53(4):15921597.

De Filippo, C., D. Cavalieri, M. Di Paola, M. Ramazzotti, J.B. Poullet, S. Massart, S. Collini, G. Pieraccini and P. Lionetti. 2010. Impact of diet in shaping gut microbiota revealed by a comparative study in children from Europe and rural Africa. Proceedings of the National Academy of Sciences 107(33):14691-14696.

Edgar, R.C. 2010. Search and clustering orders of magnitude faster than BLAST. Bioinformatics 26: $2460-2461$. 
Engström, A., A. Erlandsson, D. Delbro and J. Wijkander. 2014. Conditioned media from macrophages of M1, but not M2 phenotype, inhibit the proliferation of the colon cancer cell lines HT-29 and CACO-2. International journal of oncology 44(2):385-392.

Erdman, S.E., J.J. Sohn, V.P. Rao, P.R. Nambiar, Z. Ge, J.G. Fox and D.B. Schauer. 2005. CD4+CD25+ regulatory lymphocytes induce regression of intestinal tumors in ApcMin/+ mice. Cancer research 65:3998-4004.

Faith, D.P. Conservation evaluation and phylogenetic diversity.1992. Biological Conservation 61:1-10.

Fearon, E.R. and B. Vogelstein. 1990. A genetic model for colorectal tumorigenesis. Cell 61:759-767.

Flint, H.J., K.P. Scott, P. Louis and S.H. Duncan. 2012. The role of the gut microbiota in nutrition and health. Nature reviews gastroenterology and hepatology 9:577-589.

Ganapathy, V., M. Thangaraju, P.D. Prasad, P.M. Martin and N. Singh. 2013. Transporters and receptors for short-chain fatty acids as the molecular link between colonic bacteria and the host. Current opinion in pharmacology 869-874.

Garrett, W. S., C. A. Gallini, T. Yatsunenko, M. Michaud, A. DuBois, M. L. Delaney, S. Punit, M. Karlsson, L. Bry, J. N. Glickman, J. I. Gordon, A. B. Onderdonk and L. H. Glimcher. 2010. Enerobacteriaceae act in concert with the gut microbiota to induce spontaneous and maternally transmitted colitis. Cell Host Microbe 8(3):292-300.

Goldin, B.R. and S.L. Gorbach. 1984. Alterations of the intestinal microflora by diet, oral antibiotics, and Lactobacillus: decreased production of free amines from aromatic nitro compounds, azo dyes, and glucuronides. Journal of the national cancer institute 73(3):689-695.

Goldin, B.R., L. Swenson, J. Dwyer, M. Sexton and S.L. Gorbach. 1980. Effect of diet and Lactobacillus acidophilus supplements on human fecal bacterial enzymes. Journal of the national institute of cancer 64(2):255-261.

Gomes-Santos, A.C., T.G. Moreira, A.B. Castro-Junior, B.C. Horta, L. Lemos, D.N. Cruz, M.A.F. Guimarães, D.C. Cara, D. McCafferty and A.M.C. Faria. 2012. New Insights into the Immunological Changes in IL-10 Deficient Mice during the Course of Spontaneous Inflammation in the Gut Mucosa. Clinical and Developmental Immunology 1212:560817.

Gunes, H., D. Gulen, R. Mutlu, A. Gumus, T. Tas and A. Eren Topkaya. 2013. Antibacterial effects of curcumin: an in vitro minimum inhibitory concentration study. Toxicology and industrial health ePub 0748233713498458. 
Greten, F.R., L. Eckmann, T.F. Greten, J.M. Park, Z.-W.Li, L.J. Egan, M.F. Kagnoff and M. Karin. 2004. Ikk $\beta$ Links Inflammation and Tumorigenesis in a Mouse Model of ColitisAssociated Cancer. Cell 118:285-296.

Hajishengallis, G., R. P. Darveau and M. A. Curtis. 2012. The Keystone Pathogen Hypothesis. Nature Reviews Microbiology 10(10):717-725.

Hall, L.J., C.T. Murphy, G. Hurley, A. Quinlan, F. Shanahan, K. Nally and S. Melgar. 2013. Natural killer cells protect against mucosal and systemic infection with the enteric pathogen Citrobacter rodentium. Infectious Immunity 81(2):460-469.

Hanahan, D. and R.A. Weinberg. 2000. The hallmarks of cancer. Cell 100(1):57-70.

Harmsen, H.J., A.C. Wildeboer-Veloo, G.C. Raangs, A.A. Wagendorp, N. Klijn, J.G. Bindels and G.W. Welling. 2000. Analysis of intestinal flora development in breast-fed and formula-fed infants by using molecular identification and detection methods. Journal of Pediatric Gastroenterology and Nutrition 30(1):61-67.

Heidland, A., A. Klassen, P. Rutkowski and U. Bahner. 2006. The contribution of Rudolf Virchow to the concept of inflammation: what is still of importance? Journal of nephrology 19(suppl 10):S102-S109.

Hooper, L.V. and J.I. Gordon. 2001. Commensal host-bacterial relationships in the gut. Science 292:1115-1118.

Houot, L., S. Chang, C. Absalon and P.I. Watnick. 2010. Vibrio cholerae Phosphoenolpyruvate Phosphotransferase System Control of Carbohydrate Transport, Biofilm Formation, and Coloniztion of the Germfree Mouse Intestine. Infectious immunity 78(4):1482-1494.

Hu, P., P. Huang and W.M. Chen. 2013. Curcumin inhibits the Sortase A activity of the Streptococcus mutans UA159. Applied biochemistry and biotechnology 171(2):396-402.

Jang, S.E., M.J. Han, S.Y. Kim and D.H. Kim. 2014. Lactobacillus plantarum CLP-0611 ameliorates colitis in mice by polarizing M1 to M2-like macrophages. International immunopharmacology ePub: S1567-5769(14)00157-X.

Ji, H-F. and L. Shen. 2014. Can improving bioavailability improve the bioactivity of curcumin? Trends in pharmacological sciences (Regular ed.) Epub S0165-6147(14)00051-0.

Johnson, R.L. and J.C. Fleet. 2013. Animal models of colorectal cancer. Cancer Metastasis Review 32:39-61.

Kanneganti, M., M. Mino-Kenudson and E. Mizoguchi. 2011. Animal Models of ColitisAssociated Carcinogenesis. Journal of Biomedicine and Biotechnology 2011, ePub ID 342637. 
Kiela, P.R., A.J. Midura, N. Kuscuoglu, S.D. Jolad, A.M. Solyom, D.G. Besselsen, B.N. Timmermann and F.K. Ghishan. 2004. Effects of Boswellia serrata in mouse models of chemically induced colitis. American Journal of Physiology: Gastrointestinal and Liver Physiology 288(4):G798-808.

Kitamura, H., K. Iwakabe, T. Yahata, S. Nishimura, A. Ohta, M. Sato, K. Takeda, K. Okumura, L. Van Kaer, T. Kawano, M. Taniguchi and T. Nishimura. 1999. The natural killer T (NKT) cell ligand a-galactosylceramide demonstrates its immunopotentiating effect by inducing interleukin (IL)-12 production by dendritic cells and IL-12 receptor expression on NKT cells. Journal of experimental medicine 189:1121-1128.

Klein, R.S., R.A. Recco, M.T. Catalano, S.C. Edberg, J.I. Casey and N.H. Steigbigel. 1977. Association of Streptococcus bovis with carcinoma of the colon. New England journal of medicine 297(15):800-802.

Kostic, A.D., D. Gevers, C.S. Pedamallu, M. Michaud, F. Duke, A.M. Earl, A.I. Ojesina, J. Jung, A.J. Bass, J. Tabernero, J. Baselga, C. Liu, R.A. Shivdasani, S. Ogino, B.W. Birren, C. Huttenhower, W.S. Garett and M. Meyerson. 2012. Genome Research 22(2):292-298.

Kühn, R., J. Löhler, D. Rennick, K. Rajewsky and W. Müller. 1993. Interleukin-10-deficient mice develop chronic entercolitis. Cell 75(2):263-274.

Kruskal, W. 1952. Use of ranks in one-criterion variance analysis. Journal of the American Statistical Association 47 (260): 583-621.

Langille, M.G.I., J. Zaneveld, J.G. Caporaso, D. McDonald, D. Knights, J.A. Reyes, J.C. Clemente, D.E. Burkepile, R.L. Vega Thurber, R. Knight, R.G. Beiko and C. Huttenhower. 2013. Predictive functional profiling of microbial communities using 16S rRNA marker gene sequences. Nature Biotechnology 31: 814-821.

Larmonier, C.B., M.T. Midura-Kiela, R. Ramalingham, D. Laubitz, N. Janikashvili, N. Larmonier, F. K. Ghishan and P.R. Kiela. 2011. Modulation of Neutrophil Motility by Curcumin: Implications for Inflammatory Bowel Disease. Inflammatory Bowel Disease 17(2):503-515.

Larmonier, C.B., J.K. Uno, K.M. Lee, T. Karrasch, D. Laubitz, R. Thurston, M.T. Midura-Kiela, F.K. Ghishan, R.B. Sartor, C. Jobin and P.R. Kiela. 2008. Limited effects of dietary curcumin on Th-1 driven colitis in IL-10 deficient mice suggest an IL-10-dependent mechanism of protection. American journal of physiology: gastrointestinal and liver physiology 295(5):G1079-1091.

Lao, C.D., M.T. Ruffin IV, D. Normolle, D.D. Heath, S.I. Murray, J.M. Bailey, M.E. Boggs, J. Crowell, C.L. Rock and D.E. Brenner. 2006. Dose escalation of a curcuminoid formulation. BMC Complementary and Alternative Medicine 6:10. 
Leary, R.J., J.C. Lin, J. Cummins, S. Boca, L.D. Wood, D.W. Parsons, S. Jones, T. Sjöblom, B.H. Park, R. Parsons, J. Willis, D. Dawson, J.K.V. Willson, T. Nikolskaya, Y. Nikolsky, L. Kopelovich, N. Papadopoulos, L.A. Pennacchio, T.L. Wang, S.D. Markowitz, G. Parmigiani, K.W. Kinzler, B. Vogelstein and V.E. Velculescu. 2008. Integrated analysis of homozygous deletions, focal amplifications and sequence alterations in breast and colorectal cancers.

Proceedings of the National Academy of Sciences 105:16224-16229.

Li, L., D. Xiang, S. Shigdar, W. Yang, Q. Li, J. Lin, K. Liu and W. Duan. 2014. Epithelial cell adhesion molecule aptamer functionalized PLGA-lecithin-curcumin-PEG nanoparticles for targeted drug delivery to human colorectal adenocarcinoma cells. International Journal of Nanomedicine 9:1083-1096.

Liboredo, J.C., L.R. Anastácio, C. Pelúzio Mdo, F.X. Valente, L.C. Penido, J.R. Nicoli and M.I. Correia. 2013. Effect of probiotics on the development of dimethylhyrazine-induced preneoplastic lesions in the mouse colon. Acta cirúrgica brasileira 28(5):367-372.

Lin, W.W. and M. Karin. 2007. A cytokine-mediated link between innate immunity, inflammation, and cancer. Journal of Clinical Investigation 117:1175-1183.

Lozupone, C.A. and R. Knight. UniFrac: A new phylogenetic method for comparing microbial communities. 2005. Applied Environmental Microbiology 71(12):8228-8235.

Lozupone, C.A., J.I. Strombaugh, J.I. Gordon, J.K. Jansson and R. Knight. 2012. Diversity, stability and resilience of the human gut microbiota. Nature 489:220-230.

Magesh, H., A. Kumar, A. Alam, Priyam, U. Sekar, V.N. Sumantran and R. Vaidyanathan. 2013. Identification of natural compounds which inhibit biofilm formation in clinical isolates of Klebsiella pneumoniae. Indian Journal of Experimental Biology 51(9):764-772.

Manichanh, C., L. Rigottier-Gois, E. Bonnaud, K. Gloux, E. Pelletier, L. Frangeul, R. Nalin, C. Jarrin, P. Chardon, P. Marteau, J. Roca and J. Dore. 2006. Reduced diversity of faecal microbiota in Crohn's disease revealed by a metagenomic approach. Gut 55(2):205-211.

Marchesi, J.R., B.E. Dutilh, N. Hall, W.H. Peters, R. Roelofs, A. Boleij and H. Tjalsma. 2011. Towards the human colorectal cancer microbiome. PLoS One 6(5):e20447.

Marshall, B.J. 1995. Helicobacter pylori The Etiologic Agent for Peptic Ulcer. JAMA 274(13):1064-1066.

Martin, H.M., B.J. Campbell, C.A. Hart, C. Mpofu, M. Nayar, R. Singh, H. Englyst, H.F. Williams and J.M. Rhodes. 2004. Enhanced Escherichia coli adherence and invasion in Crohn's disease and colon cancer. Gastroenterology 127(1):80-93.

Martinez, F.O. and S. Gordon. 2014. The M1 and M2 paradigm of macrophage activation: time for reassessment. F1000Prime Reports 6:13. 
McCoy, A.N., F. Araújo-Pérez, A. Azcárate-Peril, J.J. Yeh, R.S. Sandler and T.O. Keku. 2013. Fusobacterium is associated with colorectal adenomas. PLoS One 8(1):e53653.

McDonald D, Price MN, Goodrich J, Nawrocki EP, DeSantis TZ, A. Probst, G.L. Andersen, R. Knight and P. Hugenholtz. 2012. An improved Greengenes taxonomy with explicit ranks for ecological and evolutionary analyses of bacteria and archaea. ISME Journal: Multidisciplinary Journal of Microbial Ecology 6: 610-618.

Midura-Kiela, M.T., V.M. Radhakrishnan, C.B. Larmonier, D. Laubitz, F.K. Ghishan and P.R. Kiela. 2011. Curcumin inhibits interferon-y signaling in colonic epithelial cells. American journal of physiology: gastrointestinal and liver physiology 302(1):G85-96.

Mitrophanov, A.Y. and E.A. Groisman. 2008. Signal integration in bacterial two-component regulatory systems. Genes \& Development 22:2601-2611.

Miyaki, M., T. Iijima, J. Kimura, M. Yasuno, T. Mori, Y. Hayashi, M. Koike, N. Shitara, T. Iwama and T. Kuroki. 1999. Frequent mutation of beta-catenin and APC genes in primary colorectal tumors from patients with hereditary nonpolyposis colorectal cancer. Cancer Research 59(18):4506-4509.

Moore, W.E. and L.H. Moore. 1995. Intestinal floras of populations that have a high risk of colon cancer. Applied and environmental microbiology 61(9):3202-3207.

Morgan, X.C. and C. Huttenhower. 2014. Meta'omic Analytic Techniques for Studying the Intestinal Microbiome. Gastroenterology 146(6):1437-1448.

Morgan, X.C., T.L. Tickle, H. Sokol, D. Gevers, K.L. Devaney, D.V. Ward, J.A. Reyes, S.A. Shah, N. LeLeiko, S.B. Snapper, A. Bousvaros, J. Korzenik, B.E. Sands, R.J. Xavier and C. Huttenhower. 2012. Dysfunction of the intestinal microbiome in inflammatory bowel disease and treatment. Genome Biology 13(9):R79.

Mukhopadhya, I., R. Hansen, C.E. Nicholl, Y.A. Alhaiden, J.M. Thomson, S.H. Berry, C. Pattinson, D.A. Stead, R.K. Russell, E.M. El-Omar and G.L. Hold. 2011. A Comprehensive Evaluation of Colonic Mucosal Isolates of Sutterella wadsworthensis from Inflammatory Bowel Disease. PLoS One 6(10):e27076.

Na, H.S., M.H. Cha, D.R. Oh, C.W. Cho, J.H. Rhee and Y.R. Kim. 2011. Protective mechanism of curcumin against Vibrio vulnificus infection. FEMS immunology and medicinal microbiology 63(3):355-362.

Nagamine, C.M., A.B. Rogers, J.G. Fox and D.B. Schauer. 2008. Helicobacter hepaticus promotes azoxymethane-initiated colon tumorigenesis in BALB/c-IL10-deficient mice. International journal of cancer 122(4):832-838.

Nakagama, H., M. Nakanishi and M. Ochiai. 2005. Modeling human colon cancer in rodents using a food-borne carcinogen, PhIP. Cancer Science 96(10):627-636. 
Neufert, C., C. Becker and M.F. Neurath. 2007. An inducible mouse model of colon carcinogenesis for the analysis of sporadic and inflammation-driven tumor progression. Nature Protocols 2(8):1998-2004.

Newmark, H.L., M. Lipkin and N. Mahashwari. 1990. Colonic hyperplasia and hyperproliferation induced by a nutritional stress diet with four components of Western-style diet. Journal of the National Cancer Institute 82:491-496.

Newmark, H.L., K. Yang, N. Kurihara, K. Fan, L.H. Augenlicht and M. Lipkin. 2009. Western diet-induced colonic tumors and their modulation by calcium and vitamin D in C57B1/6 mice: a preclinical model for human sporadic colon cancer. Carcinogenesis 30:88-92.

Nobile, S., P. Gionchetti, F. Rizzello, C. Calabrese and M. Campieri. 2014. Mucosal healing in pediatric Crohn's disease after anti-TNF therapy: a long-term experience at a single center. European journal of gastroenterology and hepatology 26(4):458-465.

Onizawa, M., T. Nagaishi, T. Kanai, K-I. Nagano, S. Oshima, Y. Nemoto, A. Yoshioka, T. Totsuka, R. Okamoto, T. Nakamura, N. Sakamoto, K. Tsuchiya, K. Aoki, K. Ohya, H. Yagita and M. Watanabe. 2009. Signaling pathway via TNF-a/NF-kB in intestinal epithelial cells may be directly involved in colitis-associated carcinogenesis. American journal of physiology: Gastrointestinal and liver physiology 296:G850-G859.

Ostanin, D.V., J. Bao, I. Koboziev, L. Gray, S.A. Robinson-Jackson, M. Kosloski-Davidson, V.H. Price and M.B. Grisham. 2009. T cell transfer model of chronic colitis: concepts, considerations, and tricks of the trade. Americal journal of gastroenterology: Gastroenterology and physiology 296(2):G135-146.

Ott, S.J., M. Musfeldt, D.F. Wenderoth, J. Hempe, O. Brant, U.R. Fölsch, K.N. Timmis and S. Schreiber. 2004. Reduction in diversity of the colonic mucosa associated bacterial microflora in patients with active inflammatory bowel disease. Gut 53(5):685-693.

Popivanova, B.K., K. Kitamura, Y. Wu, T. Kondo, T. Kagaya, S. Kaneko, M. Oshima, C. Fujii and N. Mkaida. 2008. Blocking TNF-alpha in mice reduces colorectal carcinogenesis associated with chronic colitis. Journal of clinical investigations 118:560-570.

Price M.N., P.S. Dehal and A.P. Arkin. 2010. FastTree 2-approximately maximum-likelihood trees for large alignments. PloS One 5: e9490.

Radhakrishnan, V.M., P. Kojs, G. Young, R. Ramalingam, B. Jahadish, E.A. Mash, J.D. Martinez, F.K. Ghishan and P.R. Kiela. 2014. pTyr421 cortactin is overexpressed in colon cancer and is dephosphorylated by curcumin involvement of non-receptor type 1 protein tyrosine phosphatase (PTPN1). PLoS One 9(1):e85796.

Ramalingam, R., C.B. Larmonier, R.D. Thurston, M.T. Midura-Kiela, S.G. Zheng, F.K. Ghishan and P.R. Kiela. 2012. Dendritic cell-specific disruption of TGF-ß receptor II leads to altered 
regulatory $\mathrm{T}$ cell phenotype and spontaneous multiorgan autoimmunity. Journal of Immunology 189(8):3878-3893.

Ramamoorthi, G. and N. Sivalingam. 2014. Molecular mechanism of TGF- $\beta$ signaling pathway in colon carcinogenesis and status of curcumin as chemopreventive strategy. Tumour biology epub ahead of print.

Rautava, S., R. Luoto, S. Salminen and E. Isolauri. 2012. Microbial contact during pregnancy, colonization and human disease. Nature Reviews Gastroenterology and Hepatology 9:565-576.

Richter, F., H.L. Newmark, A. Richter, D. Leung and M. Lipkin. 1995. Inhibition of Westerndiet induced hyperproliferation and hyperplasia in mouse colon by two sources of calcium. Carcinogenesis 16:2685-2689.

Rigby R.J., J.G. Simmons, C.J. Greenhalgh, W.S. Alexander and P.K. Lund. 2007. Suppressor of cytokine signaling 3 (SOCS3) limits damage-induced crypt hyper-proliferation and inflammation-associated tumorigenesis in the colon. Oncogene 26:4833-4841.

Risio, M., M. Lipkin, H. Newmark, K. Yang, F.P. Rossini, V.E. Steele, C.W. Boone and G.J. Kelloff. 1996. Apoptosis, cell replication, and Western-style diet-induced tumorigenesis in mouse colon. Cancer Research 56(21):4910-4916.

Rizzo, A., F. Pallone, G. Monteleone and M.C. Fantini. 2011. Intestinal inflammation and colorectal cancer: A double-edged sword? World Journal of Gastroenterology 17(26):30923100 .

Roger, L.C., A. Costabile, D.T. Holland, L. Hoyles and A.L. McCartney. 2010. Examination of faecal Bifidobacterium populations in breast- and formula-fed infants during the first 18 months of life. Microbiology 156(Pt 11):3329-3341.

Roger, L.C. and A.L. McCartney. 2010. Longitudinal investigation of the faecal microbiota of healthy full-term infants using fluorescence in-situ hybridization and denaturing gradient gel electrophoresis. Microbiology 156:3317-3328.

Rudrappa, T. and H.P. Bais. 2008. Curcumin, a known phenolic from Curcuma longa, attenuates the virulence of Pseudomonas aeruginosa PAO1 in whole plant and animal pathogenicity models. Journal of agricultural and food chemistry 56(6):1955-1962.

Sanapareddy, N., R.M. Legge, B. Jovov, A. McCoy, L. Burcal, F. Araujo-Perez, T.A. Randall, J. Galanko, A. Benson, R.S. Sandler, J.F. Rawls, Z. Abdo, A.A. Fodor and T.O. Keku. 2012. Increased rectal microbial richness is associated with the presence of colorectal adenomas in humans. ISME Journal 6(10):1858-1868.

Saubermann, L.J., P. Beck, Y.P. De Jong, R.S. Pitman, M.S. Ryan, H.S. Kim, M. Exley, S. Snapper, S.P. Balk, S.J. Hagen, O. Kanauchi, K. Motoki, T. Sakai, C. Terhorst, Y. Koezuka, D.K. Podolsky and R.S. Blumberg. 2000. Activation of natural killer T cells by alpha- 
galactosylceramide in the presence of CD1d provides protection against colitis in mice. Gastroenterology 119(1):119-128.

Schwabe, R.F and C. Jobin. 2013. The microbiome and cancer. Nature Reviews Cancer 13(11):800-812.

Shakibaei, M., C. Buhrmann, P. Kraehe, P. Shayan, C. Lueders and A. Groel. 2014. Curcumin chemosensitizes 5-flurouracil resistant MMR-deficient human colon cancer cells in high density cultures. PLoS One 9(1):e85397.

Sharma, G., K. Raturi, S. Dang, S. Gupta and R. Gabrani. 2014. Combinatorial antimicrobial effect of curcumin with selected phytochemicals on Staphylococcus epidermidis. Journal of Asian Natural Products Research 16(5):535-541.

Shen, X.J., J.F. Rawls, T. Randall... 2014. Molecular characterization of mucosal adherent bacteria and associations with colorectal adenomas. Gut Microbes 1:138-147.

Shishodia, S., M.M. Chaturvedi and B.B. Aggarwal. 2007. Role of curcumin in cancer therapy. Current problems in cancer 31(4):243-305.

Shoba, G., D. Joy, T. Joseph, M. Majeed, R. Rajendran and P.S. Srinivas. 1998. Influence of piperine on the pharmacokinetics of curcumin in animals and human volunteers. Planta medicia 64(4):353-356.

Sobhani, I., J. Tap, F. Roudot-Thoraval, J.P. Roperch, S. Letulle, P. Langella, G. Corthier, J. Tran Van Nhieu and J.P. Furet. 2011. Microbial dysbiosis in colorectal cancer )CRC) patients. PLoS One 6:e16393.

Soghani, I., J. Tap, F. Roudot-Thoraval, J.P. Roperch, S. Letulle, P. Langella, G. Corthier, J. Tran Van Nhieu and J.P. Furet. 2011. Microbial dysbiosis in colorectal cancer (CRC) patients. PLoS One 6(1):e16393.

Sokol, H., C. Lay, P. Seksik and G.W. Tannock. 2008. Analysis of bacterial bowel communities of IBD patients: what has it revealed? Inflammatory Bowel Disease 14(6):858-867.

Soni, D. and B. Salh. 2012. A Neutraceutical by Design: The Clinical Application of Curcumin in Colonic Inflammation and Cancer. Scientifica ePub 2012:757890.

Terabe, M., S. Matsui, N. Noben-Trauth, H. Chen, C. Watson, D.D. Donaldson, D.P. Carbone, W.E. Paul and J.A. Berzofsky. 2000. NKT cell-mediated repression of tumor immunosurveillance by IL-13 and the IL-4R-STAT6 pathway. Nature immunology 1:515-520.

Ting, W.C., L.M. Chen, L.C. Huang, M.J. Hour, Y.H. Lan, H.Z. Lee, B.J. You, T.Y. Chang and B.Y. Bao. 2013. Impact of interleukin-10 gene polymorphisms on survival in patients with colorectal cancer. Journal of Korean medical science 28(9):1302-1306. 
Ullman, T.A. and S.H. Itzkowitz. 2011. Intestinal inflammation and cancer. Gastroenterology 140:1807-1816.

Uronis, J.M. M. Mühlbauer, H.H. Herfarth, T.C. Rubinas, G.S. Jones and C. Jobin. 2009. Modulation of the intestinal microbiota alters colitis-associated colorectal cancer susceptibility. PLoS One 4(6):e6026.

Vargas, A.J. and P.A. Thompson. 2012. Diet and Nutrient Factors in Colorectal Cancer Risk. Nutrition in clinical practice 27:613-623.

Wan, Y., Y. Xin, C. Zhang, D. Wu, D. Ding, L. Tang, L. Owusu, J. Bai and W. Li. 2014. Fermentation supernatants of Lactobacillus delbrueckii inhibit growth of human colon cancer cells and induce apoptosis through a caspase 3-dependent pathway. Oncology letters 7(5):17381742 .

Wang, D., K. Peregrina, E. Dhima, E.Y. Lin, J.M. Mariadason and L.H. Augenlicht. 2010. Paneth cell marker expression in intestinal villi and colon crypts characterizes dietary induced risk for mouse sporadic intestinal cancer. Proceedings of the National Academy of Sciences 108(25):10272-10277.

Wang, S.M., L.W. Zhang, R.B. Fan, X. Han, H.X. Yi, L.L. Zhang, C.H. Xue, H.B. Li, Y.H. Zhang and N. Shigwedha. 2014. Induction of HT-29 cells apoptosis by lactobacilli isolated from fermented products. Research in microbiology 165(3):202-214.

Wang, T., G. Cai, Y. Qiu, N. Fei, M. Zhang, X. Pang, W. Jia, S. Cai and L. Zhao. 2012. Structural segregation of gut microbiota between colorectal cancer patients and healthy volunteers. ISME Journal 6(2):320-329.

Wang, X., T.D. Allen, R.J. May, S. Lightfoot, C.W. Houchen and M.M. Huycke. 2008. Enterococcus faecalis induces aneuploidy and tetrapoidy in colonic epithelial cells through a bystander effect. Cancer research 68(23):9909-9917.

Wirtz, S. and M.F. Neurath. 2007. Mouse models of inflammatory bowel disease. Advanced drug delivery reviews 59(11):1073-1083.

Wu, S., K.J. Rhee, E. Albesiano, S. Rabizadeh, X. Wu, H.R. Yen, D.L. Huso, F.L. Brancati, E. Wick, F. McAllister, F. Housseau, D.M. Pardoll and C.L. Sears. 2009. A human colonic commensal promotes colon tumorigenesis via activation of $\mathrm{T}$ helper type $17 \mathrm{~T}$ cell responses. Nature medicine 15(9):1016-1022.

Yang, J., W. Zhang, P.M. Evans, X. Chen, X. He and C. Liu. 2006. Adenomatous Polyposis Coli (APC) Differentially Regulates B-Catenin Phosphorylation and Ubiquitination in Colon Cancer Cells. The Journal of Biological Chemistry 281:17751-17757. 
Yang, Y., X. Wang, T. Huycke, D.R. Moore, S.A. Lightfoot and M.M. Huycke. 2013. Colon Macrophages Polarized by Commensal Bacteria Cause Colitis and Cancer through the Bystander Effect. Translational oncology 6(5):596-606.

Yang, Y.F., M. Tomura, S. Ono, T. Hamaoka and H. Fujiwara. 2000. Requirement for IFNgamma in IL-12 production induced by collaboration between v(a)14(+) NKT cells and antigenpresenting cells. International immunology 12:1669-1675.

Youngster, I., J. Sauk, C. Pindar, R.G. Wilson, J.L. Kaplan, M.B. Smith, E.J. Alm, D. Gevers, G.H. Russell and E.L. Hohmann. 2014. Fecal Microbiota Transplant for Relapsing Clostridium difficile Infection Using Inoculum From Unrelated Donors: A Randomized, Open-Label, Controlled Pilot Study. Clinical infectious diseases 58(11):1515-1522.

Zackular, J.P., N.T. Baxter, K.D. Iverson, W.D. Sadler, J.F. Petrosino, G.Y. Chen and P.D. Schloss. 2013. The gut microbiome modulates colon tumorigenesis. mBio 4(6):e00692.

Zhan, Y., P.-J. Chen, W.D. Sadler, F. Wang, S. Poe, G. Nuñez, K.A. Eaton and G.Y. Chen. 2013. Gut microbiota protects against gastrointestinal tumorigenesis caused by epithelial injury. Cancer Research 73(24):7199-7210.

Zhang, Z., T. Su, L. He, H. Wang, G. Ji, X. Liu, Y. Zhang and G. Dong. 2012. Identification and functional analysis of ligands for natural killer cell activating receptors in colon carcinoma. Tohoku journal of experimental medicine 226(1):59-68.

Zhu, Y., T.M. Luo, C. Jobin and H.A. Young. 2011. Gut Microbiota and Probiotics in Colon Tumorigenesis. Cancer Letters 309(2):119-127. 